\title{
Structure-based Discovery of M-89 as a Highly Potent Inhibitor of the Menin-Mixed Lineage Leukemia (Menin-MLL) Protein- Protein Interaction
}

\author{
Angelo Aguilar ${ }^{\dagger,+, \pm}, \mathrm{Ke} \mathrm{Zheng}^{\dagger,+, \pm, \&}$, Tianfeng $\mathrm{Xu}^{\dagger,+, \pm}$, Shilin $\mathrm{Xu}^{\dagger,+, \pm}$, Liyue Huang ${ }^{\dagger,+, \pm}$, Ester \\ Fernandez-Salas $^{\dagger, \wedge}$, Liu Liu $^{\dagger,+}$, Denzil Bernard ${ }^{\dagger,+}$, Kaitlin P. Harvey ${ }^{\dagger,+}$, Caroline Foster ${ }^{\dagger,+}$, \\ Donna McEachern ${ }^{\dagger+}$, Jeanne Stuckey\#, Krishnapriya Chinnaswamy\#, James Delproposto\#, \\ Jeff W. Kampf ${ }^{\nabla}$, Shaomeng Wang ${ }^{\dagger,+, \Pi, \S,{ }^{*}}$ \\ ${ }^{\dagger}$ Rogel Cancer Center, University of Michigan, Ann Arbor, Michigan 48109, United States \\ +Department of Internal Medicine, University of Michigan, Ann Arbor, Michigan 48109, United \\ States \\ IDepartment of Pharmacology, University of Michigan, Ann Arbor, Michigan 48109, United States \\ $\S$ Department of Medicinal Chemistry, University of Michigan, Ann Arbor, Michigan 48109, United \\ States \\ ^Department of Pathology University of Michigan, Ann Arbor, Michigan 48109, United States \\ ${ }^{\nabla}$ Department of Chemistry, University of Michigan, Ann Arbor, Michigan 48109, United States \\ \#Department of Life Sciences Institute, University of Michigan, Ann Arbor, Michigan 48109, United \\ States
}

\section{Abstract}

\begin{abstract}
Inhibition of the menin-MLL protein-protein interaction is a promising new therapeutic strategy for the treatment of acute leukemia carrying MLL fusion (MLL leukemia). We describe herein our structure-based design, synthesis and evaluation of a new class of small-molecule inhibitors of the menin-MLL interaction (hereafter called menin inhibitors). Our efforts have resulted in the discovery of highly potent menin inhibitors, as exemplified by compound 42 (M-89). M-89 binds to menin with a $\mathrm{K}_{\mathrm{d}}$ value of $1.4 \mathrm{nM}$ and effectively engages cellular menin protein at low nanomolar concentrations. M-89 inhibits cell growth in the MV4;11 and MOLM-13 leukemia cell
\end{abstract}

\footnotetext{
"Corresponding Author Professor Shaomeng Wang at shaomeng@umich.edu.

${ }^{ \pm}$Author Contributions These authors contributed equally.

\&Present Addresses College of Chemistry, Sichuan University, Chengdu, Sichuan, People's Republic of China

The University of Michigan has filed a patent application on these menin inhibitors reported in this study, which has been licensed to Medsyn Biopharma, LLC. S. Wang, A. Aguilar, K. Zheng, T. Xu, S. Xu, L. Huang, E. Fernandez-Salas, D. Bernard, and J. Stuckey are co-inventors on the patent application, and receive royalties on the patent from the University of Michigan. S. Wang is a co-founder of Medsyn Biopharma. The University of Michigan and S. Wang own stock in Medsyn Biopharma.

Supporting Information. Single crystal structure of compound 103 and a table of crystal data and structure refinement of 103; electron density maps of the co-crystal structure of M-89 complexed with menin and a table of crystallographic data collection and refinement statistics for the menin/M-89 co-crystal. CSV file containing SMILES, binding and cellular data for final target compounds.
}

Accession Codes. The coordinates for M-89 complexed with menin has been deposited with the Protein Data Bank with the PDB ID code: $6 \mathrm{E} 1 \mathrm{~A}$. Authors will release the atomic coordinates and experimental data upon article publication. 
lines carrying MLL fusion with $\mathrm{IC}_{50}$ values of $25 \mathrm{nM}$ and $55 \mathrm{nM}$, respectively, and demonstrates $>100$-fold selectivity over the HL-60 leukemia cell line lacking MLL fusion. Determination of a co-crystal structure of M-89 in a complex with menin provides the structural basis for their highaffinity interaction. Further optimization of M-89 may lead to a new class of therapy for the treatment of MLL leukemia.

\section{Graphical Abstract}

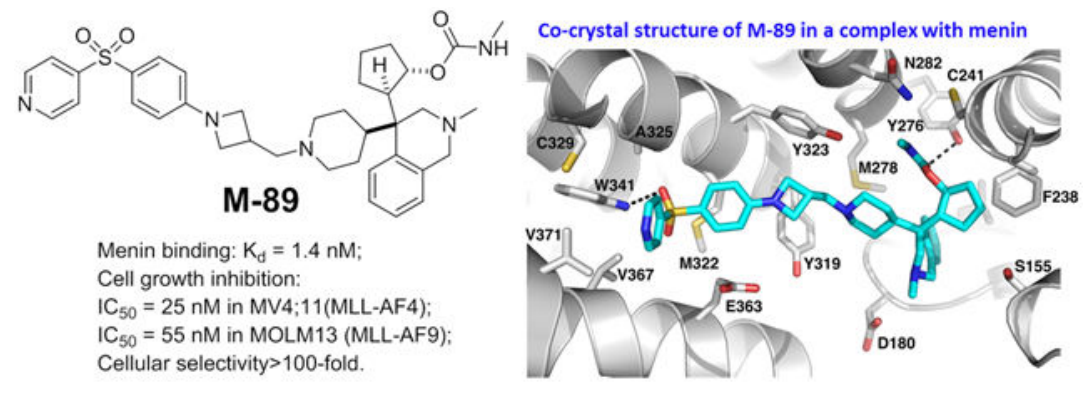

\section{Introduction}

Mixed lineage leukemia protein (MLL, also called MLL1 to distinguish it from MLL2-4) is a histone methyltransferase (HMT), and specifically methylates histone H3 lysine 4 residue (H3K4). MLL gene rearrangement is found in $5-10 \%$ of acute myeloid leukemia (AML) in adults and almost $70 \%$ of acute lymphoblastic leukemia (ALL) in infants. ${ }^{1-5}$ Adult leukemia patients carrying a MLL rearrangement, or MLL leukemia, have very poor prognosis with current treatments. ${ }^{6,7}$ Accordingly, there is an urgent need to develop new and effective therapies for the treatment of MLL leukemia.

The most common MLL rearrangements are balanced MLL translocations, in which only one MLL allele is truncated and fused with one of over 70 partners. ${ }^{8,}{ }^{9}$ Approximately 1400 amino acids from the MLL N-terminus are retained in all the MLL fusion proteins, and interact directly with the oncogenic cofactor menin. 3, 8, 10-14 The menin-MLL proteinprotein interaction is essential for expression of $H O X$ and MEIS1 genes, which drive leukemogenesis in MLL leukemia. ${ }^{12,14,15}$ Consequently, targeting the menin-MLL proteinprotein interaction has been proposed to be a promising, targeted therapeutic strategy for the treatment of MLL leukemia.

Structural studies have shown that menin protein has an approximately $5000 \AA^{3}$ cavity, which serves as the binding site for MLL protein. ${ }^{16-18}$ This very large binding site suggests that targeting the menin-MLL interaction using non-peptide small-molecules, hereafter also called menin inhibitors, could be quite challenging. However, recent efforts have led to the discovery of potent, non-peptide small-molecule menin inhibitors (Figure 1). ${ }^{18-22}$ The most promising non-covalent menin inhibitors reported to date are 1 (MI-463), 2 (MI-503), 3 (MI-538), and 5 (MI-1481) which belong to the same chemical class of 5-(piperidin-1ylmethyl)-1H-indoles. These menin inhibitors bind to menin with $\mathrm{K}_{\mathrm{d}}$ values of $\sim 10 \mathrm{nM}$ and achieve sub-micromolar cellular activity in MLL leukemia cell lines and good antitumor activity in vivo against MLL leukemia tumors. ${ }^{23}$ Importantly, small-molecule menin 
inhibitors can effectively block oncogenic transformation by MLL-fusion proteins in a manner independent of the MLL fusion partner ${ }^{24}$, suggesting a broad therapeutic potential of menin inhibitors for the treatment of MLL leukemia. These studies have provided an important preclinical proof-of-concept that small-molecule inhibitors targeting the meninMLL protein-protein interaction may have a promising therapeutic potential for the treatment of human MLL leukemia.

Recently we reported the discovery of M-525 as a first-in-class, highly potent, covalent menin inhibitor. ${ }^{25} \mathrm{M}-525$ binds to menin covalently with an $\mathrm{IC}_{50}$ value of $3 \mathrm{nM}$ and achieves low nanomolar cellular potencies in inhibition of cell growth in a panel of leukemia cell lines carrying MLL fusion. ${ }^{25} \mathrm{M}-525$ represents a promising covalent menin inhibitor for further optimization.

Despite these major progresses, development of menin inhibitors for the treatment of MLL leukemia is still in its early stage. In the present study, we describe our structure-based design and synthesis of menin inhibitors, which has yielded a class of potent, non-covalent menin inhibitors. The most potent compound, 42 (M-89), binds to menin with a $K_{d}$ value of $1.4 \mathrm{nM}$, achieves low nanomolar potency in inhibition of cell growth in human MLL leukemia cell lines and demonstrates $>100$-fold selectivity over leukemia cells lacking the MLL fusion. M-89 represents a class of promising non-covalent menin inhibitors.

\section{Results and Discussion}

We employed a previously reported menin inhibitor 4 (MIV-6, Figure 1$)^{20}$ as the starting point for our optimization efforts based on the following considerations: (1) MIV-6 has a good binding affinity to menin with a reported $K_{d}=85 \mathrm{nM}$; (2) MIV-6 is cell permeable and inhibits growth of the human leukemia MV4;11 cell line with MLL-AF4 fusion with a reported $\mathrm{IC}_{50}=2.8 \mu \mathrm{M}$; (3) Its available co-crystal structure in a complex with menin provides a solid foundation for effective structure-based optimization.

Comparison of previously published co-crystal structures of MIV-6/menin and MLL/menin shows that MIV-6 captures the interactions of the Phe9, Pro10 and Pro13 residues in MLL with menin (Figure 2). Additionally, the nitrile of the benzonitrile "tail" group in MIV-6 forms an additional hydrogen bond with the NH of Trp341 of the menin protein.

Conformational constraint of a small-molecule inhibitor not only can enhance the binding affinity to its intended target protein by reducing conformational entropic costs upon binding but also can improve the binding selectivity by reducing accessible, low-energy conformational space. We thus investigated the possibilities of locking the bound conformation of MIV-6 to menin. Our analysis of the co-crystal structure of MIV-6/menin suggested that the primary amino group in MIV- 6 can be cyclized with its adjacent phenyl group, which led to the design of compound $\mathbf{6}$ (Table 1). This compound (6) was synthesized and was found to bind to menin with a $\mathrm{K}_{\mathrm{i}}=22 \mathrm{nM}$, which is 2-3 times more potent than MIV-6 in our binding assay (Table 1), supporting our conformational constraint strategy.

Encouraged by the successful design of compound 6, we next focused on rigidification of the flexible linker (Table 1). Since the flexible linker in the MIV-6/menin complex does not 
adopt an extended conformation, we investigated if other linker lengths can adopt a favorable conformation for interaction with the menin protein and give insight to the design of the rigid linker. We tested compounds with a linker one atom shorter (7), and a linker with one atom longer (8), than that in $\mathbf{6}$. Both modifications significantly reduced the binding affinity to menin, suggesting that a linker with 4 atoms has the optimal length between the core-piperidine nitrogen and the para-position of the benzonitrile group. To rigidify the linker, we explored several cyclic amines, compounds $\mathbf{9 - 1 2}$, that maintain approximately the 4-atom linker length. Compounds 9 and 10, containing a piperidine in the linker, are approximately 10 - and 100-times less potent than $\mathbf{6}$, while compound $\mathbf{1 1}$, containing a pyrrolidine in the linker, is as potent as $\mathbf{6}$. Compound $\mathbf{1 2}$ containing an azetidine is 2-times more potent than $\mathbf{6}$. Hence, through cyclization of the core and rigidification of the linker, we obtained compound $\mathbf{1 2}$ which is 5-times more potent than MIV-6 (Table 1).

The co-crystal structure of MIV-6/menin (Figure 2) shows that the terminal nitrile group forms a hydrogen bond with the indole NH group in Trp341. Additionally, there is a welldefined hydrophobic pocket formed by Trp341, Val371, Cys329, Val367 and Ala325 adjacent to the nitrile group, which can be utilized to further enhance the binding affinity to menin. To maintain the hydrogen bonding interaction and at the same time to capture additional interactions with this well-defined hydrophobic pocket, we replaced the nitrile group in MIV-6 with a substituted sulfonyl group (Table 1).

Replacing the terminal nitrile group with a simple methylsulfonyl group resulted in 13, which has a $\mathrm{K}_{\mathrm{i}}$ value of $45 \mathrm{nM}$ to menin and is thus 4-times less potent than $\mathbf{1 2}$. However, replacing the methyl group in $\mathbf{1 3}$ with an ethyl group, which yielded 14, restored the binding affinity $\left(\mathrm{K}_{\mathrm{i}}=10 \mathrm{nM}\right)$. Encouraged with the strong binding affinity for 14, we next systematically explored this site using a variety of alkyl or aryl substituted sulfonyl groups and obtained the results shown in Table 1. Replacing the methyl group in $\mathbf{1 3}$ with an isopropyl group led to $\mathbf{1 5}$, which is 2-times more potent than $\mathbf{1 3}$ but 2-times less potent than $\mathbf{1 4}$ in binding to menin. Changing the isopropyl group in $\mathbf{1 5}$ to a cyclopropyl group led to 16, which is 2-3 times more potent than $\mathbf{1 5}$. Encouraged by the high binding affinity of 16, we replaced the cyclopropyl group in 16 with a cyclobutyl (17), cyclopentyl (18), or a cyclohexyl group (19). Compounds 17, 18 and 19 are all high affinity menin inhibitors with $\mathrm{K}_{\mathrm{i}}$ values of 11, 4.6 and $2.4 \mathrm{nM}$ to menin respectively. We next replaced the cyclohexyl group in $\mathbf{1 9}$ with a phenyl or a pyridinyl group, which yielded $\mathbf{2 0}$ and $\mathbf{2 1}$, respectively. Compounds 20 and 21 bind to menin with $\mathrm{K}_{\mathrm{i}}$ values of $5.6 \mathrm{nM}$ and $4.6 \mathrm{nM}$, respectively.

We next evaluated these new menin inhibitors for their cell growth inhibitory activity in the MV4;11 cell line carrying MLL-AF4 fusion, which was shown to be sensitive to menin inhibitors. $^{23}$ The data are summarized in Table 1.

Consistent with their improved binding affinity to menin over MIV-6, a number of these new menin inhibitors are also more potent than MIV-6 in inhibition of cell growth in the MV4;11 cell line (Table 1). For example, compounds 18 - 21 have $\mathrm{IC}_{50}$ values $0.9,1.1,0.5$ and 1.3 $\mu \mathrm{M}$ respectively, and are $3-7$ times more potent than MIV-6. However, the most potent compound $\mathbf{2 0}$ in this series only achieves a submicromolar cellular potency, indicating the need for further optimization. 
Although compound $\mathbf{2 0}$ is more potent than $\mathbf{2 1}$ in inhibition of cell growth in the MV4;11 cell line, $\mathbf{2 1}$ is more soluble than $\mathbf{2 0}$. Accordingly, we used compound $\mathbf{2 1}$ as the template for further optimization.

We moved the nitrogen atom in the tetrahydroisoquinoline core one atom away from the quaternary carbon center in compound $\mathbf{2 1}$ to render the functionalization of this nitrogen atom more synthetically feasible, which yielded compound $\mathbf{2 2}$ (Table 2). Compound $\mathbf{2 2}$ binds to menin with a $\mathrm{K}_{\mathrm{i}}=1.8 \mathrm{nM}$ and is therefore 2-3 times more potent than 21. However, $\mathbf{2 2}$ is only slightly more potent than $\mathbf{2 1}$ in inhibition of cell growth in the MV4;11 cell line. To further improve the cellular potency, we introduced a variety of small hydrophobic groups as a substituent on the nitrogen atom (Table 2). Substitution of the nitrogen with a small, aliphatic group, such as methyl (23), ethyl (24), isopropyl (25) and cyclobutyl (26), resulted in compounds with high binding affinities to menin, with $K_{i}$ values $=1-2 \mathrm{nM}$. Substitution of the nitrogen atom with an electron withdrawing group such benzylpyridine (29), however, significantly reduces the binding affinity to menin. Despite the high binding affinities to menin, compounds $\mathbf{2 3}, \mathbf{2 4}, \mathbf{2 5}$ and $\mathbf{2 6}$ only achieve IC $_{50}$ values of $\sim 0.4 \mu \mathrm{M}-1$ $\mu \mathrm{M}$ in inhibition of cell growth in the MV4;11 cell line, suggesting a much greater improvement in binding affinity is needed to achieve much more potent cellular activity.

In the co-crystal structures of MIV-6/menin and MLL/menin (Figure 3), there is a welldefined binding pocket (the $\mathrm{P} 1$ pocket) adjacent to the cyclopentyl group and formed by Cys241, Tyr276 and Met278 residues of menin, and this pocket is accessed by an alanine residue (Ala11) in MLL (Figure 3). We reasoned that installation of an appropriate group onto the cyclopentyl ring to capture additional interactions with the residues forming the P1 pocket should greatly enhance the binding affinity. Since it was synthetically difficult to install diverse groups onto the cyclopentyl ring in both MIV-6 and 23, we synthesized 31, in which the quaternary amino group in the core of MIV-6 is replaced by a nitrile group but the rigid linker in $\mathbf{2 3}$ is retained. Compound $\mathbf{3 1}$ binds to menin with a modest affinity $\left(\mathrm{K}_{\mathrm{i}}=0.96\right.$ $\mu \mathrm{M})$ and is thus 16-times weaker than MIV-6, suggesting that the basic nitrogen in $\mathbf{2 3}$ and its analogues greatly enhances the binding affinity to menin as compared to the neutral nitrile group in 31. Despite the modest binding affinity for 31, it provided us with a synthetically more accessible template molecule with which to explore the $\mathrm{P} 1$ pocket.

Since the P1 pocket is hydrophobic in nature, we decided to install a small hydrophobic group onto the cyclopentyl ring, with the results summarized in Table 3. An alkoxy group was placed on the cyclopentyl ring, adjacent to the bond linking the cyclopentyl ring to the tertiary carbon atom and this produced two diastereomers ( $\mathbf{3 2}$ and $\mathbf{3 3}$ ) with relative stereochemistry. Compounds $\mathbf{3 2}$ and $\mathbf{3 3}$ bind to menin with similar affinities $\left(\mathrm{K}_{\mathrm{i}}\right.$ values $=4.9$ and $6.1 \mu \mathrm{M}$ ), which are weaker than compound $\mathbf{3 1}$. When the methoxy group in $\mathbf{3 2}$ is replaced by an ethoxy group, the resulting compound $\mathbf{3 4}$ has an improved binding affinity $\left(\mathrm{K}_{\mathrm{i}}=1.7 \mu \mathrm{M}\right)$ over 32 but is still a weaker binder than $\mathbf{3 1}$. When the methoxy group in $\mathbf{3 2}$ was replaced by an acetoxyl group, the resulting compound 35 has a $K_{i}=12 \mathrm{nM}$ and is thus 80-times more potent than $\mathbf{3 1}$. However, when the methoxy group in 33, the diastereomer of 32, was replaced by an acetoxyl group, the resulting compound (36) has a $K_{i}$ value of 1.1 
$\mu \mathrm{M}$, and is equipotent with $\mathbf{3 1}$. The difference in binding affinities of the diastereomers 35 and $\mathbf{3 6}$ to menin clearly demonstrates the stereospecific nature of the binding to menin.

Encouraged by its excellent binding affinity, we performed further modifications of $\mathbf{3 5}$ to optimize the interactions with the P1 pocket (Table 3). Changing the acetoxyl group in $\mathbf{3 5}$ to a propionoxyl generated 37 , which has a $\mathrm{K}_{\mathrm{i}}$ value of $9.7 \mathrm{nM}$ - slightly more potent than $\mathbf{3 5}$. However, converting the propionoxyl group in $\mathbf{3 7}$ to a butyroxyl group, producing $\mathbf{3 8}$, results in a 30-fold loss in binding affinity to menin, consistent with the limited space in the P1 pocket.

Because ester groups are typically not metabolically stable, we converted the acetoxyl group in 37 into a methyl carbamate (39), an acetamide (40) or a reverse carbamate (41).

Compounds 39, 40 and 41 bind to menin with $K_{\mathrm{i}}$ values of $2.7 \mathrm{nM}, 3.2 \mathrm{nM}$ and $8.5 \mathrm{nM}$, respectively (Table 3 ), and are therefore high-affinity menin inhibitors.

These menin inhibitors in Table 3 were evaluated for their inhibition of cell growth in the MV4;11 cell line, giving the results in Table 3. The majority of these menin inhibitors have $\mathrm{IC}_{50}$ values only in the micromolar range, but compound $\mathbf{3 9}$ with the highest binding affinity achieves the best $\mathrm{IC}_{50}$ value of $0.3 \mu \mathrm{M}$ in inhibition of cell growth in the MV4;11 cell line among this series of compounds.

Taken together, the data show that substitution of a methyl carbamate in the cyclopentyl group of the modestly potent inhibitor $\mathbf{3 1}$, which generates $\mathbf{3 9}$, enhances the binding to menin by a factor of $>100$ and the cellular activity in the MV4;11 cell line by a factor of $>50$. These data indicate that the additional interactions with residues in the $\mathrm{P} 1$ pocket greatly enhance the binding affinity to menin and cellular activity.

We next combined the best structural modifications in $\mathbf{2 3}$ and $\mathbf{3 9}$ and designed and synthesized compound $\mathbf{4 2}$ (M-89) (Table 4).

In our FP-based binding assay, M-89 achieves an $\mathrm{IC}_{50}$ value of $5 \mathrm{nM}$ with an estimated $\mathrm{K}_{\mathrm{i}}$ value $<1 \mathrm{nM}$. Because the binding affinity of M-89 exceeds the lower limit in our FP-based assay, we employed a biolayer interferometry (BLI) assay to further evaluate its binding affinity. The BLI assay determined that M-89 has a $\mathrm{K}_{\mathrm{d}}$ value of $1.4 \mathrm{nM}$, a $k_{\text {off }}$ value of $2.9 * 10^{-4} \mathrm{~s}^{-1}$ and a $k_{\mathrm{on}}$ value of $2.3 * 10^{5} \mathrm{M}^{-1} \mathrm{~s}^{-1}$. In comparison, MIV-6 has a $\mathrm{K}_{\mathrm{d}}$ value of $110 \mathrm{nM}$, a $k_{\text {off }}$ value of $460 * 10^{-4} \mathrm{~s}^{-1}$ and a $k_{\text {on }}$ value of $4.1 * 10^{5} \mathrm{M}^{-1} \mathrm{~s}^{-1}$ in our experiments. Hence, M-89 has a high affinity to menin and an off-rate, which is 158 -times slower than that of MIV-6.

M-89 was evaluated for its ability to inhibit cell growth in the MV4;11 leukemia cell line carrying MLL-AF4 fusion and in the HL-60 leukemia cell line lacking the MLL fusion. Our data showed that M-89 potently inhibits cell growth in the MV4;11 cell line, achieving an $\mathrm{IC}_{50}$ value of $25 \mathrm{nM}$. In comparison, M-89 has an $\mathrm{IC}_{50}$ value of $10.2 \mu \mathrm{M}$ in the HL-60 cell line. We further evaluated M-89 for its cell growth inhibitory activity in the MOLM-13 leukemia cell line carrying MLL-AF9 fusion and found that it achieves an $\mathrm{IC}_{50}$ value of 54 nM. Thus M-89 displays a potent cell growth inhibitory activity in the MV4;11 and 
MOLM-13 leukemia cell lines carrying MLL fusion and >100-fold specificity over the HL-60 cell line lacking MLL fusion.

To gain structural insights into the high binding affinity of M-89 with menin, we determined their co-crystal structure (PDB ID: 6E1A). This co-crystal structure (Figure 4) shows that M-89 not only maintains the key interactions observed for MIV-6, but captures additional interactions. Consistent with our design, the carbamate group on the cyclopentyl fits precisely into the available $\mathrm{P} 1$ pocket in menin and the carbonyl group forms a strong hydrogen bond with the hydroxyl group of Tyr276 of menin. The sulfonyl group forms a strong hydrogen bond with the $\mathrm{NH}$ of Trp341 and the pyridyl group has additional hydrophobic contacts with menin. The inflexible azetidine linker constrains the molecule into a conformation ideal for effective interactions with menin. This co-crystal structure provides structural insights into the high-affinity binding of M-89 with menin and a solid structural basis for further structure-based optimization.

The cellular thermal shift assay (CETSA) is a powerful assay with which to examine cellular protein thermal stability and to determine if a small-molecule inhibitor targets a specific protein in cells. ${ }^{26,27}$ We employed the CETSA assay to assess if M-89 stabilizes menin protein in cells. Our CETSA data (Figure 5A) show that M-89 stabilizes cellular menin protein in both MV4;11 and MOLM-13 cells in a dose-dependent manner. It significantly enhances the thermal stability of cellular menin protein at concentrations as low as $3.7 \mathrm{nM}$ and reaches a maximal effect at 33-100 nM. Since the cells were treated with M-89 for only $1 \mathrm{~h}$, the thermal stabilization of cellular menin by the compound is expected to be a direct effect. Our CETSA data thus provide clear evidence that M-89 targets cellular menin protein at low nanomolar concentrations, consistent with its excellent cellular potency in inhibition of cell growth in leukemia cells carrying MLL fusion.

The menin-MLL protein-protein interaction has been shown to play a key role in regulation of $H_{o x a} 9$ and MEIS1 gene expression in leukemia cells carrying an MLL fusion. ${ }^{23}$

Accordingly, we evaluated M-89 for its ability to suppress expression of Hoxa9 and MEIS1 in the MV4;11 cells carrying MLL-AF4 fusion and in MOML-13 cells carrying MLL-AF9 fusion by qRT-PCR. Our data (Figure 5B) showed that M-89 potently and effectively inhibits Hoxa9 and MEIS1 gene transcription in both cell lines, consistent with its potencies in cell growth inhibition assay.

Using flow cytometry, we evaluated the ability of M-89 to induce apoptosis and cell differentiation in the MV4;11 cell line. Treatment of the MV4;11 cells with M- 89 for 24 or $48 \mathrm{~h}$ resulted in time- and dose-dependent induction of apoptosis (Figure $5 \mathrm{C}$, left panel). Robust apoptosis induction was observed at concentrations as low as $100-300 \mathrm{nM}$ with a 48 $\mathrm{h}$ treatment. While M-89 only has a modest effect on cell differentiation with $24 \mathrm{~h}$ treatment, it effectively induces cell differentiation with $48 \mathrm{~h}$ treatment in a dose-dependent manner in the MV4;11 cells (Figure 5C, right panel).

We evaluated the pharmacodynamic (PD) effect of M-89 in mice bearing MV4;11 xenograft tumors. Previous study showed that for reversible menin inhibitors, repeated administration was needed to observe their PD effect in vivo. ${ }^{23}$ Therefore, mice bearing MV4;11 xenograft 
tumors were dosed with M-89 at $50 \mathrm{mg} / \mathrm{kg}$ daily for three days with intraperitoneal (IP) administration. Mice were sacrificed at different time points to harvest tumor tissues for RTPCR analysis of the expression levels of Hoxa9 and MEIS1 genes, with the data provided in Figure 6. Our data showed that M-89 significantly decreases the expression of Hoxa9 and MEIS1 genes in the MV4;11 xenograft tumor tissue at 6, 24 and $48 \mathrm{~h}$ time-points.

\section{Chemistry}

The compounds in Table 1 were synthesized as shown in Schemes 1 and 2. Amide coupling of 43 with 44 yielded 45 that was cyclized to produce an imine (46). A Grignard reaction of 46 with cyclopentyl magnesium bromide produced an intermediate (47) that was deprotected by catalytic hydrogenation to produce a core intermediate $(\mathbf{4 8})$ with a reactive piperidine that could be used as a synthetic handle for exploration of tail groups. The tail groups were installed using either a convergent or a linear synthetic method. In the convergent method, the tail portion $(49,50$ or $\mathbf{5 1})$ with a chloride or bromide leaving group was reacted with the intermediate (48) to produce compounds $6-\mathbf{8}$. In the linear method, the piperidine compound (48) was reacted with keto- or aldehyde-N-Boc-protected cyclic amine linker groups in a reductive amination which was followed by acid deprotection of their corresponding Boc-amino groups to produce intermediates $52-\mathbf{5 5}$. The final compounds 9 - 12 were obtained through an $\mathrm{S}_{\mathrm{N}} \mathrm{Ar}$ reaction between the free amino groups in compounds $52-55$ and $p$-fluorobenzonitrile (56).

To explore replacement of the tail nitrile with sulfones, we used $p$-fluorophenyl sulfones ( 67 -75) in the final $S_{N} A r$ reactions to produce compounds $\mathbf{1 3 - 2 1}$. The $p$-fluorophenyl sulfones that are not commercially available were synthesized as shown in Scheme 2.

$p$-Fluorothiophenol (56) was used to substitute alkyl bromides or in an $\mathrm{S}_{\mathrm{N}} \mathrm{Ar}$ reaction with 4-bromopyridine to produce the sulfides $(\mathbf{6 2}-\mathbf{6 6})$. Subsequent oxidation to the sulfones $(\mathbf{6 7}$ - 71) was accomplished with mCPBA for thioalkyls $(62-65)$ and Oxone ${ }^{\circledR}$ (potassium peroxymonosulfate) for the thiopyridine (66).

For further exploration we took advantage of the pyridine sulfone and nitrile tail groups. Their reactive intermediates $(\mathbf{7 8}, \mathbf{7 9})$ were synthesized (Scheme 3 ) and used in a convergent method to install on our modified cores. To obtain these intermediates, first an $\mathrm{S}_{\mathrm{N}} \mathrm{Ar}$ reaction of azetidin-3-ylmethanol to either $\mathbf{7 1}$ or $\mathbf{5 6}$ produced alcohols $(\mathbf{7 6}, \mathbf{7 7})$ that were converted to their corresponding mesylates $\mathbf{7 8}$ and $\mathbf{7 9}$, respectively.

Compounds in Table 2 were synthesized according to the route shown in Scheme 4. Condensation of $\mathbf{8 0}$ and $\mathbf{8 1}$ followed by reduction of the double bond in compound $\mathbf{8 2}$ yielded the intermediate (83). Deprotonation of the hydrogen next to the nitrile group generated a nucleophilic carbon that was reacted with cyclopentyl bromide to yield $\mathbf{8 4}$. The nitrile in $\mathbf{8 4}$ was reduced in two steps. Treatment with DIBALH in toluene yielded the imine that was sufficiently stable to be isolated. This imine was treated with $\mathrm{NaBH}_{4}$ to obtain the amine (85) that was then converted to a methyl carbamate (86). An intramolecular Friedel Crafts reaction produced the dihydroisoquinolin-1(2H)-one (87) which was efficiently reduced with the soluble aluminum reagent Red-Al ${ }^{\circledR}$ to produce the tetrahydroisoquinoline 
(88). Boc protection of $\mathbf{8 8}$ produced $\mathbf{8 9}$ which was debenzylated by catalytic hydrogenation and the resulting piperidine was reacted with $\mathbf{7 8}$ in an $\mathrm{S}_{\mathrm{N}} 2$ reaction to produce an intermediate (90). Acidic removal of the Boc yielded 22, whose free nitrogen was then substituted by either an $\mathrm{S}_{\mathrm{N}} 2$ reaction or by reductive amination to produce the final compounds $(\mathbf{2 3}-\mathbf{3 0})$.

Functionalization of the cyclopentyl group extending from a core structure that has a diversely substituted quaternary center was necessary, and would result in formation of three stereogenic centers. To simplify the situation, we decided to explore this modification with intermediate $\mathbf{8 3}$ which has an easily generated nucleophilic carbon atom and is an early intermediate in the synthesis of tetrahydroisoquinolines. Reacting the carbanion of compound 83 with either a cyclopentene-epoxide (93) or cyclopentene- $N$-Boc-aziridine (94) produced a (1:1) diastereomeric mixture of intermediates 95a and $95 \mathbf{b}$, or $96 \mathbf{a}$ and $96 \mathbf{b}$, respectively. Acid removal of Boc from 96a followed by reaction with acetic anhydride or methyl chloroformate produced 97a and 98a, respectively. Removal of the benzyl protecting group on the piperidine followed by $\mathrm{S}_{\mathrm{N}} 2$ reaction with the tail intermediate $\mathbf{7 9}$ produced target molecules 31(from 84b), 40 and 41 and the intermediates 102a and 102b with a hydroxyl that could be substituted, as a handle. Compounds $\mathbf{3 2}$ to $\mathbf{3 9}$ were produced by substitution of the hydroxyl group. Consistently the diastereomer with same relative stereochemistry as the intermediate (95a) was the more potent and its stereochemistry was confirmed by the single crystal structure of the compound (103) which was obtained from the diastereomeric compound (95a).

After determining the appropriate substituents and stereochemistry of the cyclopentyl group this modification was applied to the more active tetrahydroisoquinoline core. First, the hydroxyl group of the active diastereomer (95a) was benzylated and this was followed by reduction of the nitrile group using DIBALH, to produce an amine (105) which was converted to a methyl carbamate to facilitate a Pictet-Spengler cyclization forming the tetrahydroisoquinoline (107) whose methylcarbamate was reduced with the soluble aluminum hydride reagent Red-Al ${ }^{\circledR}$ to produce the intermediate core compound (108). Upon hydrogenation, both benzyl protecting groups were removed and the piperidine ring in the product (109) was regioselectively reacted with $\mathbf{7 8}$ in an $S_{N} 2$ reaction to produce compound 110. Reaction of 110 with methyl isocyanate produced the final compound $\mathbf{4 2}$ (M-89).

\section{Conclusions:}

Starting from a previously reported menin inhibitor (MIV-6), we have performed extensive structure-based optimization to dramatically improve its binding affinity, cellular potency and selectivity. Through systematic optimization of four different sites in the molecule, we have successfully obtained M-89 as a high-affinity menin inhibitor. M- 89 has a $\mathrm{K}_{\mathrm{d}}$ value of $1.4 \mathrm{nM}$ to menin and is $>50$-times more potent than MIV-6. M-89 achieves IC $_{50}$ values of 25 $\mathrm{nM}$ and $54 \mathrm{nM}$, respectively, in the MV4;11 and MOLM-13 cell lines carrying MLL fusion, and is $>100$-times more potent than MIV-6. Significantly, M-89 demonstrates $>100$-fold cellular selectivity in inhibition of cell growth in the MV4;11 and MOLM-13 leukemia cell lines over the HL-60 leukemia cell line lacking MLL fusion. M-89 stabilizes cellular menin protein and effectively suppresses expression of $\mathrm{Hoxa}$ and $\mathrm{MEIS} 1$ genes at low nanomolar 
concentrations in both MV4;11 and MOLM-13 leukemia cell lines. M-89 is also effective in induction of apoptosis and cell differentiation in the MV4;11 cell line. Our pharmacodynamic experiment in mice bearing MV4;11 xenograft tumors showed that M-89 effectively down-regulates the expression of MEIS1 and Hoxa9 genes in the MV4;11 xenograft tumor tissue. Determination of the co-crystal structure of M-89 in a complex with menin provides a solid structural basis for its high-affinity binding and for further structurebased optimization.

Taken together, our study has led to the discovery of M-89 as a highly potent and specific menin inhibitor. M-89 represents a promising lead compound for further optimization toward development of a menin inhibitor for the treatment of MLL leukemia.

\section{Experimental}

\section{General Information.}

Unless otherwise stated, all commercial reagents were used as supplied without further purification and all reactions were performed under a nitrogen atmosphere in dry solvent under anhydrous conditions. NMR spectra were obtained on a Bruker 400 Ascend $^{\mathrm{TM}}$ spectrometer at a ${ }^{1} \mathrm{H}$ frequency of $400 \mathrm{MHz}$ and a ${ }^{13} \mathrm{C}$ frequency of $100 \mathrm{MHz}$. Chemical shifts $(\delta)$ are reported in parts per million (ppm) relative to an internal standard. The final products were purified on a preparative HPLC column (Waters 2545, Quaternary Gradient Module) with a SunFire Prep C18 OBD $5 \mu \mathrm{m} 50$ x $100 \mathrm{~mm}$ reverse phase column. The mobile phase was a gradient of solvent $\mathrm{A}\left(\mathrm{H}_{2} \mathrm{O}\right.$ with $0.1 \%$ TFA) and solvent $\mathrm{B}$ (MeCN with $0.1 \%$ TFA) at a flow rate of $60 \mathrm{~mL} / \mathrm{min}$ and $1 \% / \mathrm{min}$ increase of solvent B. All final compounds have purity $\geq 95 \%$ as determined by Waters ACQUITY UPLC using reverse phase column (SunFire, C18-5 $\mu \mathrm{m}, 4.6$ x $150 \mathrm{~mm}$ ) and a solvent gradient of A $\left(\mathrm{H}_{2} \mathrm{O}\right.$ with $0.1 \%$ of TFA) and solvent $\mathrm{B}\left(\mathrm{CH}_{3} \mathrm{CN}\right.$ with $0.1 \%$ of TFA). ESI mass spectral analysis was performed on a Thermo-Scientific LCQ Fleet mass spectrometer.

\section{4-(3-(4-(1-Cyclopentyl-1,2,3,4-tetrahydroisoquinolin-1-yl)piperidin-1-} yl)propoxy)-benzonitrile (6): Compound 49 (75 mg, $0.384 \mathrm{mmol}$ ), $\mathrm{K}_{2} \mathrm{CO}_{3}$ (88 mg, 0.640 $\mathrm{mmol}$ ) and $\mathrm{KI}$ (catalytic) were added to a solution of the intermediate $\mathbf{4 8}(91 \mathrm{mg}, 0.320$ mmol) in $\mathrm{MeCN}(2 \mathrm{~mL})$. The mixture was stirred at $80^{\circ} \mathrm{C}$ overnight and then extracted with EtOAc, washed with brine, dried over $\mathrm{Na}_{2} \mathrm{SO}_{4}$, and the solvent was evaporated. The residue was purified with preparative HPLC to give the title compound (80 mg, $56 \%) .{ }^{1} \mathrm{H}$ NMR (400 MHz, $\left.\mathrm{CDCl}_{3}\right) \delta 7.57$ (d, J= 8.4 Hz, 2H), 7.36-7.29 (m, 2H), 7.23-7.15 (m, 2H), 6.90 (d, $J=8.5 \mathrm{~Hz}, 2 \mathrm{H}), 4.10(\mathrm{~s}, 2 \mathrm{H}), 3.84-3.71(\mathrm{~m}, 1 \mathrm{H}), 3.67-3.52(\mathrm{~m}, 2 \mathrm{H}), 3.49-3.36(\mathrm{~m}, 1 \mathrm{H})$, 3.27-2.93 (m, 4H), 2.90-2.72 (m, 3H), 2.58-2.43 (m, 1H), 2.36-2.17 (m, 4H), 2.06-1.84 (m, $2 \mathrm{H}), 1.77-1.45$ (m, 4H), 1.37-1.12 (m, 2H). MS (ESI) m/z $444.3[\mathrm{M}+\mathrm{H}]^{+}$

\section{4-(2-(4-(1-Cyclopentyl-1,2,3,4-tetrahydroisoquinolin-1-yl)piperidin-1-} yl)ethoxy)benzonitrile (7): Compound 7 was prepared from compound 48 and 50 according to the procedure used to produce compound 6. ${ }^{1} \mathrm{H} \mathrm{NMR}\left(400 \mathrm{MHz}, \mathrm{MeOH}-\mathrm{d}_{4}\right) \delta$ $7.69(\mathrm{~d}, J=8.9 \mathrm{~Hz}, 2 \mathrm{H}), 7.47-7.42(\mathrm{~m}, 1 \mathrm{H}), 7.41-7.28(\mathrm{~m}, 3 \mathrm{H}), 7.13(\mathrm{~d}, J=9.0 \mathrm{~Hz}, 2 \mathrm{H})$, $4.44(\mathrm{t}, J=4.8 \mathrm{~Hz}, 2 \mathrm{H}), 3.82-3.65(\mathrm{~m}, 2 \mathrm{H}), 3.63-3.51(\mathrm{~m}, 3 \mathrm{H}), 3.51-3.41(\mathrm{~m}, 1 \mathrm{H}), 3.23$ $-3.05(\mathrm{~m}, 4 \mathrm{H}), 2.81$ (p, $J=9.7 \mathrm{~Hz}, 1 \mathrm{H}), 2.67-2.53(\mathrm{~m}, 1 \mathrm{H}), 2.24$ (d, $J=14.1 \mathrm{~Hz}, 1 \mathrm{H}), 2.06$ 
$-1.90(\mathrm{~m}, 2 \mathrm{H}), 1.90-1.51(\mathrm{~m}, 7 \mathrm{H}), 1.52-1.37(\mathrm{~m}, 1 \mathrm{H}), 1.32-1.17(\mathrm{~m}, 1 \mathrm{H}) . \mathrm{MS}$ (ESI)

$\mathrm{m} / \mathrm{z} 430.26[\mathrm{M}+\mathrm{H}]^{+}$

4-(4-(4-(1-Cyclopentyl-1,2,3,4-tetrahydroisoquinolin-1-yl)piperidin-1-yl)butoxy)benzonitrile (8): Compound 8 was prepared from compound 48 and $\mathbf{5 1}$ according to the procedure used to make compound 6. ${ }^{1} \mathrm{H}$ NMR $\left(400 \mathrm{MHz}, \mathrm{MeOH}-\mathrm{d}_{4}\right) \delta 7.65(\mathrm{~d}, J=8.9 \mathrm{~Hz}$, 2H), $7.47-7.41(\mathrm{~m}, 1 \mathrm{H}), 7.40-7.29(\mathrm{~m}, 3 \mathrm{H}), 7.05(\mathrm{~d}, J=8.9 \mathrm{~Hz}, 2 \mathrm{H}), 4.11(\mathrm{t}, J=5.5 \mathrm{~Hz}$, $2 \mathrm{H}), 3.73-3.59(\mathrm{~m}, 2 \mathrm{H}), 3.59-3.40(\mathrm{~m}, 2 \mathrm{H}), 3.21-3.06(\mathrm{~m}, 4 \mathrm{H}), 3.06-2.94(\mathrm{~m}, 2 \mathrm{H})$, $2.87-2.73(\mathrm{~m}, 1 \mathrm{H}), 2.58(\mathrm{t}, J=12.0 \mathrm{~Hz}, 1 \mathrm{H}), 2.23(\mathrm{~d}, J=14.1 \mathrm{~Hz}, 1 \mathrm{H}), 2.01-1.79(\mathrm{~m}$, 7H), $1.79-1.51$ (m, 6H), $1.51-1.37$ (m, 1H), $1.32-1.15$ (m, 1H). MS (ESI) m/z 458.30 $[\mathrm{M}+\mathrm{H}]^{+}$

4-(4-(1-Cyclopentyl-1,2,3,4-tetrahydroisoquinolin-1-yl)-[1,4'-bipiperidin]-1'yl)benzonitrile (9): Compound 9 was prepared according to the procedure used to make compound 12. ${ }^{1} \mathrm{H} \mathrm{NMR}\left(400 \mathrm{MHz}, \mathrm{MeOH}-\mathrm{d}_{4}\right) \delta 7.53(\mathrm{~d}, J=9.0 \mathrm{~Hz}, 2 \mathrm{H}), 7.47$ - $7.41(\mathrm{~m}$, $1 \mathrm{H}), 7.40-7.29(\mathrm{~m}, 3 \mathrm{H}), 7.04(\mathrm{~d}, J=9.0 \mathrm{~Hz}, 2 \mathrm{H}), 4.11(\mathrm{~d}, J=13.2 \mathrm{~Hz}, 2 \mathrm{H}), 3.70-3.51(\mathrm{~m}$, $3 \mathrm{H}), 3.51-3.39(\mathrm{~m}, 2 \mathrm{H}), 3.17-3.04(\mathrm{~m}, 4 \mathrm{H}), 2.93(\mathrm{t}, J=12.7 \mathrm{~Hz}, 2 \mathrm{H}), 2.86-2.74(\mathrm{~m}$, $1 \mathrm{H}), 2.60(\mathrm{t}, J=12.0 \mathrm{~Hz}, 1 \mathrm{H}), 2.27(\mathrm{~d}, J=14.0 \mathrm{~Hz}, 1 \mathrm{H}), 2.16(\mathrm{~d}, J=12.1 \mathrm{~Hz}, 2 \mathrm{H}), 2.02-$ $1.51(\mathrm{~m}, 11 \mathrm{H}), 1.52-1.39(\mathrm{~m}, 1 \mathrm{H}), 1.28-1.16(\mathrm{~m}, 1 \mathrm{H}) . \mathrm{MS}(\mathrm{ESI}) \mathrm{m} / \mathrm{z} 469.31[\mathrm{M}+\mathrm{H}]^{+}$

\section{4-(3-((4-(1-Cyclopentyl-1,2,3,4-tetrahydroisoquinolin-1-yl)piperidin-1-} yl)methyl)piperidin-1-yl)benzonitrile (10): Compound 10 was prepared according to the procedure used to make compound 12. ${ }^{1} \mathrm{H}$ NMR (400 MHz, MeOH-d $\left.)_{4}\right) \delta 7.54-7.41$ (m, 3H), $7.42-7.27(\mathrm{~m}, 3 \mathrm{H}), 7.04(\mathrm{dd}, J=9.2,2.3 \mathrm{~Hz}, 2 \mathrm{H}), 3.96(\mathrm{~d}, J=12.9 \mathrm{~Hz}, 1 \mathrm{H}), 3.84$ $-3.58(\mathrm{~m}, 3 \mathrm{H}), 3.57-3.43(\mathrm{~m}, 2 \mathrm{H}), 3.20-2.86(\mathrm{~m}, 7 \mathrm{H}), 2.75(\mathrm{dd}, J=12.6,9.8 \mathrm{~Hz}, 2 \mathrm{H})$, $2.65(\mathrm{t}, J=12.6 \mathrm{~Hz}, 1 \mathrm{H}), 2.30-2.30-2.01(\mathrm{~m}, 3 \mathrm{H}), 2.01-1.87(\mathrm{~m}, 3 \mathrm{H}), 1.87-1.42(\mathrm{~m}$, $9 \mathrm{H}), 1.42-1.27(\mathrm{~m}, 1 \mathrm{H}), 1.24-1.07(\mathrm{~m}, 1 \mathrm{H}) . \mathrm{MS}(\mathrm{ESI}) \mathrm{m} / \mathrm{z} 483.3[\mathrm{M}+\mathrm{H}]^{+}$

4-(3-((4-(1-Cyclopentyl-1,2,3,4-tetrahydroisoquinolin-1-yl)piperidin-1yl)methyl)-pyrrolidin-1-yl)benzonitrile (11): Compound 11 was prepared according to the procedure used to make compound 12. ${ }^{1} \mathrm{H}$ NMR $\left(400 \mathrm{MHz}, \mathrm{MeOH}-\mathrm{d}_{4}\right) \delta 7.50-7.43$ $(\mathrm{m}, 3 \mathrm{H}), 7.36$ (tt, $J=12.0,7.0 \mathrm{~Hz}, 3 \mathrm{H}), 6.62(\mathrm{~d}, J=8.7 \mathrm{~Hz}, 2 \mathrm{H}), 3.85-3.70(\mathrm{~m}, 2 \mathrm{H}), 3.66$ $(\mathrm{t}, J=8.8 \mathrm{~Hz}, 1 \mathrm{H}), 3.58-3.44(\mathrm{~m}, 3 \mathrm{H}), 3.42-3.34(\mathrm{~m}, 1 \mathrm{H}), 3.26(\mathrm{~d}, J=6.8 \mathrm{~Hz}, 2 \mathrm{H}), 3.19-$ $2.97(\mathrm{~m}, 5 \mathrm{H}), 2.89-2.72(\mathrm{~m}, 2 \mathrm{H}), 2.69-2.55(\mathrm{~m}, 1 \mathrm{H}), 2.37-2.20(\mathrm{~m}, 2 \mathrm{H}), 2.12-1.73(\mathrm{~m}$, $6 \mathrm{H}), 1.73-1.40(\mathrm{~m}, 5 \mathrm{H}), 1.27-1.14(\mathrm{~m}, 1 \mathrm{H}) . \mathrm{MS}(\mathrm{ESI}) \mathrm{m} / \mathrm{z} 469.3[\mathrm{M}+\mathrm{H}]^{+}$

\section{4-(3-((4-(1-Cyclopentyl-1,2,3,4-tetrahydroisoquinolin-1-yl)piperidin-1- yl)methyl)azetidin-1-yl)benzonitrile (12): $p$-Fluorobenzonitrile (56) (18 mg, 0.148} mmol) was added to a solution of compound $55(26 \mathrm{mg}, 0.074 \mathrm{mmol})$ and $\mathrm{K}_{2} \mathrm{CO}_{3}(41 \mathrm{mg}$, $0.295 \mathrm{mmol})$ in DMSO $(2 \mathrm{~mL})$ then stirred and heated to $80^{\circ} \mathrm{C}$. After being stirred overnight, the reaction was quenched with TFA $(0.5 \mathrm{~mL})$, diluted with $3: 1 \mathrm{MeOH} / \mathrm{H}_{2} \mathrm{O}$ and purified by preparative HPLC. The pure fractions were combined, concentrated, rediluted with $\mathrm{H}_{2} \mathrm{O}$, frozen and lyophilized to give $\mathbf{1 2}(14 \mathrm{mg}, 42 \%)$ as white powder. ${ }^{1} \mathrm{H}$ NMR (400 MHz, MeOH-d $\left.{ }_{4}\right) \delta 7.48(\mathrm{~d}, J=7.3 \mathrm{~Hz}, 2 \mathrm{H}), 7.45(\mathrm{~d}, J=9.7 \mathrm{~Hz}, 1 \mathrm{H}), 7.41-7.28(\mathrm{~m}, 3 \mathrm{H})$, $6.47(\mathrm{~d}, J=7.5 \mathrm{~Hz}, 2 \mathrm{H}), 4.17(\mathrm{t}, J=8.0 \mathrm{~Hz}, 2 \mathrm{H}), 3.80-3.71(\mathrm{~m}, 2 \mathrm{H}), 3.63(\mathrm{~d}, J=11.7 \mathrm{~Hz}$, 
$1 \mathrm{H}), 3.60-3.40(\mathrm{~m}, 7 \mathrm{H}), 3.12-2.95(\mathrm{~m}, 3 \mathrm{H}), 2.87-2.71(\mathrm{~m}, 1 \mathrm{H}), 2.65-2.50(\mathrm{~m}, 1 \mathrm{H})$, $2.23(\mathrm{~d}, J=14.9 \mathrm{~Hz}, 1 \mathrm{H}), 2.01-1.87(\mathrm{~m}, 2 \mathrm{H}), 1.86-1.40(\mathrm{~m}, 8 \mathrm{H}), 1.22(\mathrm{~s}, 1 \mathrm{H})$. ESI-MS $\mathrm{m} / \mathrm{z} 455.83(\mathrm{M}+\mathrm{H})^{+}$

1-Cyclopentyl-1-(1-((1-(4-(methylsulfonyl)phenyl)azetidin-3yl)methyl)piperidin-4-yl)-1,2,3,4-tetrahydroisoquinoline (13): Starting with intermediates 55 and 72, the target molecule was prepared according to the procedure described for compound 12. ${ }^{1} \mathrm{H}$ NMR $\left(400 \mathrm{MHz}, \mathrm{MeOH}-\mathrm{d}_{4}\right) \delta 7.71(\mathrm{~d}, J=8.8 \mathrm{~Hz}, 2 \mathrm{H}), 7.48$ $-7.41(\mathrm{~m}, 1 \mathrm{H}), 7.41-7.28(\mathrm{~m}, 3 \mathrm{H}), 6.52(\mathrm{~d}, J=8.8 \mathrm{~Hz}, 2 \mathrm{H}), 4.19(\mathrm{t}, J=8.0 \mathrm{~Hz}, 2 \mathrm{H})$, 3.80-3.74 (m, 2H), $3.64(\mathrm{~d}, J=11.7 \mathrm{~Hz}, 1 \mathrm{H}), 3.61-3.42(\mathrm{~m}, 6 \mathrm{H}), 3.15-3.04(\mathrm{~m}, 4 \mathrm{H}), 3.02$ (s, 3H), $2.86-2.71(\mathrm{~m}, 1 \mathrm{H}), 2.62(\mathrm{t}, J=12.2 \mathrm{~Hz}, 1 \mathrm{H}), 2.25(\mathrm{~d}, J=14.2 \mathrm{~Hz}, 1 \mathrm{H}), 2.03-1.89$ $(\mathrm{m}, 2 \mathrm{H}), 1.86-1.39(\mathrm{~m}, 8 \mathrm{H}), 1.28-1.12(\mathrm{~m}, 1 \mathrm{H})$. ESI-MS m/z $508.83(\mathrm{M}+\mathrm{H})^{+}$

1-Cyclopentyl-1-(1-((1-(4-(ethylsulfonyl)phenyl)azetidin-3-yl)methyl)piperidin-4yl)-1,2,3,4-tetrahydroisoquinoline (14): Starting with intermediates 55 and 73, the target molecule was prepared according to the procedure described for compound $12 .{ }^{1} \mathrm{H}$ NMR $\left(400 \mathrm{MHz}, \mathrm{MeOH}-\mathrm{d}_{4}\right) \delta 7.66(\mathrm{~d}, J=8.2 \mathrm{~Hz}, 2 \mathrm{H}), 7.44(\mathrm{~d}, J=6.8 \mathrm{~Hz}, 1 \mathrm{H}), 7.41-7.29$ $(\mathrm{m}, 3 \mathrm{H}), 6.52(\mathrm{~d}, J=8.4 \mathrm{~Hz}, 2 \mathrm{H}), 4.19(\mathrm{t}, J=8.0 \mathrm{~Hz}, 2 \mathrm{H}), 3.78(\mathrm{t}, J=6.5 \mathrm{~Hz}, 2 \mathrm{H}), 3.65(\mathrm{~d}, J$ $=12.0 \mathrm{~Hz}, 1 \mathrm{H}), 3.61-3.42(\mathrm{~m}, 5 \mathrm{H}), 3.19-2.97(\mathrm{~m}, 6 \mathrm{H}), 2.78(\mathrm{dt}, J=18.1,9.6 \mathrm{~Hz}, 1 \mathrm{H})$, $2.64(\mathrm{t}, J=12.1 \mathrm{~Hz}, 1 \mathrm{H}), 2.25(\mathrm{~d}, J=14.0 \mathrm{~Hz}, 1 \mathrm{H}), 2.02-1.89(\mathrm{~m}, 2 \mathrm{H}), 1.86-1.72(\mathrm{~m}$, $3 \mathrm{H}), 1.73-1.42(\mathrm{~m}, 5 \mathrm{H}), 1.36-1.08(\mathrm{~m}, 5 \mathrm{H})$. ESI-MS m/z $522.50(\mathrm{M}+\mathrm{H})^{+}$

\section{1-Cyclopentyl-1-(1-((1-(4-(isopropylsulfonyl)phenyl)azetidin-3-} yl)methyl)piperidin-4-yl)-1,2,3,4-tetrahydroisoquinoline (15): Starting with intermediates 55 and 74, the target molecule was prepared according to the procedure described for compound 12. ${ }^{1} \mathrm{H}$ NMR $\left(400 \mathrm{MHz}, \mathrm{MeOH}-\mathrm{d}_{4}\right) \delta 7.63(\mathrm{~d}, J=8.8 \mathrm{~Hz}, 2 \mathrm{H}), 7.48$ $-7.42(\mathrm{~m}, 1 \mathrm{H}), 7.41-7.28(\mathrm{~m}, 3 \mathrm{H}), 6.53(\mathrm{~d}, J=8.8 \mathrm{~Hz}, 2 \mathrm{H}), 4.23-4.16(\mathrm{~m}, 2 \mathrm{H}), 3.78$ (ddd, $J=8.0,5.6,2.2 \mathrm{~Hz}, 2 \mathrm{H}), 3.65(\mathrm{~d}, J=12.3 \mathrm{~Hz}, 1 \mathrm{H}), 3.61-3.40(\mathrm{~m}, 5 \mathrm{H}), 3.29-3.24$ (m, 1H), $3.24-3.14(\mathrm{~m}, 1 \mathrm{H}), 3.13-2.98(\mathrm{~m}, 4 \mathrm{H}), 2.79$ (p, $J=9.6 \mathrm{~Hz}, 1 \mathrm{H}), 2.64$ (d, $J=12.2$ $\mathrm{Hz}, 1 \mathrm{H}), 2.25(\mathrm{~d}, J=14.0 \mathrm{~Hz}, 1 \mathrm{H}), 2.02-1.89(\mathrm{~m}, 2 \mathrm{H}), 1.87-1.40(\mathrm{~m}, 8 \mathrm{H}), 1.27-1.14(\mathrm{~m}$, 7H). ESI-MS m/z $536.67(\mathrm{M}+\mathrm{H})^{+}$

\section{1-Cyclopentyl-1-(1-((1-(4-(cyclopropylsulfonyl)phenyl)azetidin-3-} yl)methyl)piperidin-4-yl)-1,2,3,4-tetrahydroisoquinoline (16): Starting with intermediates 55 and $\mathbf{6 7}$, the target molecule was prepared according to the procedure described for compound 12. ${ }^{1} \mathrm{H}$ NMR $\left(400 \mathrm{MHz}, \mathrm{MeOH}-\mathrm{d}_{4}\right) \delta 7.66(\mathrm{~d}, J=7.5 \mathrm{~Hz}, 2 \mathrm{H}), 7.45$ (d, $J=7.4 \mathrm{~Hz}, 1 \mathrm{H}), 7.41-7.27$ (m, 3H), 6.52 (d, $J=7.8 \mathrm{~Hz}, 2 \mathrm{H}), 4.19$ (t, $J=7.9 \mathrm{~Hz}, 2 \mathrm{H}$ ), $3.82-3.73(\mathrm{~m}, 2 \mathrm{H}), 3.64(\mathrm{~d}, J=12.0 \mathrm{~Hz}, 1 \mathrm{H}), 3.60-3.41(\mathrm{~m}, 5 \mathrm{H}), 3.18-2.94(\mathrm{~m}, 4 \mathrm{H})$, $2.86-2.71(\mathrm{~m}, 1 \mathrm{H}), 2.69-2.50(\mathrm{~m}, 2 \mathrm{H}), 2.25(\mathrm{~d}, J=14.7 \mathrm{~Hz}, 1 \mathrm{H}), 2.04-1.88(\mathrm{~m}, 2 \mathrm{H})$, $1.87-1.40(\mathrm{~m}, 8 \mathrm{H}), 1.32-1.09(\mathrm{~m}, 4 \mathrm{H}), 1.06-0.90(\mathrm{~m}, 2 \mathrm{H})$; ESI-MS m/z $534.50(\mathrm{M}+\mathrm{H})^{+}$

1-(1-((1-(4-(Cyclobutylsulfonyl)phenyl)azetidin-3-yl)methyl)piperidin-4-yl)-1cyclopentyl-1,2,3,4-tetrahydroisoquinoline (17): Starting with intermediates 55 and 68, the target molecule was prepared according to the procedure described for compound $\mathbf{1 2}$. ${ }^{1} \mathrm{H}$ NMR (400 MHz, MeOH-d 4 ) $67.63(\mathrm{~d}, J=8.8 \mathrm{~Hz}, 2 \mathrm{H}), 7.48-7.42(\mathrm{~m}, 1 \mathrm{H}), 7.41-7.29$ 
$(\mathrm{m}, 3 \mathrm{H}), 6.52(\mathrm{~d}, J=8.8 \mathrm{~Hz}, 2 \mathrm{H}), 4.18(\mathrm{t}, J=7.9 \mathrm{~Hz}, 2 \mathrm{H}), 3.88(\mathrm{pd}, J=8.2,0.8 \mathrm{~Hz}, 1 \mathrm{H})$, 3.77 (ddd, $J=8.0,5.6,2.2 \mathrm{~Hz}, 2 \mathrm{H}), 3.65(\mathrm{~d}, J=12.1 \mathrm{~Hz}, 1 \mathrm{H}), 3.61-3.40(\mathrm{~m}, 5 \mathrm{H}), 3.29-$ $3.20(\mathrm{~m}, 1 \mathrm{H}), 3.15-2.97(\mathrm{~m}, 4 \mathrm{H}), 2.79(\mathrm{p}, J=9.8 \mathrm{~Hz}, 1 \mathrm{H}), 2.63(\mathrm{t}, J=12.8 \mathrm{~Hz}, 1 \mathrm{H}), 2.48-$ $2.33(\mathrm{~m}, 2 \mathrm{H}), 2.25(\mathrm{~d}, J=13.9 \mathrm{~Hz}, 1 \mathrm{H}), 2.22-2.08(\mathrm{~m}, 2 \mathrm{H}), 2.04-1.85(\mathrm{~m}, 4 \mathrm{H}), 1.85-$ $1.40(\mathrm{~m}, 8 \mathrm{H}), 1.28-1.13(\mathrm{~m}, 1 \mathrm{H}) . \mathrm{MS}(\mathrm{ESI}) \mathrm{m} / \mathrm{z} 548.3[\mathrm{M}+\mathrm{H}]^{+}$

1-Cyclopentyl-1-(1-((1-(4-(cyclopentylsulfonyl)phenyl)azetidin-3yl)methyl)piperidin-4-yl)-1,2,3,4-tetrahydroisoquinoline (18): Starting with intermediates 55 and 69 , the target molecule was prepared according to the procedure described for compound 12. ${ }^{1} \mathrm{H}$ NMR $\left(400 \mathrm{MHz}, \mathrm{MeOH}-\mathrm{d}_{4}\right) \delta 7.65(\mathrm{~d}, J=8.7 \mathrm{~Hz}, 2 \mathrm{H}), 7.47$ - $7.41(\mathrm{~m}, 1 \mathrm{H}), 7.40-7.27(\mathrm{~m}, 3 \mathrm{H}), 6.52(\mathrm{~d}, J=8.8 \mathrm{~Hz}, 2 \mathrm{H}), 4.18(\mathrm{t}, J=8.0 \mathrm{~Hz}, 2 \mathrm{H}), 3.82$ $3.73(\mathrm{~m}, 2 \mathrm{H}), 3.64(\mathrm{~d}, J=11.8 \mathrm{~Hz}, 1 \mathrm{H}), 3.60-3.40(\mathrm{~m}, 6 \mathrm{H}), 3.17-2.96(\mathrm{~m}, 4 \mathrm{H}), 2.79$ (dt, $J$ $=17.7,8.0 \mathrm{~Hz}, 1 \mathrm{H}), 2.70-2.54(\mathrm{~m}, 1 \mathrm{H}), 2.25(\mathrm{~d}, J=14.2 \mathrm{~Hz}, 1 \mathrm{H}), 2.03-1.40(\mathrm{~m}, 19 \mathrm{H})$, $1.31-1.10(\mathrm{~m}, 1 \mathrm{H})$. ESI-MS m/z $562.92(\mathrm{M}+\mathrm{H})^{+}$

1-(1-((1-(4-(Cyclohexylsulfonyl)phenyl)azetidin-3-yl)methyl)piperidin-4-yl)-1cyclopentyl-1,2,3,4-tetrahydroisoquinoline (19): Starting with intermediates 55 and 70, the target molecule was prepared according to the procedure described for compound $\mathbf{1 2}$. ${ }^{1} \mathrm{H}$ NMR $\left(400 \mathrm{MHz}, \mathrm{MeOH}-\mathrm{d}_{4}\right) \delta 7.61(\mathrm{~d}, J=7.4 \mathrm{~Hz}, 2 \mathrm{H}), 7.45(\mathrm{~d}, J=6.5 \mathrm{~Hz}, 1 \mathrm{H})$, 7.41-7.29 (m, 3H), $6.52(\mathrm{~d}, J=7.6 \mathrm{~Hz}, 2 \mathrm{H}), 4.19(\mathrm{t}, J=8.0 \mathrm{~Hz}, 2 \mathrm{H}), 3.78(\mathrm{t}, J=6.7 \mathrm{~Hz}, 2 \mathrm{H})$, $3.65(\mathrm{~d}, J=11.9 \mathrm{~Hz}, 1 \mathrm{H}), 3.60-3.44(\mathrm{~m}, 5 \mathrm{H}), 3.29-3.22(\mathrm{~m}, 1 \mathrm{H}), 3.16-3.01(\mathrm{~m}, 4 \mathrm{H})$, 2.98-2.87 (m, 1H), 2.84-2.73 (m, 1H), 2.70-2.58 (m, 1H), $2.25(\mathrm{~d}, J=14.8 \mathrm{~Hz}, 1 \mathrm{H})$, 2.06-1.91 (m, 4H), 1.89-1.73 (m, 5H), 1.72-1.60 (m, 4H), 1.58-1.43 (m, 2H), 1.38-1.19 (m, $5 \mathrm{H}), 1.19-1.05(\mathrm{~m}, 1 \mathrm{H})$. MS (ESI) $\mathrm{m} / \mathrm{z} 576.4[\mathrm{M}+\mathrm{H}]^{+}$

\section{1-Cyclopentyl-1-(1-((1-(4-(phenylsulfonyl)phenyl)azetidin-3-} yl)methyl)piperidin-4-yl)-1,2,3,4-tetrahydroisoquinoline (20): Starting with intermediates $\mathbf{5 5}$ and $\mathbf{7 5}$, the target molecule was prepared according to the procedure described for compound 12. ${ }^{1} \mathrm{H}$ NMR $\left(400 \mathrm{MHz}, \mathrm{MeOH}-\mathrm{d}_{4}\right) \delta 7.90-7.83(\mathrm{~m}, 2 \mathrm{H}), 7.72(\mathrm{~d}$, $J=8.8 \mathrm{~Hz}, 2 \mathrm{H}), 7.61-7.49(\mathrm{~m}, 3 \mathrm{H}), 7.47-7.40(\mathrm{~m}, 1 \mathrm{H}), 7.40-7.27(\mathrm{~m}, 3 \mathrm{H}), 6.47(\mathrm{~d}, J=$ $8.9 \mathrm{~Hz}, 2 \mathrm{H}), 4.14(\mathrm{t}, J=8.0 \mathrm{~Hz}, 2 \mathrm{H}), 3.73(\mathrm{ddd}, J=8.0,5.5,2.3 \mathrm{~Hz}, 2 \mathrm{H}), 3.62(\mathrm{~d}, J=12.2$ $\mathrm{Hz}, 1 \mathrm{H}), 3.59-3.36(\mathrm{~m}, 5 \mathrm{H}), 3.24$ (p, $J=6.6 \mathrm{~Hz}, 1 \mathrm{H}), 3.17-2.95(\mathrm{~m}, 4 \mathrm{H}), 2.77$ (p, $J=9.6$ $\mathrm{Hz}, 1 \mathrm{H}), 2.68-2.54(\mathrm{~m}, 1 \mathrm{H}), 2.24(\mathrm{~d}, J=14.0 \mathrm{~Hz}, 1 \mathrm{H}), 2.02-1.88(\mathrm{~m}, 2 \mathrm{H}), 1.86-1.39(\mathrm{~m}$, $8 \mathrm{H}), 1.27-1.09(\mathrm{~m}, 1 \mathrm{H})$. ESI-MS m/z $570.50(\mathrm{M}+\mathrm{H})^{+}$

\section{1-Cyclopentyl-1-(1-((1-(4-(pyridin-4-ylsulfonyl)phenyl)azetidin-3-} yl)methyl)piperidin-4-yl)-1,2,3,4-tetrahydroisoquinoline (21): Starting with intermediates 55 and 71, the target molecule was prepared according to the procedure described for compound 12. ${ }^{1} \mathrm{H}$ NMR $\left(400 \mathrm{MHz}, \mathrm{MeOH}-\mathrm{d}_{4}\right) \delta 8.75(\mathrm{~d}, J=5.2 \mathrm{~Hz}, 2 \mathrm{H}), 7.88$ $-7.79(\mathrm{~m}, 2 \mathrm{H}), 7.76(\mathrm{~d}, J=8.9 \mathrm{~Hz}, 2 \mathrm{H}), 7.48-7.40(\mathrm{~m}, 1 \mathrm{H}), 7.42-7.27(\mathrm{~m}, 3 \mathrm{H}), 6.51(\mathrm{~d}, J$ $=8.9 \mathrm{~Hz}, 1 \mathrm{H}), 4.19(\mathrm{t}, J=7.9 \mathrm{~Hz}, 2 \mathrm{H}), 3.77(\mathrm{t}, J=6.7 \mathrm{~Hz}, 2 \mathrm{H}), 3.67-3.41(\mathrm{~m}, 7 \mathrm{H}), 3.17-$ $2.97(\mathrm{~m}, 4 \mathrm{H}), 2.89-2.72(\mathrm{~m}, 1 \mathrm{H}), 2.68-2.50(\mathrm{~m}, 1 \mathrm{H}), 2.24(\mathrm{~d}, J=14.5 \mathrm{~Hz}, 1 \mathrm{H}), 2.04-$ $1.86(\mathrm{~m}, 2 \mathrm{H}), 1.88-1.37(\mathrm{~m}, 8 \mathrm{H}), 1.35-1.16(\mathrm{~m}, 1 \mathrm{H})$; ESI-MS m/z $571.67(\mathrm{M}+\mathrm{H})^{+}$ 
4-Cyclopentyl-4-(1-((1-(4-(pyridin-4-ylsulfonyl)phenyl)azetidin-3yl)methyl)piperidin-4-yl)-1,2,3,4-tetrahydroisoquinoline (22): Compound 90 (20 $\mathrm{mg}, 0.0298 \mathrm{mmol}$ ) was dissolved in TFA $(1 \mathrm{~mL})$. After $30 \mathrm{~min}$ the TFA was removed in vacuo and the crude was purified by preparative HPLC to yield 22-TFA salt (12 mg) as a yellow solid. ${ }^{1} \mathrm{H}$ NMR (400 MHz, MeOH-d 4 ) $\delta 8.76(\mathrm{~s}, 2 \mathrm{H}), 7.83(\mathrm{~d}, J=5.1 \mathrm{~Hz}, 2 \mathrm{H}), 7.76$ $(\mathrm{d}, J=8.6 \mathrm{~Hz}, 2 \mathrm{H}), 7.55(\mathrm{~d}, J=8.0 \mathrm{~Hz}, 1 \mathrm{H}), 7.47-7.37(\mathrm{~m}, 1 \mathrm{H}), 7.38-7.22(\mathrm{~m}, 2 \mathrm{H}), 6.50$ (d, $J=8.6 \mathrm{~Hz}, 2 \mathrm{H}), 4.33-4.22(\mathrm{~m}, 2 \mathrm{H}), 4.23-4.11(\mathrm{~m}, 2 \mathrm{H}), 3.76(\mathrm{t}, J=6.8 \mathrm{~Hz}, 2 \mathrm{H}), 3.66-$ $3.37(\mathrm{~m}, 7 \mathrm{H}), 3.09-2.90(\mathrm{~m}, 2 \mathrm{H}), 2.64-2.47(\mathrm{~m}, 1 \mathrm{H}), 2.34-2.19(\mathrm{~m}, 1 \mathrm{H}), 2.14(\mathrm{~d}, J=$ $14.0 \mathrm{~Hz}, 1 \mathrm{H}), 1.89-1.70(\mathrm{~m}, 3 \mathrm{H}), 1.72-1.44(\mathrm{~m}, 6 \mathrm{H}), 1.36-1.21(\mathrm{~m}, 1 \mathrm{H}), 1.18-1.00(\mathrm{~m}$, 1H); ESI-MS m/z $571.58(\mathrm{M}+\mathrm{H})^{+}$

\section{4-Cyclopentyl-2-methyl-4-(1-((1-(4-(pyridin-4-ylsulfonyl)phenyl)azetidin-3- yl)methyl)piperidin-4-yl)-1,2,3,4-tetrahydroisoquinoline (23): Crude 22 (0.0298 $\mathrm{mmol}$ ) was dissolved in $\mathrm{MeCN}(1 \mathrm{~mL})$, followed by addition of $\mathrm{K}_{2} \mathrm{CO}_{3}(16 \mathrm{mg}, 0.119$ $\mathrm{mmol})$, and $\mathrm{MeI}(8.4 \mathrm{mg}, 0.0596 \mathrm{mmol})$ at $\mathrm{rt}$. After $1 \mathrm{~h}$, the reaction was filtered through celite, concentrated and purified by preparative HPLC to produce 23-TFA salt. ${ }^{1} \mathrm{H}$ NMR $\left(400 \mathrm{MHz}, \mathrm{MeOH}-\mathrm{d}_{4}\right) \delta 8.75(\mathrm{~d}, J=6.3 \mathrm{~Hz}, 2 \mathrm{H}), 7.82(\mathrm{~d}, J=6.2 \mathrm{~Hz}, 2 \mathrm{H}), 7.76(\mathrm{~d}, J=8.9$ $\mathrm{Hz}, 2 \mathrm{H}), 7.60-7.55(\mathrm{~m}, 1 \mathrm{H}), 7.46$ (t, $J=7.5 \mathrm{~Hz}, 1 \mathrm{H}), 7.36$ (td, $J=7.4,1.1 \mathrm{~Hz}, 1 \mathrm{H}), 7.31-$ $7.25(\mathrm{~m}, 1 \mathrm{H}), 6.50(\mathrm{~d}, J=8.8 \mathrm{~Hz}, 2 \mathrm{H}), 4.46-4.23(\mathrm{~m}, 2 \mathrm{H}), 4.18(\mathrm{t}, J=8.1 \mathrm{~Hz}, 2 \mathrm{H}), 3.76(\mathrm{~s}$, $2 \mathrm{H}), 3.68-3.46(\mathrm{~m}, 3 \mathrm{H}), 3.46-3.37$ (m, 2H), $3.29-3.18(\mathrm{~m}, 1 \mathrm{H}), 3.15(\mathrm{~s}, 3 \mathrm{H}), 3.07-2.90$ $(\mathrm{m}, 2 \mathrm{H}), 2.52-2.29(\mathrm{~m}, 1 \mathrm{H}), 2.22-2.01(\mathrm{~m}, 2 \mathrm{H}), 1.95-1.41(\mathrm{~m}, 10 \mathrm{H}), 1.40-1.20(\mathrm{~m}$, 2H). MS (ESI) $\mathrm{m} / \mathrm{z} 585.26[\mathrm{M}+\mathrm{H}]^{+}$}

\section{4-Cyclopentyl-2-ethyl-4-(1-((1-(4-(pyridin-4-ylsulfonyl)phenyl)azetidin-3-} yl)methyl)-piperidin-4-yl)-1,2,3,4-tetrahydroisoquinoline (24): Acetaldehyde (3.9 $\mathrm{mg}, 0.0894 \mathrm{mmol})$ was added to a solution of crude $22(0.0298 \mathrm{mmol})$ in DCM/AcOH (1:1, $2 \mathrm{~mL}$ ). After $10 \mathrm{~min}, \mathrm{NaBH}(\mathrm{OAc})_{3}(38 \mathrm{mg}, 0.179 \mathrm{mmol})$ was slowly added to the reaction. After standing overnight, the reaction was slowly quenched with saturated $\mathrm{NaHCO}_{3}$, extracted with EtOAc, dried over $\mathrm{Na}_{2} \mathrm{SO}_{4}$, filtered, and concentrated to produce a crude product that was purified by preparative HPLC to yielded 24-TFA salt. ${ }^{1} \mathrm{H}$ NMR $(400 \mathrm{MHz}$, MeOH-d $\left.{ }_{4}\right) \delta 8.80-8.72(\mathrm{~m}, 2 \mathrm{H}), 7.82(\mathrm{~d}, J=6.2 \mathrm{~Hz}, 2 \mathrm{H}), 7.76(\mathrm{~d}, J=8.9 \mathrm{~Hz}, 2 \mathrm{H}), 7.61-$ $7.55(\mathrm{~m}, 1 \mathrm{H}), 7.51-7.43(\mathrm{~m}, 1 \mathrm{H}), 7.35$ (ddd, $J=16.2,7.9,6.6 \mathrm{~Hz}, 2 \mathrm{H}), 6.51(\mathrm{~d}, J=8.9 \mathrm{~Hz}$, $2 \mathrm{H}), 4.51-4.11(\mathrm{~m}, 4 \mathrm{H}), 3.90-3.60(\mathrm{~m}, 4 \mathrm{H}), 3.58-3.37(\mathrm{~m}, 6 \mathrm{H}), 3.26-3.15(\mathrm{~m}, 1 \mathrm{H})$, $3.10-2.91(\mathrm{~m}, 2 \mathrm{H}), 2.87-2.66(\mathrm{~m}, 1 \mathrm{H}), 2.59-2.26(\mathrm{~m}, 2 \mathrm{H}), 2.16(\mathrm{~d}, J=14.0 \mathrm{~Hz}, 1 \mathrm{H}), 2.10$ - $1.92(\mathrm{~m}, 1 \mathrm{H}), 1.92-1.80(\mathrm{~m}, 1 \mathrm{H}), 1.80-1.52(\mathrm{~m}, 6 \mathrm{H}), 1.48(\mathrm{t}, J=7.3 \mathrm{~Hz}, 3 \mathrm{H}), 1.36-$ $1.16(\mathrm{~m}, 1 \mathrm{H}), 1.16-0.99(\mathrm{~m}, 1 \mathrm{H}) ;$ ESI-MS m/z $599.67(\mathrm{M}+\mathrm{H})^{+}$

\section{4-Cyclopentyl-2-isopropyl-4-(1-((1-(4-(pyridin-4-ylsulfonyl)phenyl)azetidin-3- yl)methyl)-piperidin-4-yl)-1,2,3,4-tetrahydroisoquinoline (25): Compound 25 was} prepared from crude 22 and $\mathrm{Me}_{2} \mathrm{CO}$ according to the procedure described for compound $\mathbf{2 4}$. ${ }^{1} \mathrm{H}$ NMR (400 MHz, MeOH-d 4 ) $\delta 8.75$ (s, 2H), $7.90-7.79(\mathrm{~m}, 2 \mathrm{H}), 7.76(\mathrm{~d}, J=8.9 \mathrm{~Hz}$, $2 \mathrm{H}), 7.56(\mathrm{~d}, J=8.0 \mathrm{~Hz}, 1 \mathrm{H}), 7.46(\mathrm{td}, J=8.0,7.5,1.8 \mathrm{~Hz}, 1 \mathrm{H}), 7.40-7.25(\mathrm{~m}, 2 \mathrm{H}), 6.49$ $(\mathrm{d}, J=8.7 \mathrm{~Hz}, 2 \mathrm{H}), 4.45-4.25(\mathrm{~m}, 2 \mathrm{H}), 4.25-4.05(\mathrm{~m}, 2 \mathrm{H}), 3.87-3.60(\mathrm{~m}, 5 \mathrm{H}), 3.56-$ $3.38(\mathrm{~m}, 4 \mathrm{H}), 3.09-2.89(\mathrm{~m}, 2 \mathrm{H}), 2.84-2.64(\mathrm{~m}, 1 \mathrm{H}), 2.64-2.45(\mathrm{~m}, 1 \mathrm{H}), 2.45-2.24(\mathrm{~m}$, 
1H), $2.24-(\mathrm{m}, 2 \mathrm{H}), 1.93-1.78(\mathrm{~m}, 2 \mathrm{H}), 1.78-1.59(\mathrm{~m}, 6 \mathrm{H}), 1.51(\mathrm{~d}, J=6.6 \mathrm{~Hz}, 6 \mathrm{H}), 1.38$ $-1.08(\mathrm{~m}, 2 \mathrm{H}) ; \mathrm{ESI}-\mathrm{MS} \mathrm{m} / \mathrm{z} 613.58(\mathrm{M}+\mathrm{H})^{+}$

2-Cyclobutyl-4-cyclopentyl-4-(1-((1-(4-(pyridin-4-ylsulfonyl)phenyl)azetidin-3yl)methyl)-piperidin-4-yl)-1,2,3,4-tetrahydroisoquinoline (26): Compound 26 was prepared from crude $\mathbf{2 2}$ and cyclobutanone according to the procedure described for compound 24; ${ }^{1} \mathrm{H}$ NMR (400 MHz, MeOH-d $\left.{ }_{4}\right) \delta 8.75(\mathrm{~d}, J=5.9 \mathrm{~Hz}, 2 \mathrm{H}), 7.82(\mathrm{~d}, J=6.1$ $\mathrm{Hz}, 2 \mathrm{H}), 7.76(\mathrm{~d}, J=8.8 \mathrm{~Hz}, 2 \mathrm{H}), 7.57(\mathrm{~d}, J=8.0 \mathrm{~Hz}, 1 \mathrm{H}), 7.47(\mathrm{t}, J=7.5 \mathrm{~Hz}, 1 \mathrm{H}), 7.36(\mathrm{q}$, $J=7.8 \mathrm{~Hz}, 2 \mathrm{H}), 6.50(\mathrm{~d}, J=8.8 \mathrm{~Hz}, 2 \mathrm{H}), 4.45-4.26(\mathrm{~m}, 1 \mathrm{H}), 4.17(\mathrm{t}, J=7.8 \mathrm{~Hz}, 2 \mathrm{H}), 4.04-$ $3.89(\mathrm{~m}, 1 \mathrm{H}), 3.83-3.68(\mathrm{~m}, 2 \mathrm{H}), 3.68-3.36(\mathrm{~m}, 5 \mathrm{H}), 3.24-3.15(\mathrm{~m}, 1 \mathrm{H}), 3.09-2.92(\mathrm{~m}$, $2 \mathrm{H}), 2.88-2.73(\mathrm{~m}, 1 \mathrm{H}), 2.65-2.19(\mathrm{~m}, 6 \mathrm{H}), 2.15(\mathrm{~d}, J=15.8 \mathrm{~Hz}, 1 \mathrm{H}), 2.03-1.80(\mathrm{~m}$, $4 \mathrm{H}), 1.80-1.37$ (m, 8H), $1.34-1.17(\mathrm{~m}, 2 \mathrm{H})$. ESI-MS m/z $625.58(\mathrm{M}+\mathrm{H})^{+}$

4-Cyclopentyl-2-(cyclopropylmethyl)-4-(1-((1-(4-(pyridin-4ylsulfonyl)phenyl)azetidin-3-yl)methyl)piperidin-4-yl)-1,2,3,4tetrahydroisoquinoline (27): Compound 27 was prepared from crude 22 and (bromomethyl)cyclopropane according to the procedure described for compound 23 . ${ }^{1} \mathrm{H}$ NMR (400 MHz, MeOH-d $\left.)_{4}\right) 8.75(\mathrm{~d}, J=5.6 \mathrm{~Hz}, 2 \mathrm{H}), 7.82(\mathrm{~d}, J=6.1 \mathrm{~Hz}, 2 \mathrm{H}), 7.76(\mathrm{~d}, J=$ $8.9 \mathrm{~Hz}, 2 \mathrm{H}), 7.58(\mathrm{~d}, J=7.8 \mathrm{~Hz}, 1 \mathrm{H}), 7.47(\mathrm{t}, J=7.4 \mathrm{~Hz}, 1 \mathrm{H}), 7.37$ (t, $J=7.4 \mathrm{~Hz}, 1 \mathrm{H}), 7.32$ $(\mathrm{d}, J=6.7 \mathrm{~Hz}, 1 \mathrm{H}), 6.50(\mathrm{~d}, J=8.9 \mathrm{~Hz}, 2 \mathrm{H}), 4.62-4.24(\mathrm{~m}, 2 \mathrm{H}), 4.17(\mathrm{t}, J=8.3 \mathrm{~Hz}, 2 \mathrm{H})$, $4.07-3.85(\mathrm{~m}, 1 \mathrm{H}), 3.83-3.69(\mathrm{~m}, 2 \mathrm{H}), 3.58-3.37(\mathrm{~m}, 5 \mathrm{H}), 3.10-2.89(\mathrm{~m}, 2 \mathrm{H}), 2.88-$ $2.66(\mathrm{~m}, 1 \mathrm{H}), 2.60-2.25(\mathrm{~m}, 2 \mathrm{H}), 2.17(\mathrm{~d}, J=14.0 \mathrm{~Hz}, 1 \mathrm{H}), 1.94-1.36(\mathrm{~m}, 10 \mathrm{H}), 1.36-$ $1.17(\mathrm{~m}, 3 \mathrm{H}), 1.16-0.97(\mathrm{~m}, 1 \mathrm{H}), 0.94-0.70(\mathrm{~m}, 2 \mathrm{H}), 0.59-0.43(\mathrm{~m}, 2 \mathrm{H})$. ESI-MS m/z $625.75(\mathrm{M}+\mathrm{H})^{+}$

\section{4-Cyclopentyl-2-(oxetan-3-ylmethyl)-4-(1-((1-(4-(pyridin-4-} ylsulfonyl)phenyl)azetidin-3-yl)-methyl)piperidin-4-yl)-1,2,3,4tetrahydroisoquinoline (28): Compound 28 was prepared from crude 22 and oxetane-3carbaldehyde according to the procedure described for compound 24. ${ }^{1} \mathrm{H}$ NMR (400 MHz, MeOH-d $\left.{ }_{4}\right) \delta 8.76(\mathrm{~d}, J=5.8 \mathrm{~Hz}, 2 \mathrm{H}), 7.84(\mathrm{~d}, J=6.1 \mathrm{~Hz}, 2 \mathrm{H}), 7.76(\mathrm{~d}, J=8.8 \mathrm{~Hz}, 2 \mathrm{H}), 7.60$ $-7.49(\mathrm{~m}, 1 \mathrm{H}), 7.45(\mathrm{t}, J=7.5 \mathrm{~Hz}, 1 \mathrm{H}), 7.36(\mathrm{t}, J=7.4 \mathrm{~Hz}, 1 \mathrm{H}), 7.30(\mathrm{~d}, J=7.4 \mathrm{~Hz}, 1 \mathrm{H})$, $6.50(\mathrm{~d}, J=8.8 \mathrm{~Hz}, 2 \mathrm{H}), 4.18(\mathrm{t}, J=8.1 \mathrm{~Hz}, 2 \mathrm{H}), 3.88-3.70(\mathrm{~m}, 5 \mathrm{H}), 3.70-3.54(\mathrm{~m}, 5 \mathrm{H})$, $3.54-3.37$ (m, 4H), $3.09-2.88(\mathrm{~m}, 2 \mathrm{H}), 2.68-2.42(\mathrm{~m}, 2 \mathrm{H}), 2.41-2.23(\mathrm{~m}, 1 \mathrm{H}), 2.17(\mathrm{~d}$, $J=14.3 \mathrm{~Hz}, 1 \mathrm{H}), 1.93-1.75(\mathrm{~m}, 3 \mathrm{H}), 1.75-1.21(\mathrm{~m}, 10 \mathrm{H}), 1.12-0.93(\mathrm{~m}, 1 \mathrm{H})$. ESI-MS $\mathrm{m} / \mathrm{z} 641.93(\mathrm{M}+\mathrm{H})^{+}$

4-Cyclopentyl-2-(pyridin-4-ylmethyl)-4-(1-((1-(4-(pyridin-4y(sulfonyl)phenyl)azetidin-3-yl)methyl)piperidin-4-yl)-1,2,3,4tetrahydroisoquinoline (29): Compound 29 was prepared from crude 22 and isonicotinaldehyde according to the procedure described for compound 24. ${ }^{1} \mathrm{H}$ NMR (400 $\left.\mathrm{MHz}, \mathrm{MeOH}-\mathrm{d}_{4}\right) \delta 8.78(\mathrm{dd}, J=12.1,3.8 \mathrm{~Hz}, 4 \mathrm{H}), 8.07(\mathrm{~d}, J=5.7 \mathrm{~Hz}, 2 \mathrm{H}), 7.84(\mathrm{~d}, J=4.7$ $\mathrm{Hz}, 2 \mathrm{H}), 7.76(\mathrm{~d}, J=8.7 \mathrm{~Hz}, 2 \mathrm{H}), 7.41(\mathrm{~d}, J=7.6 \mathrm{~Hz}, 1 \mathrm{H}), 7.24(\mathrm{t}, J=7.1 \mathrm{~Hz}, 1 \mathrm{H}), 7.14(\mathrm{t}, J$ $=7.4 \mathrm{~Hz}, 1 \mathrm{H}), 6.99(\mathrm{~d}, J=7.2 \mathrm{~Hz}, 1 \mathrm{H}), 6.50(\mathrm{~d}, J=8.8 \mathrm{~Hz}, 2 \mathrm{H}), 4.26-4.06(\mathrm{~m}, 3 \mathrm{H}), 3.93$ (d, $J=15.6 \mathrm{~Hz}, 1 \mathrm{H}), 3.84-3.70(\mathrm{~m}, 2 \mathrm{H}), 3.68-3.37(\mathrm{~m}, 7 \mathrm{H}), 3.10-2.95(\mathrm{~m}, 2 \mathrm{H}), 2.90(\mathrm{t}$, $J=12.7 \mathrm{~Hz}, 1 \mathrm{H}), 2.78(\mathrm{~d}, J=12.0 \mathrm{~Hz}, 1 \mathrm{H}), 2.58-2.44(\mathrm{~m}, 1 \mathrm{H}), 2.40(\mathrm{~d}, J=13.8 \mathrm{~Hz}, 1 \mathrm{H})$, 
$2.25-2.10(\mathrm{~m}, 1 \mathrm{H}), 2.02-1.80(\mathrm{~m}, 2 \mathrm{H}), 1.73(\mathrm{~d}, J=14.3 \mathrm{~Hz}, 1 \mathrm{H}), 1.66-1.38(\mathrm{~m}, 6 \mathrm{H})$, $1.38-1.27(\mathrm{~m}, 1 \mathrm{H}), 1.27-1.12(\mathrm{~m}, 1 \mathrm{H})$. ESI-MS m/z $662.58(\mathrm{M}+\mathrm{H})^{+}$

4-(2-(4-Cyclopentyl-4-(1-((1-(4-(pyridin-4-ylsulfonyl)phenyl)azetidin-3yl)methyl)piperidin-4-yl)-3,4-dihydroisoquinolin-2(1H)-yl)ethyl)morpholine

(30): Compound 30 was prepared from crude 22 and 4-(2-bromoethyl)morpholine according to the procedure described for compound $23 .{ }^{1} \mathrm{H} \mathrm{NMR}\left(400 \mathrm{MHz}, \mathrm{MeOH}-\mathrm{d}_{4}\right) \delta$ $8.75(\mathrm{~d}, J=5.4 \mathrm{~Hz}, 2 \mathrm{H}), 7.82(\mathrm{~d}, J=6.1 \mathrm{~Hz}, 2 \mathrm{H}), 7.76(\mathrm{~d}, J=8.8 \mathrm{~Hz}, 2 \mathrm{H}), 7.41(\mathrm{~d}, J=7.7$ $\mathrm{Hz}, 1 \mathrm{H}), 7.25(\mathrm{t}, J=7.6 \mathrm{~Hz}, 1 \mathrm{H}), 7.18(\mathrm{t}, J=7.7 \mathrm{~Hz}, 1 \mathrm{H}), 7.12(\mathrm{~d}, J=6.7 \mathrm{~Hz}, 1 \mathrm{H}), 6.50(\mathrm{~d}, J$ $=8.9 \mathrm{~Hz}, 2 \mathrm{H}), 4.18(\mathrm{t}, J=7.9 \mathrm{~Hz}, 2 \mathrm{H}), 3.98-3.85(\mathrm{~m}, 4 \mathrm{H}), 3.83(\mathrm{~s}, 1 \mathrm{H}), 3.75(\mathrm{dd}, J=9.6$, $4.0 \mathrm{~Hz}, 2 \mathrm{H}), 3.62-3.38(\mathrm{~m}, 9 \mathrm{H}), 3.27-3.17(\mathrm{~m}, 1 \mathrm{H}), 3.16-2.81(\mathrm{~m}, 6 \mathrm{H}), 2.70(\mathrm{~d}, J=12.3$ $\mathrm{Hz}, 1 \mathrm{H}), 2.48(\mathrm{dt}, J=17.6,8.7 \mathrm{~Hz}, 1 \mathrm{H}), 2.32(\mathrm{~d}, J=14.4 \mathrm{~Hz}, 1 \mathrm{H}), 2.23-2.10(\mathrm{~m}, 1 \mathrm{H}), 2.01$ $-1.85(\mathrm{~m}, 1 \mathrm{H}), 1.85-1.73(\mathrm{~m}, 1 \mathrm{H}), 1.67(\mathrm{~d}, J=13.9 \mathrm{~Hz}, 1 \mathrm{H}), 1.63-1.37(\mathrm{~m}, 7 \mathrm{H}), 1.37-$ $1.24(\mathrm{~m}, 1 \mathrm{H}), 1.24-1.09(\mathrm{~m}, 1 \mathrm{H})$. ESI-MS m/z $684.50(\mathrm{M}+\mathrm{H})^{+}$

rac-4-(3-((4-(cyano(cyclopentyl)(phenyl)methyl)piperidin-1yl)methyl)azetidin-1-yl)benzonitrile (31): Compound $\mathbf{3 1}$ was synthesized using the method described for compound 102a from the intermediate 84 and 79. ${ }^{1} \mathrm{H}$ NMR (400 MHz,

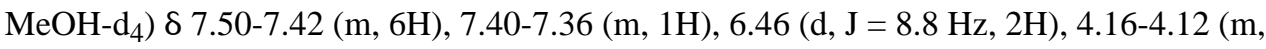
$2 \mathrm{H}), 3.72-3.69(\mathrm{~m}, 2 \mathrm{H}), 3.54(\mathrm{t}, \mathrm{J}=14.1 \mathrm{~Hz}, 2 \mathrm{H}), 3.41(\mathrm{~d}, \mathrm{~J}=7.2 \mathrm{~Hz}, 2 \mathrm{H}), 3.24-3.16(\mathrm{~m}$, $1 \mathrm{H}), 3.12-2.98(\mathrm{~m}, 2 \mathrm{H}), 2.97-2.89(\mathrm{~m}, 1 \mathrm{H}), 2.42-2.36(\mathrm{~m}, 1 \mathrm{H}), 2.28(\mathrm{~d}, \mathrm{~J}=14.3 \mathrm{~Hz}, 1 \mathrm{H})$, 2.08-2.00 (m, 2H), 1.76-1.67 (m 2H), 1.65-1.55 (m, 4H), 1.53-1.38 (m, 2H), 1.29-1.16 (m, $1 \mathrm{H}) ; \mathrm{ESI}-\mathrm{MS} \mathrm{m} / \mathrm{z} 439.42(\mathrm{M}+\mathrm{H})^{+}$.

rac-4-(3-((4-((S)-Cyano((1R,2S)-2-methoxycyclopentyl) (phenyl)methyl)piperidin-1-yl)-methyl)azetidin-1-yl)benzonitrile (32): $\mathrm{NaH}$ (60\% dispersion in mineral oil, $5.3 \mathrm{mg}, 0.132 \mathrm{mmol})$ at $0{ }^{\circ} \mathrm{C}$ was added to a solution of the intermediate 102a (30 mg, $0.066 \mathrm{mmol}$ ) in DMF (1mL). After stirring for $10 \mathrm{~min}$, MeI (9.4 $\mathrm{mg}, 0.066 \mathrm{mmol}$ ) was added. The reaction mixture was stirred for additional $3 \mathrm{~h}$, then was quenched with $\mathrm{H}_{2} \mathrm{O}$. The mixture was purified directly by reverse phase preparative HPLC to give the title compound as a TFA salt $(14 \mathrm{mg}, 38 \%) .{ }^{1} \mathrm{H} \mathrm{NMR}\left(400 \mathrm{MHz}, \mathrm{MeOH}-\mathrm{d}_{4}\right) \delta$ $7.53(\mathrm{~d}, J=7.2 \mathrm{~Hz}, 2 \mathrm{H}), 7.49-7.44(\mathrm{~m}, 4 \mathrm{H}), 7.43-7.39(\mathrm{~m}, 1 \mathrm{H}), 6.46(\mathrm{~d}, \mathrm{~J}=8.8 \mathrm{~Hz}, 2 \mathrm{H})$, 4.17-4.12 (m, 2H), 3.74-3.70 (m, 2H), $3.58(\mathrm{~d}, \mathrm{~J}=12.2 \mathrm{~Hz}, 1 \mathrm{H}), 3.51(\mathrm{~d}, 12.5 \mathrm{~Hz}, 1 \mathrm{H}), 3.42$ $(\mathrm{d}, \mathrm{J}=7.1 \mathrm{~Hz}, 2 \mathrm{H}), 3.39-3.35(\mathrm{~m}, 1 \mathrm{H}), 3.25-3.15(\mathrm{~m}, 1 \mathrm{H}), 3.11-3.00(\mathrm{~m}, 2 \mathrm{H}), 2.98(\mathrm{~s}, 3 \mathrm{H})$, 2.89-2.83 (m, 1H), 2.50-2.44 (m, 1H), 2.39-2.36 (m, 1H), 2.14-2.08 (m, 1H), $1.96(\mathrm{~d}, \mathrm{~J}=$ $14.4 \mathrm{~Hz}, 1 \mathrm{H}), 1.78-1.72(\mathrm{~m}, 1 \mathrm{H}), 1.71-1.65(\mathrm{~m}, 2 \mathrm{H}), 1.62-1.45$ (m, 4H); ESI-MS m/z [M + $\mathrm{H}]^{+}=469.41$.

rac-4-(3-((4-((R)-Cyano((1R,2S)-2-methoxycyclopentyl) (phenyl)methyl)piperidin-1-yl)-methyl)azetidin-1-yl)benzonitrile (33): Compound $\mathbf{3 3}$ was synthesized from the intermediate $\mathbf{9 5 b}$ using the method described for compound $\mathbf{3 2}$. ${ }^{1} \mathrm{H}$ NMR $\left(400 \mathrm{MHz}, \mathrm{MeOH}-\mathrm{d}_{4}\right)$ 8 7.54-7.42 (m, 6H), 7.41-7.36 (m, 1H), $6.46(\mathrm{~d}, J=8.8 \mathrm{~Hz}$, $2 \mathrm{H}), 4.16-4.11(\mathrm{~m}, 2 \mathrm{H}), 3.93-3.88(\mathrm{~m}, 1 \mathrm{H}), 3.72-3.69(\mathrm{~m}, 2 \mathrm{H}), 3.58-3.51(\mathrm{~m}, 2 \mathrm{H}), 3.41(\mathrm{~d}, \mathrm{~J}$ $=7.2 \mathrm{~Hz}, 2 \mathrm{H}), 3.39(\mathrm{~s}, 3 \mathrm{H}), 3.23-3.09(\mathrm{~m}, 2 \mathrm{H}), 2.99-2.90(\mathrm{~m}, 2 \mathrm{H}), 2.49-2.43(\mathrm{~m}, 1 \mathrm{H}), 2.30$ 
$(\mathrm{d}, \mathrm{J}=14.4 \mathrm{~Hz}, 1 \mathrm{H}), 2.21(\mathrm{~d}, \mathrm{~J}=14.1 \mathrm{~Hz}, 1 \mathrm{H}), 1.89-1.76(\mathrm{~m}, 2 \mathrm{H}), 1.75-1.55(\mathrm{~m}, 3 \mathrm{H})$, 1.49-1.34 (m, 2H), 1.29-1.16 (m, 1H); ESI-MS m/z [M + H] ${ }^{+}=469.41$.

rac-4-(3-((4-((S)-Cyano((1R,2S)-2-ethoxycyclopentyl) (phenyl)methyl)piperidin-1-yl)-methyl)azetidin-1-yl)benzonitrile (34): Compound 34 was obtained according to the procedure described for compound $\mathbf{3 2}$ using EtI. ${ }^{1} \mathrm{H}$ NMR $\left(400 \mathrm{MHz}, \mathrm{MeOH}-\mathrm{d}_{4}\right) \delta 7.54(\mathrm{~d}, \mathrm{~J}=7.3 \mathrm{~Hz}, 2 \mathrm{H}), 7.49-7.38(\mathrm{~m}, 5 \mathrm{H}), 6.46(\mathrm{~d}, \mathrm{~J}=8.8 \mathrm{~Hz}$, $2 \mathrm{H}), 4.17-4.12(\mathrm{~m}, 2 \mathrm{H}), 3.73-3.70(\mathrm{~m}, 2 \mathrm{H}), 3.60-3.47(\mathrm{~m}, 3 \mathrm{H}), 3.42(\mathrm{~d}, \mathrm{~J}=7.1 \mathrm{~Hz}, 2 \mathrm{H})$, 3.36-3.32 (m, $1 \mathrm{H}), 3.23-3.16(\mathrm{~m}, 1 \mathrm{H}), 3.09-3.00(\mathrm{~m}, 2 \mathrm{H}), 2.90-2.81(\mathrm{~m}, 2 \mathrm{H}), 2.48-2.35(\mathrm{~m}$, $2 \mathrm{H}), 2.15-2.09(\mathrm{~m}, 1 \mathrm{H}), 1.98(\mathrm{~d}, \mathrm{~J}=14.4 \mathrm{~Hz}, 1 \mathrm{H}), 1.74-1.67(\mathrm{~m}, 3 \mathrm{H}), 1.65-1.56(\mathrm{~m}, 1 \mathrm{H})$, 1.54-1.42 (m, 3H), $0.95(\mathrm{t}, \mathrm{J}=7.0 \mathrm{~Hz}, 3 \mathrm{H})$; ESI-MS m/z [M + H $]^{+}=483.42$.

rac-(1S,2R)-2-((S)-Cyano(1-((1-(4-cyanophenyl)azetidin-3-yl)methyl)piperidin-4yl)(phenyl)methyl)cyclopentyl acetate (35): Acetic anhydride (9 mg, $0.088 \mathrm{mmol})$ was added at $0{ }^{\circ} \mathrm{C}$ to a solution of the intermediate 102a ( $\left.20 \mathrm{mg}, 0.044 \mathrm{mmol}\right)$ and $\mathrm{Et}_{3} \mathrm{~N}$ (13 $\mathrm{mg}, 0.131 \mathrm{mmol})$ in DCM $(2 \mathrm{~mL})$. The reaction mixture was stirred for $1 \mathrm{~h}$ at $\mathrm{rt}$. Then the reaction was concentrated under vacuum. The residue was purified directly by reverse phase preparative HPLC to give the title compound as a TFA salt (13 mg, 50\%). ${ }^{1} \mathrm{H}$ NMR (400 $\left.\mathrm{MHz}, \mathrm{MeOH}-\mathrm{d}_{4}\right) \delta$ 7.51-7.36 (m, 7H), $6.46(\mathrm{~d}, \mathrm{~J}=8.8 \mathrm{~Hz}, 2 \mathrm{H}), 4.91-4.88(\mathrm{~m}, 1 \mathrm{H})$, 4.16-4.12 (m, 2H), 3.72-3.69 (m, 2H), $3.55(\mathrm{t}, \mathrm{J}=11.6 \mathrm{~Hz}, 2 \mathrm{H}), 3.41(\mathrm{~d}, \mathrm{~J}=7.1 \mathrm{~Hz}, 2 \mathrm{H})$, 3.24-3.13 (m, 2H), 3.10-3.01 (m, 2H), $2.41(\mathrm{t}, \mathrm{J}=12.3 \mathrm{~Hz}, 1 \mathrm{H}), 2.28-2.25(\mathrm{~m}, 2 \mathrm{H}), 2.06(\mathrm{~d}$, $\mathrm{J}=14.3 \mathrm{~Hz}, 1 \mathrm{H}), 1.87-1.77(\mathrm{~m}, 3 \mathrm{H}), 1.76(\mathrm{~s}, 3 \mathrm{H}), 1.73-1.62(\mathrm{~m}, 2 \mathrm{H}), 1.59-1.48(\mathrm{~m}, 1 \mathrm{H})$, 1.45-1.34 (m, 1H); ESI-MS m/z [M + H $]^{+}=497.42$.

rac-(1S,2R)-2-((R)-Cyano(1-((1-(4-cyanophenyl)azetidin-3-yl)methyl)piperidin-4yl)-(phenyl)methyl)cyclopentyl acetate (36): Compound 36 was synthesized from the intermediate 95b using the method described for compound 35. ${ }^{1} \mathrm{H}$ NMR $(400 \mathrm{MHz}$, MeOH-d $\left.{ }_{4}\right)$ 反 7.50-7.44 (m, 6H), 7.42-7.38 (m, 1H), $6.46(\mathrm{~d}, \mathrm{~J}=8.8 \mathrm{~Hz}, 2 \mathrm{H}), 5.21-5.18(\mathrm{~m}$, $1 \mathrm{H}), 4.16-4.11(\mathrm{~m}, 2 \mathrm{H}), 3.73-3.69(\mathrm{~m}, 2 \mathrm{H}), 3.56(\mathrm{t}, \mathrm{J}=14.0 \mathrm{~Hz}, 2 \mathrm{H}), 3.42(\mathrm{~d}, \mathrm{~J}=7.1 \mathrm{~Hz}$, 2H), 3.23-3.18 (m, 1H), 3.16-3.09 (m, 2H), $2.96(\mathrm{t}, \mathrm{J}=12.4 \mathrm{~Hz}, 1 \mathrm{H}), 2.54(\mathrm{t}, \mathrm{J}=12.1 \mathrm{~Hz}$, $1 \mathrm{H}), 2.31-2.27(\mathrm{~m}, 1 \mathrm{H}), 2.11(\mathrm{~s}, 3 \mathrm{H}), 2.04(\mathrm{~d}, \mathrm{~J}=14.3 \mathrm{~Hz}, 1 \mathrm{H}), 1.99-1.91(\mathrm{~m}, 1 \mathrm{H}), 1.90-1.82$ $(\mathrm{m}, 1 \mathrm{H}), 1.76-1.68(\mathrm{~m}, 2 \mathrm{H}), 1.67-1.58(\mathrm{~m}, 1 \mathrm{H}), 1.56-1.41(\mathrm{~m}, 2 \mathrm{H}), 1.33-1.22(\mathrm{~m}, 1 \mathrm{H})$. ESIMS m/z $[\mathrm{M}+\mathrm{H}]^{+}=497.38$.

rac-(1S,2R)-2-((S)-Cyano(1-((1-(4-cyanophenyl)azetidin-3-yl)methyl)piperidin-4yl)-(phenyl)methyl)cyclopentyl propionate (37): Compound 37 was obtained according to the procedure described for compound 35. ${ }^{1} \mathrm{H}$ NMR $\left(400 \mathrm{MHz}, \mathrm{MeOH}-\mathrm{d}_{4}\right) \delta$ 7.51-7.36 (m, 7H), $7.46(\mathrm{~d}, \mathrm{~J}=8.8 \mathrm{~Hz}, 2 \mathrm{H}), 4.93-4.88(\mathrm{~m}, 1 \mathrm{H}), 4.16-4.12(\mathrm{~m}, 2 \mathrm{H}), 3.71(\mathrm{t}, \mathrm{J}$ $=6.7 \mathrm{~Hz}, 2 \mathrm{H}), 3.54(\mathrm{t}, \mathrm{J}=9.8 \mathrm{~Hz}, 2 \mathrm{H}), 3.41(\mathrm{~d}, \mathrm{~J}=7.1 \mathrm{~Hz}, 2 \mathrm{H}), 3.22-3.13(\mathrm{~m}, 2 \mathrm{H})$, 3.09-3.01 (m, 2H), $2.40(\mathrm{t}, \mathrm{J}=12.3 \mathrm{~Hz}, 1 \mathrm{H}), 2.27-2.23(\mathrm{~m}, 2 \mathrm{H}), 2.15-1.96(\mathrm{~m}, 3 \mathrm{H})$, 1.88-1.74 (m, 3H), 1.73-1.61 (m, 2H), 1.58-1.47 (m, 1H), 1.43-1.29 (m, 1H), $0.93(\mathrm{t}, \mathrm{J}=7.5$ $\mathrm{Hz}, 3 \mathrm{H}) ; \mathrm{ESI}-\mathrm{MS} \mathrm{m} / \mathrm{z}[\mathrm{M}+\mathrm{H}]^{+}=511.38$.

rac-(1S,2R)-2-((S)-Cyano(1-((1-(4-cyanophenyl)azetidin-3-yl)methyl)piperidin-4yl)-(phenyl)methyl)cyclopentyl butyrate (38): Compound 38 was obtained according 
to the procedure described for compound 35. ${ }^{1} \mathrm{H}$ NMR $\left(400 \mathrm{MHz}, \mathrm{MeOH}-\mathrm{d}_{4}\right) \delta 7.51-7.42$ (m, 6H), 7.40-7.36 (m, 1H), 6,46 (d, J = 8.8 Hz, 2H), 4.93-4.88 (m, 1H), 4.16-4.12 (m, 2H), $3.71(\mathrm{t}, \mathrm{J}=5.9 \mathrm{~Hz}, 2 \mathrm{H}), 3.54(\mathrm{t}, \mathrm{J}=9.9 \mathrm{~Hz}, 2 \mathrm{H}), 3.41(\mathrm{~d}, \mathrm{~J}=7.1 \mathrm{~Hz}, 2 \mathrm{H}), 3.23-3.12(\mathrm{~m}, 2 \mathrm{H})$, 3.09-3.00 (m, 2H), $2.39(\mathrm{t}, \mathrm{J}=12.4 \mathrm{~Hz}, 1 \mathrm{H}), 2.27-2.24(\mathrm{~m}, 2 \mathrm{H}), 2.11-1.94(\mathrm{~m}, 3 \mathrm{H})$, $1.88-1.61(\mathrm{~m}, 5 \mathrm{H}), 1.57-1.50(\mathrm{~m}, 1 \mathrm{H}), 1.49-1.40(\mathrm{~m}, 2 \mathrm{H}), 1.39-1.29(\mathrm{~m}, 1 \mathrm{H}), 0.84(\mathrm{t}, \mathrm{J}=7.4$ $\mathrm{Hz}, 3 \mathrm{H}) ; \mathrm{ESI}-\mathrm{MS} \mathrm{m} / \mathrm{z}[\mathrm{M}+\mathrm{H}]^{+}=525.37$.

rac-(1S,2R)-2-((S)-Cyano(1-((1-(4-cyanophenyl)azetidin-3-yl)methyl)piperidin-4yl)-(phenyl)methyl)cyclopentyl methylcarbamate (39): Methylisocyanate (8 mg, $0.145 \mathrm{mmol}$ ) was added at $0{ }^{\circ} \mathrm{C}$ to a solution of the intermediate 102a $(22 \mathrm{mg}, 0.048 \mathrm{mmol})$ and $\mathrm{Et}_{3} \mathrm{~N}(15 \mathrm{mg}, 0.145 \mathrm{mmol})$ in DCM $(2 \mathrm{~mL})$. The reaction mixture was stirred overnight at rt. Then the reaction was concentrated under vacuum. The residue was purified directly by reverse phase preparative HPLC to give the title compound as a salt of TFA (13 mg, 34\%). ${ }^{1} \mathrm{H}$ NMR $\left(400 \mathrm{MHz}, \mathrm{MeOH}-\mathrm{d}_{4}\right)$ 6 7.51-7.37 (m, 7H), $6.46(\mathrm{~d}, J=8.8 \mathrm{~Hz}, 2 \mathrm{H}), 4.88-4.86(\mathrm{~m}$, $1 \mathrm{H}), 4.17-4.12(\mathrm{~m}, 2 \mathrm{H}), 3.73-3.70(\mathrm{~m}, 2 \mathrm{H}), 3.58(\mathrm{~d}, J=12.2 \mathrm{~Hz}, 1 \mathrm{H}), 3.52(\mathrm{~d}, J=12.3 \mathrm{~Hz}$, $1 \mathrm{H}), 3.43(\mathrm{~d}, J=7.1 \mathrm{~Hz}, 2 \mathrm{H}), 3.23-3.17(\mathrm{~m}, 1 \mathrm{H}), 3.08-3.01(\mathrm{~m}, 3 \mathrm{H}), 2.56(\mathrm{~s}, 3 \mathrm{H}), 2.45(\mathrm{t}, J=$ $12.0 \mathrm{~Hz}, 1 \mathrm{H}), 2.32(\mathrm{~d}, J=14.3 \mathrm{~Hz}, 1 \mathrm{H}), 2.22-2.16(\mathrm{~m}, 1 \mathrm{H}), 1.97(\mathrm{~d}, J=14.1 \mathrm{~Hz}, 1 \mathrm{H})$, 1.74-1.63 (m, 4H), 1.60-1.47 (m, 3H); ESI-MS m/z [M + H $]^{+}=512.40$.

rac-N-((1S,2R)-2-((S)-Cyano(1-((1-(4-cyanophenyl)azetidin-3yl)methyl)piperidin-4-yl)-(phenyl)methyl)cyclopentyl)acetamide (40): Compound 40 was synthesized using the method described for compound 102a from the intermediate 97a and 79. ${ }^{1} \mathrm{H} \mathrm{NMR}\left(400 \mathrm{MHz}, \mathrm{MeOH}-\mathrm{d}_{4}\right) \delta 7.54(\mathrm{~d}, J=7.7 \mathrm{~Hz}, 2 \mathrm{H}), 7.51-7.36(\mathrm{~m}, 5 \mathrm{H})$, $6.48(\mathrm{~d}, J=8.8 \mathrm{~Hz}, 2 \mathrm{H}), 4.26-4.12(\mathrm{~m}, 3 \mathrm{H}), 3.77-3.68(\mathrm{~m}, 2 \mathrm{H}), 3.59(\mathrm{~d}, J=12.4 \mathrm{~Hz}, 1 \mathrm{H})$, $3.53(\mathrm{~d}, J=12.2 \mathrm{~Hz}, 1 \mathrm{H}), 3.43(\mathrm{~d}, J=7.1 \mathrm{~Hz}, 2 \mathrm{H}), 3.26-3.14(\mathrm{~m}, 1 \mathrm{H}), 3.04(\mathrm{t}, J=13.1 \mathrm{~Hz}$, 2H), $2.84(\mathrm{q}, J=7.7 \mathrm{~Hz}, 1 \mathrm{H}), 2.54(\mathrm{t}, J=12.2 \mathrm{~Hz}, 1 \mathrm{H}), 2.25(\mathrm{~d}, J=14.7 \mathrm{~Hz}, 1 \mathrm{H}), 2.20-$ $2.10(\mathrm{~m}, 1 \mathrm{H}), 1.99-1.90(\mathrm{~m}, 1 \mathrm{H}), 1.79-1.67(\mathrm{~m}, 3 \mathrm{H}), 1.66(\mathrm{~s}, 3 \mathrm{H}), 1.65-1.41(\mathrm{~m}, 4 \mathrm{H})$. MS (ESI) m/z $496.47[\mathrm{M}+\mathrm{H}]^{+}$

rac-Methyl ((1S,2R)-2-((S)-cyano(1-((1-(4-cyanophenyl)azetidin-3yl)methyl)piperidin-4-yl)(phenyl)methyl)cyclopentyl)carbamate (41): ${ }^{25}$ Compound 41 was synthesized using the method described for compound 102a starting from the intermediate 101a and 79. ${ }^{1} \mathrm{H}$ NMR $\left(400 \mathrm{MHz}, \mathrm{MeOH}-\mathrm{d}_{4}\right) \delta 7.52(\mathrm{~d}, J=7.2 \mathrm{~Hz}$, $2 \mathrm{H}), 7.47$ (d, $J=8.8 \mathrm{~Hz}, 2 \mathrm{H}), 7.45-7.36(\mathrm{~m}, 3 \mathrm{H}), 6.47$ (d, $J=8.8 \mathrm{~Hz}, 2 \mathrm{H}), 4.17-4.12(\mathrm{~m}$, $2 \mathrm{H}), 3.93-3.88(\mathrm{~m}, 1 \mathrm{H}), 3.73-3.70(\mathrm{~m}, 2 \mathrm{H}), 3.60-3.51(\mathrm{~m}, 2 \mathrm{H}), 3.44(\mathrm{~s}, 3 \mathrm{H}), 3.42(\mathrm{~s}, 2 \mathrm{H})$, $3.23-3.17(\mathrm{~m}, 1 \mathrm{H}), 3.07-2.99(\mathrm{~m}, 2 \mathrm{H}), 2.89-2.83(\mathrm{~m}, 1 \mathrm{H}), 2.50(\mathrm{t}, J=10.2 \mathrm{~Hz}, 1 \mathrm{H}), 2.28(\mathrm{~d}$, $J=14.6 \mathrm{~Hz}, 1 \mathrm{H}), 2.16-2.10(\mathrm{~m}, 1 \mathrm{H}), 1.94(\mathrm{~d}, J=14.3 \mathrm{~Hz}, 1 \mathrm{H}), 1.79-1.44(\mathrm{~m}, 7 \mathrm{H})$; ESI-MS $\mathrm{m} / \mathrm{z}[\mathrm{M}+\mathrm{H}]^{+}=512.42$.

rac-(1S,2R)-2-((S)-2-Methyl-4-(1-((1-(4-(pyridin-4-ylsulfonyl)phenyl)azetidin-3yl)methyl)piperidin-4-yl)-1,2,3,4-tetrahydroisoquinolin-4-yl)cyclopentyl methylcarbamate 42 (M-89): Methylisocyanate $(0.3 \mathrm{mmol})$ was added to a solution of compound 110 (30 mg, $0.05 \mathrm{mmol})$ and $\mathrm{NEt}_{3}(28 \mu \mathrm{L}, 0.2 \mathrm{mmol})$ in DCM $(1 \mathrm{~mL})$ then stirred at $\mathrm{rt}$ for $4 \mathrm{~h}$. The reaction was diluted with $3: 1 \mathrm{MeOH} / \mathrm{H}_{2} \mathrm{O}(10 \% \mathrm{TFA})$ and purified by preparative HPLC. The pure fractions were combined, concentrated, diluted with $\mathrm{H}_{2} \mathrm{O}$, 
frozen and lyophilized to give $\mathbf{4 2}$ (M-89) as a yellow powder. ${ }^{1} \mathrm{H}$ NMR (400 MHz, MeOH$\left.\mathrm{d}_{4}\right) \delta 8.75(\mathrm{~d}, J=5.6 \mathrm{~Hz}, 2 \mathrm{H}), 7.83(\mathrm{~d}, J=5.5 \mathrm{~Hz}, 2 \mathrm{H}), 7.75(\mathrm{~d}, J=8.6 \mathrm{~Hz}, 2 \mathrm{H}), 7.54(\mathrm{~d}, J=$ $7.8 \mathrm{~Hz}, 1 \mathrm{H}), 7.41$ (t, $J=7.7 \mathrm{~Hz}, 1 \mathrm{H}), 7.34(\mathrm{t}, J=7.4 \mathrm{~Hz}, 1 \mathrm{H}), 7.24(\mathrm{~d}, J=7.4 \mathrm{~Hz}, 1 \mathrm{H}), 6.48$ $(\mathrm{d}, J=8.7 \mathrm{~Hz}, 2 \mathrm{H}), 5.17-5.04(\mathrm{~m}, 1 \mathrm{H}), 4.44-4.25(\mathrm{~m}, 3 \mathrm{H}), 4.15(\mathrm{t}, J=8.2 \mathrm{~Hz}, 2 \mathrm{H}), 3.77-$ $3.67(\mathrm{~m}, 2 \mathrm{H}), 3.55(\mathrm{~d}, J=12.2 \mathrm{~Hz}, 1 \mathrm{H}), 3.38(\mathrm{~d}, J=7.3 \mathrm{~Hz}, 2 \mathrm{H}), 3.24-3.14(\mathrm{~m}, 4 \mathrm{H}), 3.05-$ $2.84(\mathrm{~m}, 4 \mathrm{H}), 2.28$ (s, 3H), $2.14-1.99$ (m, 4H), $1.92-1.55$ (m, 8H). MS (ESI) m/z: [M + $\mathrm{H}]^{+}=658.4$.

1-Benzyl-N-phenethylpiperidine-4-carboxamide (45): DMF (1 drop) was added to a suspension of 1-benzylpiperidine-4-carboxylic acid (15 g, $68.4 \mathrm{mmol})$ in DCM $(100 \mathrm{~mL})$ and this was followed by dropwise addition of oxalyl chloride $(7 \mathrm{~mL}, 82 \mathrm{mmol})$. The mixture was stirred for $4 \mathrm{~h}$ then concentrated under vacuum, affording an acid chloride, which was rediluted with DCM $(100 \mathrm{~mL})$. Triethylamine $(23.8 \mathrm{~mL}, 171 \mathrm{mmol})$ was added to the mixture, followed by 2-phenylethan-1-amine $(8.29 \mathrm{~g}, 68.4 \mathrm{mmol})$ at $0{ }^{\circ} \mathrm{C}$. The reaction mixture was stirred at rt overnight. The organic phase was washed with brine, dried over $\mathrm{Na}_{2} \mathrm{SO}_{4}$ and evaporated. The crude product was purified by recrystallization in DCM to obtain the title compound $(14.9 \mathrm{~g}, 68 \%) .{ }^{1} \mathrm{H} \mathrm{NMR}\left(400 \mathrm{MHz}, \mathrm{CDCl}_{3}\right) \delta 7.34-7.20(\mathrm{~m}$, $8 \mathrm{H}), 7.19-7.14(\mathrm{~m}, 2 \mathrm{H}), 5.45(\mathrm{~s}, 1 \mathrm{H}), 3.57-3.40(\mathrm{~m}, 4 \mathrm{H}), 2.90(\mathrm{dt}, J=11.2,2.5 \mathrm{~Hz}, 2 \mathrm{H})$, $2.80(\mathrm{t}, J=6.8 \mathrm{~Hz}, 2 \mathrm{H}), 2.08-1.88(\mathrm{~m}, 3 \mathrm{H}), 1.83-1.61(\mathrm{~m}, 4 \mathrm{H}) . \mathrm{MS}$ (ESI) m/z 323.2 [M $+\mathrm{H}]^{+}$

1-(1-Benzylpiperidin-4-yl)-3,4-dihydroisoquinoline (46): Phosphoryl chloride (3.3 $\mathrm{mL}, 35.4 \mathrm{mmol})$ and phosphorus pentoxide $(3.35 \mathrm{~g}, 23.6 \mathrm{mmol})$ were added to a solution of the intermediate $45(3.82 \mathrm{~g}, 11.9 \mathrm{mmol})$ in toluene $(15 \mathrm{~mL})$. The reaction mixture was stirred under reflux overnight then the mixture was quenched and basified with saturated $\mathrm{NaHCO}_{3}$, extracted with DCM, and dried over $\mathrm{Na}_{2} \mathrm{SO}_{4}$. The solvent was evaporated to give the title compound $(3.5 \mathrm{~g}, 97 \%)$, which was used in the next step without further purification. MS (ESI) m/z $305.3[\mathrm{M}+\mathrm{H}]^{+}$

\section{1-(1-Benzylpiperidin-4-yl)-1-cyclopentyl-1,2,3,4-tetrahydroisoquinoline}

(47): Boron trifluoride diethyl etherate $(0.6 \mathrm{~mL})$ was added to a solution of the intermediate $46(0.5 \mathrm{~g}, 1.64 \mathrm{mmol})$ at $0{ }^{\circ} \mathrm{C}$ under an $\mathrm{N}_{2}$ atmosphere. After the mixture was stirred for 5 $\mathrm{min}$, a $2 \mathrm{M}$ solution of cyclopentylmagnesium bromide in $\mathrm{Et}_{2} \mathrm{O}(3.3 \mathrm{~mL}, 6.6 \mathrm{mmol})$ was added into the mixture dropwise at $0{ }^{\circ} \mathrm{C}$. The reaction mixture was stirred overnight, then warmed slowly to rt. The reaction was quenched with saturated aqueous $\mathrm{NH}_{4} \mathrm{Cl}$, extracted with DCM, dried over $\mathrm{Na}_{2} \mathrm{SO}_{4}$, and the solvent was evaporated. The crude product was purified by preparative HPLC to give the title compound as its TFA salt $(740 \mathrm{mg}, 60 \%) .{ }^{1} \mathrm{H}$ NMR (400 MHz, $\left.\mathrm{CDCl}_{3}\right)$ \& 7.48-7.35 (m, 5H), 7.32-7.28 (m, 2H), 7.21-7.13 (m, 2H), 4.11 (dd, $J=25.6,12.9 \mathrm{~Hz}, 2 \mathrm{H}), 3.65-3.37(\mathrm{~m}, 4 \mathrm{H}), 3.16-2.91(\mathrm{~m}, 2 \mathrm{H}), 2.86-2.75(\mathrm{~m}, 2 \mathrm{H}), 2.69$ $(\mathrm{t}, J=11.5 \mathrm{~Hz}, 1 \mathrm{H}), 2.40(\mathrm{~d}, J=11.7 \mathrm{~Hz}, 1 \mathrm{H}), 2.27-2.12(\mathrm{~m}, 2 \mathrm{H}), 1.96-1.80(\mathrm{~m}, 2 \mathrm{H})$, $1.75-1.57$ (m, 4H), $1.46(\mathrm{dd}, J=33.9,3.1 \mathrm{~Hz}, 2 \mathrm{H}), 1.37-1.25(\mathrm{~m}, 1 \mathrm{H}), 1.22-1.09(\mathrm{~m}, 1 \mathrm{H})$. MS (ESI) m/z $375.2[\mathrm{M}+\mathrm{H}]^{+}$

1-Cyclopentyl-1-(piperidin-4-yl)-1,2,3,4-tetrahydroisoquinoline (48): Compound 47 (588 mg, $1.24 \mathrm{mmol}$ ) was dissolved in $\mathrm{MeOH}(5 \mathrm{~mL})$ and the solution was vacuumed 
briefly then put under an $\mathrm{N}_{2}$ atmosphere. This was repeated 3 times, then $\mathrm{Pd} / \mathrm{C}(10 \% \mathrm{wt} / \mathrm{wt})$ $\left(150 \mathrm{mg}\right.$ ) was quickly added to the solution which was again vacuumed and put under an $\mathrm{N}_{2}$ atmosphere. The solution was briefly vacuumed to remove the $\mathrm{N}_{2}$ atmosphere then put under $\mathrm{H}_{2}$ atmosphere. This was repeated 3 times. After $30 \mathrm{~min}$, the reaction was filtered through celite and concentrated to give a crude product (48) that was used without further purification. ${ }^{1} \mathrm{H}$ NMR (400 MHz, DMSO) $\delta$ 7.43-7.38 (m, $\left.1 \mathrm{H}\right), 7.34-7.26(\mathrm{~m}, 3 \mathrm{H})$, 3.49-3.41 (m, 1H), $3.30(\mathrm{t}, J=11.6 \mathrm{~Hz}, 3 \mathrm{H}), 3.00(\mathrm{t}, J=5.9 \mathrm{~Hz}, 2 \mathrm{H}), 2.96-2.89(\mathrm{~m}, 1 \mathrm{H})$, 2.86-2.74 (m, 2H), 2.41-2.30 (m, 1H), $1.98(\mathrm{~d}, J=13.1 \mathrm{~Hz}, 1 \mathrm{H}), 1.89-1.79(\mathrm{~m}, 1 \mathrm{H})$, 1.70-1.39 (m, 7H), 1.35-1.18 (m, 3H). MS (ESI) m/z $285.2[\mathrm{M}+\mathrm{H}]^{+}$

\section{1-(1-(Azetidin-3-ylmethyl)piperidin-4-yl)-1-cyclopentyl-1,2,3,4-} tetrahydroisoquinoline (55): 1-Boc-azetidine-3-carboxaldehyde (920 mg, $4.96 \mathrm{mmol}$ ) was added to a solution of crude $\mathbf{4 8}(1.24 \mathrm{mmol})$ in DCM/AcOH $(1: 1,6 \mathrm{~mL})$ and stirred. After $10 \mathrm{~min}, \mathrm{NaBH}(\mathrm{OAc})_{3}(2.10 \mathrm{~g}, 9.92 \mathrm{mmol})$ was slowly added to the reaction. After standing overnight, the reaction was slowly quenched with saturated $\mathrm{NaHCO}_{3}$, extracted with EtOAc, dried over $\mathrm{Na}_{2} \mathrm{SO}_{4}$, filtered, and concentrated to produce crude Bocprotected-55. To remove the Boc protecting group, the crude product was dissolved in TFA and stirred. After $10 \mathrm{~min}$, the TFA was removed in vacuo, the crude product was purified by reverse phase preparative HPLC, and the pure product was lyophilized to give 55-TFA salt $(569 \mathrm{mg})$ as white solid. ${ }^{1} \mathrm{H}$ NMR $\left(400 \mathrm{MHz}, \mathrm{MeOH}-\mathrm{d}_{4}\right) \delta 7.47-7.39(\mathrm{~m}, 1 \mathrm{H}), 7.39-7.27$ $(\mathrm{m}, 3 \mathrm{H}), 4.27-4.13(\mathrm{~m}, 2 \mathrm{H}), 4.08-3.94(\mathrm{~m}, 2 \mathrm{H}), 3.62(\mathrm{~d}, J=12.4 \mathrm{~Hz}, 1 \mathrm{H}), 3.57-3.37(\mathrm{~m}$, $6 \mathrm{H}), 3.14-2.93(\mathrm{~m}, 4 \mathrm{H}), 2.80-2.58(\mathrm{~m}, 2 \mathrm{H}), 2.24(\mathrm{~d}, J=14.3 \mathrm{~Hz}, 1 \mathrm{H}), 2.05-1.40(\mathrm{~m}$, $10 \mathrm{H}), 1.22-1.07(\mathrm{~m}, 1 \mathrm{H})$.

1-(Cyclopropylsulfonyl)-p-fluorobenzene (67): Bromocyclopropane (2.06 mL, 24.75 $\mathrm{mmol})$ was added to a solution of $p$-fluorobenzenethiol $(3.0 \mathrm{~g}, 23.41 \mathrm{mmol})$ and sodium tertbutoxide $(3.15 \mathrm{~g}, 37.77 \mathrm{mmol})$ in $60 \mathrm{~mL}$ of DMSO and the reaction was heated to $80^{\circ} \mathrm{C}$. After reacting overnight, the system was cooled, quenched with saturated $\mathrm{NH}_{4} \mathrm{Cl}$ and extracted with $\mathrm{Et}_{2} \mathrm{O}$. The combined organic layers were washed twice with saturated $\mathrm{NaHCO}_{3}$, once with brine, dried over $\mathrm{Na}_{2} \mathrm{SO}_{4}$, filtered, and concentrated to produce crude $62(2.20 \mathrm{~g})$ that was used without further purification. $m$-Chloroperbenzoic acid $(7.34 \mathrm{~g}$, $32.74 \mathrm{mmol}$, of $77 \% \mathrm{wt})$ was added to a solution, at $0{ }^{\circ} \mathrm{C}$, of crude $\mathbf{6 2}$ in DCM $(50 \mathrm{~mL})$. After standing overnight at $\mathrm{rt}$, the reaction was quenched with saturated $\mathrm{NaHCO}_{3}$, extracted with EtOAc, and purified by column chromatography to give $\mathbf{6 7}(2.11 \mathrm{~g}, 45 \%)$ as a white solid. ${ }^{1} \mathrm{H}$ NMR (400 MHz, $\left.\mathrm{CDCl}_{3}\right) \delta 7.96-7.88(\mathrm{~m}, 2 \mathrm{H}), 7.28-7.19(\mathrm{~m}, 2 \mathrm{H}), 2.45$ (tt, $J=$ $7.9,4.8 \mathrm{~Hz}, 1 \mathrm{H}), 1.39-1.31(\mathrm{~m}, 2 \mathrm{H}), 1.08-1.01(\mathrm{~m}, 2 \mathrm{H})$.

1-(Cyclobutylsulfonyl)-p-fluorobenzene (68): Compound 68 was prepared according to the procedure used to make compound 67. ${ }^{1} \mathrm{H}$ NMR $\left(400 \mathrm{MHz}, \mathrm{CDCl}_{3}\right) \delta$ 7.91-7.87 (m, $2 \mathrm{H}), 7.26-7.21(\mathrm{~m}, 2 \mathrm{H}), 3.83-3.75(\mathrm{~m}, 1 \mathrm{H}), 2.61-2.51(\mathrm{~m}, 2 \mathrm{H}), 2.25-2.15(\mathrm{~m}, 2 \mathrm{H}), 2.05-1.94$ $(\mathrm{m}, 2 \mathrm{H})$.

1-(Cyclopentylsulfonyl)-p-fluorobenzene (69): Compound 69 was prepared according to the procedure used to make compound $67 .{ }^{1} \mathrm{H} \mathrm{NMR}\left(400 \mathrm{MHz}, \mathrm{CDCl}_{3}\right) \delta 7.98-7.87(\mathrm{~m}$, 
2H), $7.29-7.19(\mathrm{~m}, 2 \mathrm{H}), 3.47(\mathrm{tt}, J=8.8,7.2 \mathrm{~Hz}, 1 \mathrm{H}), 2.12-1.98(\mathrm{~m}, 2 \mathrm{H}), 1.95-1.71(\mathrm{~m}$, $4 \mathrm{H}), 1.67-1.54(\mathrm{~m}, 2 \mathrm{H})$.

1-(Cyclohexylsulfonyl)-p-fluorobenzene (70): Compound 70 was prepared according to the procedure used to make compound $67 .{ }^{1} \mathrm{H} \mathrm{NMR}\left(400 \mathrm{MHz}, \mathrm{CDCl}_{3}\right) \delta 7.90-7.86(\mathrm{~m}$, $2 \mathrm{H}), 7.26-7.22(\mathrm{~m}, 2 \mathrm{H}), 2.93-2.85(\mathrm{~m}, 1 \mathrm{H}), 2.08-2.05(\mathrm{~m}, 2 \mathrm{H}), 1.89-1.85(\mathrm{~m}, 2 \mathrm{H})$, $1.69-1.66(\mathrm{~m}, 1 \mathrm{H}), 1.44-1.34(\mathrm{~m}, 2 \mathrm{H}), 1.28-1.11(\mathrm{~m}, 3 \mathrm{H})$.

4-((p-fluorophenyl)sulfonyl)pyridine (71): 4-Bromopyridine. $\mathrm{HCl}(4.02 \mathrm{~g}, 20.68 \mathrm{mmol})$ was added to a solution of $p$-fluorobenzenethiol $(2.41 \mathrm{~g}, 18.80 \mathrm{mmol})$ and $\mathrm{K}_{2} \mathrm{CO}_{3}(7.78 \mathrm{~g}$, $56.4 \mathrm{mmol})$ in DMSO $(20 \mathrm{~mL})$ and the reaction was maintained at $110^{\circ} \mathrm{C}$ overnight. Then the reaction was cooled, quenched with saturated $\mathrm{NH}_{4} \mathrm{Cl}$ and extracted with EtOAc. The combined organic layers were washed twice with saturated $\mathrm{NaHCO}_{3}$, once with brine, dried over $\mathrm{Na}_{2} \mathrm{SO}_{4}$, filtered, and concentrated to produce crude $\mathbf{6 6}$ (4.01 g, quantitative yield) that was used without further purification. Oxone monopersulfate $(15.03 \mathrm{~g}, 48.90 \mathrm{mmol})$ was added to a solution of crude compound 66 in $\mathrm{Me}_{2} \mathrm{CO} / \mathrm{H}_{2} \mathrm{O}(5: 1,84 \mathrm{~mL})$. After standing overnight, the reaction was quenched with saturated $\mathrm{NaHCO}_{3}$, extracted with EtOAc, and purified by column chromatography to give $\mathbf{7 1}$ (quantitative yield) as a white solid. ${ }^{1} \mathrm{H}$ NMR $\left(400 \mathrm{MHz}, \mathrm{CDCl}_{3}\right) \delta 8.88-8.81(\mathrm{~m}, 2 \mathrm{H}), 8.03-7.95(\mathrm{~m}, 2 \mathrm{H}), 7.78-7.73(\mathrm{~m}, 2 \mathrm{H}), 7.28-$ $7.21(\mathrm{~m}, 2 \mathrm{H})$.

(1-(4-(Pyridin-4-ylsulfonyl)phenyl)azetidin-3-yl)methyl methanesulfonate (78)Compound 78 was prepared according to the procedure described for compound 79. ${ }^{1} \mathrm{H}$ $\operatorname{NMR}\left(400 \mathrm{MHz}, \mathrm{CDCl}_{3}\right) \delta 8.77(\mathrm{~d}, J=6.0 \mathrm{~Hz}, 2 \mathrm{H}), 7.75(\mathrm{~d}, J=8.9 \mathrm{~Hz}, 2 \mathrm{H}), 7.70(\mathrm{~d}, J=$ $6.1 \mathrm{~Hz}, 2 \mathrm{H}), 6.40(\mathrm{~d}, J=8.9 \mathrm{~Hz}, 2 \mathrm{H}), 4.43(\mathrm{~d}, J=6.6 \mathrm{~Hz}, 2 \mathrm{H}), 4.10(\mathrm{t}, J=8.2 \mathrm{~Hz}, 2 \mathrm{H}), 3.81$ (dd, $J=8.2,5.0 \mathrm{~Hz}, 2 \mathrm{H}$ ), 3.19 (dddd, $J=11.5,7.9,6.6,2.7 \mathrm{~Hz}, 1 \mathrm{H}$ ), 3.04 (s, 3H).

(1-(4-Cyanophenyl)azetidin-3-yl)methyl methanesulfonate (79): ${ }^{25}-\mathrm{K}_{2} \mathrm{CO}_{3}(8.8 \mathrm{~g}$, $63.7 \mathrm{mmol})$ was added to a solution of $p$-fluorobenzonitrile $(2.6 \mathrm{~g}, 21.2 \mathrm{mmol})$ and azetidin-3-ylmethanol hydrochloride (3.4 g, $27.6 \mathrm{mmol})$ in DMSO. The mixture was stirred at $80{ }^{\circ} \mathrm{C}$ overnight. Then the reaction mixture was cooled to $\mathrm{rt}$, poured into ice, and extracted twice with EtOAc. The combined organic solution was dried over $\mathrm{Na}_{2} \mathrm{SO}_{4}$, filtered and the solvent was evaporated in vacuo. The residue was dissolved in DCM $(100 \mathrm{~mL})$ and $\mathrm{Et}_{3} \mathrm{~N}$ $(8.9 \mathrm{~mL}, 63.6 \mathrm{mmol})$ and methanesulfonyl chloride $(2.5 \mathrm{~mL}, 31.8 \mathrm{mmol})$ were added dropwise at $0{ }^{\circ} \mathrm{C}$. The reaction mixture was allowed to warm to rt and stirred for $5 \mathrm{~h}$. Then, the reaction mixture was quenched with saturated $\mathrm{NaHCO}_{3}$, and washed with brine, dried over $\mathrm{Na}_{2} \mathrm{SO}_{4}$, and the solvent was evaporated under vacuum. The residue was purified by flash chromatography to obtain the title compound as a white solid $(2.5 \mathrm{~g}, 44 \%) .{ }^{1} \mathrm{H}$ NMR $\left(400 \mathrm{MHz}, \mathrm{CDCl}_{3}\right) \delta 7.39$ (d, $\left.J=8.8 \mathrm{~Hz}, 2 \mathrm{H}\right), 6.31(\mathrm{~d}, J=8.8 \mathrm{~Hz}, 2 \mathrm{H}), 4.38(\mathrm{~d}, J=6.7 \mathrm{~Hz}$, $2 \mathrm{H}), 4.02(\mathrm{t}, J=8.2 \mathrm{~Hz}, 2 \mathrm{H}), 3.74-3.70(\mathrm{~m}, 2 \mathrm{H}), 3.16-3.08(\mathrm{~m}, 1 \mathrm{H}), 2.99(\mathrm{~s}, 3 \mathrm{H})$; ESI-MS $\mathrm{m} / \mathrm{z}[\mathrm{M}+\mathrm{H}]^{+}=267.11$.

2-(1-Benzylpiperidin-4-ylidene)-2-phenylacetonitrile (82): Sodium methoxide (25\% wt. in $\mathrm{MeOH})(46.8 \mathrm{~mL}, 205 \mathrm{mmol})$ was added to a solution of 1-benzylpiperidin-4-one $(32.3 \mathrm{~g}, 171 \mathrm{mmol})$ and 2-phenylacetonitrile $(20 \mathrm{~g}, 171 \mathrm{mmol})$ in anhydrous $\mathrm{MeOH}(200$ 
$\mathrm{mL}$ ) under $\mathrm{N}_{2}$, and the mixture was stirred under reflux overnight. Then the reaction mixture was cooled to $\mathrm{rt}$ and poured into ice $(200 \mathrm{~g})$. The resulting mixture was extracted with EtOAc. The separated organic layer was dried with $\mathrm{Na}_{2} \mathrm{SO}_{4}$, filtered and the solvent was evaporated in vacuum to yield the title compound (48 g, 95\%). MS (ESI) m/z 289.1 [M+H] ${ }^{+}$

2-(1-Benzylpiperidin-4-yl)-2-phenylacetonitrile (83):25—Sodium borohydride (12.6 $\mathrm{g}, 333 \mathrm{mmol}$ ) was added to a solution of intermediate 82 (48 g, $166 \mathrm{mmol})$ in $\mathrm{MeOH}$ (100 $\mathrm{ml})$. The mixture was stirred at $\mathrm{rt}$ overnight. Then a mixture of $\mathrm{H}_{2} \mathrm{O}$ and ice $(200 \mathrm{ml})$ was added; a light yellow precipitate was formed and collected by filtration. The residue was washed with $\mathrm{H}_{2} \mathrm{O}$ and dried in vacuum to yield a light yellow product ( $\left.38 \mathrm{~g}, 79 \%\right) .{ }^{1} \mathrm{H} \mathrm{NMR}$ $\left(400 \mathrm{MHz}, \mathrm{CDCl}_{3}\right) \delta$ 7.31-7.25 (m, 3H), 7.24-7.20 (m, 5H), 7.20-7.17 (m, 2H), $3.52(\mathrm{~d}, \mathrm{~J}=$ $7.6 \mathrm{~Hz}, 1 \mathrm{H}), 3.43$ (s, 2H), 2.90-2.81 (m, 2H), 1.92-1.79 (m, 3H), 1.74-1.64 (m, 1H), 1.52-1.34 (m, 3H); ESI-MS m/z [M + H $]^{+}=291.19$.

\section{2-(1-Benzylpiperidin-4-yl)-2-cyclopentyl-2-phenylacetonitrile (84):25_LiHMDS}

(1M in THF, $20.66 \mathrm{~mL}, 20.66 \mathrm{mmol})$ was added dropwise at $-78{ }^{\circ} \mathrm{C}$, to a solution of $83(3 \mathrm{~g}$, $10.33 \mathrm{mmol})$ in dry THF $(100 \mathrm{~mL})$ and stirred. After $30 \mathrm{~min}$ at $-78^{\circ} \mathrm{C}$, cyclopentyl-bromide (3.32 $\mathrm{mL}, 30.99 \mathrm{mmol}$ ) was added dropwise and the reaction was allowed to slowly warm to rt. After overnight at RT, the reaction was quenched with saturated $\mathrm{NH}_{4} \mathrm{Cl}$, extracted with EtOAc, concentrated and purified by column chromatography to produce $3.64 \mathrm{~g}$ of compound 84 as an oil. ${ }^{1} \mathrm{H}$ NMR $\left(400 \mathrm{MHz} \mathrm{CDCl}_{3}\right) \delta$ 7.31-7.24 (m, 4H), 7.23-7.15 (m, $6 \mathrm{H}), 3.39$ (s, 2H), 2.88-2.83 (m, 2H), 2.71-2.62 (m, 1H), 1.96-1.78 (m, 5H), 1.70-1.64 (m, $1 \mathrm{H}), 1.58-1.49$ (m, 4H), 1.46-1.41 (m, 2H), 1.26-1.11 (m, 3H).; ESI-MS m/z [M + H] $]^{+}=$ 359.32 .

\section{2-(1-Benzylpiperidin-4-yl)-2-cyclopentyl-2-phenylethan-1-amine (85): DIBALH}

( $25 \% \mathrm{wt}$ in toluene, $29 \mathrm{~mL}, 51.72 \mathrm{mmol}$ ) was added dropwise to a solution of $\mathbf{8 4}$ (3.0 g, 8.37 $\mathrm{mmol})$ in toluene $(60 \mathrm{~mL})$ and stirred at $\mathrm{rt}$. After $1 \mathrm{~h}$, the reaction was quenched by dropwise addition of $2 \mathrm{M} \mathrm{NaOH}$ and the aqueous was extracted with EtOAc and concentrated. The crude imine was redissolved in $\mathrm{MeOH}$ and $\mathrm{NaBH}_{4}(786 \mathrm{mg}, 20.68 \mathrm{mmol}$ ) was slowly added and the reaction was stirred. After overnight, the reaction was quenched with $\mathrm{H}_{2} \mathrm{O}$, extracted with EtOAc, dried over $\mathrm{Na}_{2} \mathrm{SO}_{4}$, filtered through celite, and concentrated to produce crude compound 85 ( $3.15 \mathrm{~g})$ that was used in the next step without further purification.

\section{4-(1-Benzylpiperidin-4-yl)-4-cyclopentyl-1,2,3,4-tetrahydroisoquinoline}

(88): Methyl chloroformate $(0.600 \mathrm{~mL}, 7.76 \mathrm{mmol})$ was added to a solution, at $0{ }^{\circ} \mathrm{C}$, of crude 85 (crude, $5.17 \mathrm{mmol}$ ) and $\mathrm{Et}_{3} \mathrm{~N}(1.4 \mathrm{~mL}, 10.34 \mathrm{mmol})$ in DCM $(50 \mathrm{~mL})$ and stirred. After $30 \mathrm{~min}$ at $0{ }^{\circ} \mathrm{C}$, the reaction was stirred at $\mathrm{rt}$. After $30 \mathrm{~min}$ at $\mathrm{rt}$, the reaction was quenched with $\mathrm{H}_{2} \mathrm{O}$ and brine, extracted with EtOAc, dried over $\mathrm{Na}_{2} \mathrm{SO}_{4}$, filtered and concentrated to give $1.77 \mathrm{~g}$ of the crude methyl carbamate (86) that was used without further purification. Polyphosphoric acid (PPA) $(20 \mathrm{~mL})$ was added to crude $\mathbf{8 6}$ and the reaction heated to $150{ }^{\circ} \mathrm{C}$. After $1.5 \mathrm{~h}$ UPLC indicated that the reaction was complete and it was cooled to a moderate temperature, diluted with $\mathrm{H}_{2} \mathrm{O}$, slowly quenched with saturated $\mathrm{NaHCO}_{3}$, extracted with EtOAc, dried over $\mathrm{Na}_{2} \mathrm{SO}_{4}$, filtered and concentrated to give crude $87(1.82 \mathrm{~g})$ that was used without further purification. Red-Al (3.2 $\mathrm{M}$ in toluene, $7.3 \mathrm{~mL})$ 
was added dropwise to a solution, at $\mathrm{rt}$, of crude $\mathbf{8 7}(1.82 \mathrm{~g}, 4.69 \mathrm{mmol})$ in toluene ( $30 \mathrm{~mL})$ and stirred. After $30 \mathrm{~min}$, the reaction was quenched by dropwise addition of $2 \mathrm{M} \mathrm{NaOH}$ and the aqueous was extracted with EtOAc and concentrated. The crude $\mathbf{8 8}$ was purified by reverse phase preparative HPLC and the pure compound was lyophilized to produce 88-TFA salt as a white powder. ${ }^{1} \mathrm{H}$ NMR (400 MHz, $\left.\mathrm{MeOH}-\mathrm{d}_{4}\right) \delta 7.60-7.20(\mathrm{~m}, 9 \mathrm{H}), 4.33-4.16$ $(\mathrm{m}, 3 \mathrm{H}), 3.58-3.37(\mathrm{~m}, 4 \mathrm{H}), 3.11-2.88(\mathrm{~m}, 2 \mathrm{H}), 2.62-2.45(\mathrm{~m}, 1 \mathrm{H}), 2.29-2.17(\mathrm{~m}, 1 \mathrm{H})$, $2.13(\mathrm{~d}, J=14.1 \mathrm{~Hz}, 1 \mathrm{H}), 1.91-1.41(\mathrm{~m}, 9 \mathrm{H}), 1.36-1.17(\mathrm{~m}, 2 \mathrm{H}), 1.10(\mathrm{p}, J=9.0 \mathrm{~Hz}, 1 \mathrm{H})$.

tert-Butyl 4-(1-benzylpiperidin-4-yl)-4-cyclopentyl-3,4dihydroisoquinoline-2(1H)-carboxylate (89): $\mathrm{At}^{\circ} \mathrm{C}^{\circ}, \mathrm{Et}_{3} \mathrm{~N}(446 \mu \mathrm{L}, 3.21 \mathrm{mmol})$ followed by $\mathrm{Boc}_{2} \mathrm{O}(350 \mathrm{mg}, 1.60 \mathrm{mmol})$ were added to a stirring solution of $\mathbf{8 8}(300 \mathrm{mg}$, $0.802 \mathrm{mmol})$ in DCM $(5 \mathrm{~mL})$ then allowed to warm to rt. After $1 \mathrm{~h}$ the solvent was removed in vacuo then purified by flash column chromatography to produce $288 \mathrm{mg}$ of $\mathbf{8 9} .{ }^{1} \mathrm{H}$ NMR $\left(400 \mathrm{MHz}, \mathrm{MeOH}-\mathrm{d}_{4}\right) \delta 7.41-7.25(\mathrm{~m}, 6 \mathrm{H}), 7.23-7.08(\mathrm{~m}, 3 \mathrm{H}), 4.65-4.33(\mathrm{~m}, 2 \mathrm{H}), 3.74$ $-3.52(\mathrm{~m}, 4 \mathrm{H}), 3.16-2.88(\mathrm{~m}, 2 \mathrm{H}), 2.52-2.35(\mathrm{~m}, 1 \mathrm{H}), 2.34-1.82(\mathrm{~m}, 4 \mathrm{H}), 1.73-1.56$ $(\mathrm{m}, 2 \mathrm{H}), 1.50(\mathrm{~s}, 9 \mathrm{H}), 1.48-1.35(\mathrm{~m}, 6 \mathrm{H}), 1.35-1.20(\mathrm{~m}, 2 \mathrm{H}), 1.06-0.92(\mathrm{~m}, 1 \mathrm{H})$.

tert-Butyl 4-cyclopentyl-4-(1-((1-(4-(pyridin-4-ylsulfonyl)phenyl)azetidin-3yl)methyl)-piperidin-4-yl)-3,4-dihydroisoquinoline-2(1H)-carboxylate

(90): Compound 89 (288 mg, $0.608 \mathrm{mmol})$ was dissolved in $\mathrm{MeOH}(5 \mathrm{~mL})$ and the solution was vacuumed briefly then put under an $\mathrm{N}_{2}$ atmosphere. This was repeated 3 times, then $\mathrm{Pd} / \mathrm{C}(10 \% \mathrm{wt} / \mathrm{wt}, 200 \mathrm{mg})$ was quickly added to the solution that was vacuumed and put under $\mathrm{N}_{2}$ atmosphere. The solution was briefly vacuumed to remove the $\mathrm{N}_{2}$ atmosphere then put under $\mathrm{H}_{2}$ atmosphere - this was repeated 3 times. After $30 \mathrm{~min}$, the reaction was filtered through celite and concentrated to give crude debenzylated-89 that was redissolved in $\mathrm{MeCN}\left(10 \mathrm{~mL}\right.$ ). $\mathrm{K}_{2} \mathrm{CO}_{3}$ (420 mg, $3.04 \mathrm{mmol}$ ), 78 (301 mg, $\left.0.790 \mathrm{mmol}\right)$, KI (cat.) were added to the crude solution which was then refluxed. After overnight reflux, the reaction was cooled, filtered through celite, concentrated and purified by flash column chromatography to produce 90 (176 mg, 43\%). ${ }^{1} \mathrm{H}$ NMR (400 MHz, MeOH-d 4 ) $\delta 8.74(\mathrm{dd}, J=4.6,1.6 \mathrm{~Hz}, 2 \mathrm{H})$, $7.80(\mathrm{dd}, J=4.5,1.6 \mathrm{~Hz}, 2 \mathrm{H}), 7.72(\mathrm{~d}, J=8.9 \mathrm{~Hz}, 2 \mathrm{H}), 7.40-7.29(\mathrm{~m}, 1 \mathrm{H}), 7.25-7.07(\mathrm{~m}$, $3 \mathrm{H}), 6.46(\mathrm{~d}, J=8.9 \mathrm{~Hz}, 2 \mathrm{H}), 4.63-4.35(\mathrm{~m}, 2 \mathrm{H}), 4.10(\mathrm{t}, J=8.1 \mathrm{~Hz}, 2 \mathrm{H}), 3.70-3.55(\mathrm{~m}$, $4 \mathrm{H}), 3.17-2.93(\mathrm{~m}, 3 \mathrm{H}), 2.87-2.69(\mathrm{~m}, 2 \mathrm{H}), 2.55-2.38(\mathrm{~m}, 1 \mathrm{H}), 2.36-2.06(\mathrm{~m}, 2 \mathrm{H})$, $2.06-1.84(\mathrm{~m}, 2 \mathrm{H}), 1.76-1.57(\mathrm{~m}, 2 \mathrm{H}), 1.50(\mathrm{~s}, 9 \mathrm{H}), 1.48-1.36(\mathrm{~m}, 6 \mathrm{H}), 1.36-1.17(\mathrm{~m}$, $2 \mathrm{H}), 1.08-0.93(\mathrm{~m}, 1 \mathrm{H})$.

tert-Butyl ((1S,2S)-2-hydroxycyclopentyl)carbamate (92)—The title compound was prepared as reported previously. ${ }^{25}{ }^{1} \mathrm{H}$ NMR $\left(400 \mathrm{MHz}, \mathrm{CDCl}_{3}\right) \delta 4.66(\mathrm{~s}, 1 \mathrm{H}), 4.00-3.96(\mathrm{~m}$, $2 \mathrm{H}), 3.66-3.59(\mathrm{~m}, 1 \mathrm{H}), 2.12-2.06(\mathrm{~m}, 1 \mathrm{H}), 2.05-1.98(\mathrm{~m}, 1 \mathrm{H}), 1.81-1.74(\mathrm{~m}, 1 \mathrm{H}), 1.70-1.63$ $(\mathrm{m}, 2 \mathrm{H}), 1.45(\mathrm{~s}, 9 \mathrm{H}), 1.38-1.31(\mathrm{~m}, 1 \mathrm{H})$.

tert-Butyl 6-azabicyclo[3.1.0]hexane-6-carboxylate (94)—The title compound was prepared as reported previously. ${ }^{25}{ }^{1} \mathrm{H}$ NMR $\left(400 \mathrm{MHz}, \mathrm{CDCl}_{3}\right) \delta 2.9(\mathrm{~s}, 2 \mathrm{H}), 2.11-2.05(\mathrm{~m}$, $2 \mathrm{H}), 1.66-1.56(\mathrm{~m}, 3 \mathrm{H}), 1.46(\mathrm{~s}, 9 \mathrm{H}), 1.30-1.13(\mathrm{~m}, 1 \mathrm{H})$. 
rac-(S)-2-(1-Benzylpiperidin-4-yl)-2-((1R,2S)-2-hydroxycyclopentyl)-2phenylacetonitrile (95a) and rac-( $R)$-2-(1-benzylpiperidin-4-yl)-2-((1R,2S)-2hydroxycyclopentyl)-2-phenylacetonitrile (95b)-To a solution of 2-(1benzylpiperidin-4-yl)-2-phenylacetonitrile (83) $(1.4 \mathrm{~g}, 4.8 \mathrm{mmol})$ in dry THF $(20 \mathrm{~mL})$ was added dropwise LiHMDS (1M in THF, $14.3 \mathrm{~mL}, 14.3 \mathrm{mmol}$ ) at $0^{\circ} \mathrm{C}$ under $\mathrm{N}_{2}$. After stirring for $30 \mathrm{~min}$, cyclopentene oxide $(1.7 \mathrm{~mL}, 19.0 \mathrm{mmol})$ was added dropwise and the reaction mixture was allowed to warm slowly to rt. After stirring overnight, the reaction was quenched with saturated $\mathrm{NH}_{4} \mathrm{Cl}$, and concentrated to remove the THF. The resulting mixture was extracted with DCM twice, dried over $\mathrm{Na}_{2} \mathrm{SO}_{4}$, filtered and concentrated under vacuum. The residue was purified by flash chromatography to obtain a diasteromeric mixture (95a/ 95b). The mixture was further separated by reverse phase preparative HPLC and basified with saturated $\mathrm{NaHCO}_{3}$ to give the title compounds $95 \mathbf{a}(0.56 \mathrm{~g}, 32 \%)$ and $95 \mathbf{b}(0.5 \mathrm{~g}, 28 \%)$ as colorless oils. Data for 95a: ${ }^{1} \mathrm{H}$ NMR $\left(400 \mathrm{MHz}, \mathrm{MeOH}-\mathrm{d}_{4}\right) \delta$ 7.50-7.47 (m, $\left.2 \mathrm{H}\right)$, 7.42-7.38 (m, 2H), 7.36-7.32 (m, 1H), 7.30-7.21 (m, 5H), 3.84-3.80 (m, 1H), $3.45(\mathrm{~s}, 2 \mathrm{H})$, 2.95-2.86 (m, 2H), 2.83-2.77 (m, 1H), 2.14-2.02 (m, 4H), 2.00-1.93 (m, 1H), 1.78-1.57 (m, 5H), 1.54-1.44 (m, 1H), 1.31-1.19 (m, 3H); ESI-MS m/z [M + H] ${ }^{+}=375.33$; Data for 95b: ${ }^{1} \mathrm{H}$ NMR (400 MHz, MeOH-d ${ }_{4}$ ) 8 7.43-7.37 (m, 4H), 7.34-7.23 (m, 6H), 4.27-4.23 (m, 1H), $3.50(\mathrm{~s}, 2 \mathrm{H}), 2.98-2.94(\mathrm{~m}, 1 \mathrm{H}), 2.91-2.87(\mathrm{~m}, 1 \mathrm{H}), 2.83-2.77(\mathrm{~m}, 1 \mathrm{H}), 2.30-2.22(\mathrm{~m}, 1 \mathrm{H})$, 2.18-2.11 (m, 1H), 2.09-2.01 (m, 2H), 1.90-1.79 (m, 2H), 1.75-1.61 (m, 3H), 1.60-1.49 (m, $1 \mathrm{H}), 1.30-1.11(\mathrm{~m}, 4 \mathrm{H})$; ESI-MS m/z $[\mathrm{M}+\mathrm{H}]^{+}=375.33$.

\section{Mixture of rac-tert-butyl ((1S,2R)-2-((S)-(1-benzylpiperidin-4-yl)(cyano) (phenyl)methyl)cyclopentyl)carbamate (96a) and rac-tert-butyl ((1S,2R)-2- ((R)-(1-benzylpiperidin-4-yl)(cyano)(phenyl)methyl)cyclopentyl)carbamate} (96b): A mixture of 96a and 96b was obtained as described in our previous publication. ${ }^{25}$ Preparative HPLC separated the diastereomers and their data are as follows. 96a ${ }^{1} \mathrm{H}$ NMR $\left(400 \mathrm{MHz}, \mathrm{MeOH}-\mathrm{d}_{4}\right) \delta 7.55-7.33(\mathrm{~m}, 10 \mathrm{H}), 4.25(\mathrm{~s}, 2 \mathrm{H}), 3.89-3.80(\mathrm{~m}, 1 \mathrm{H}), 3.52(\mathrm{~d}, J=$ $12.6 \mathrm{~Hz}, 1 \mathrm{H}), 3.45$ (d, $J=12.8 \mathrm{~Hz}, 1 \mathrm{H}), 3.06-2.94(\mathrm{~m}, 2 \mathrm{H}), 2.85-2.75(\mathrm{~m}, 1 \mathrm{H}), 2.50(\mathrm{t}, J$ $=10.8 \mathrm{~Hz}, 1 \mathrm{H}), 2.28(\mathrm{~d}, J=14.3 \mathrm{~Hz}, 1 \mathrm{H}), 2.15-2.03(\mathrm{~m}, 1 \mathrm{H}), 1.89(\mathrm{~d}, J=14.4 \mathrm{~Hz}, 1 \mathrm{H})$, $1.72-1.40(\mathrm{~m}, 7 \mathrm{H}), 1.32$ (s, 9H). 96b ${ }^{1} \mathrm{H}$ NMR $\left(400 \mathrm{MHz}, \mathrm{MeOH}-\mathrm{d}_{4}\right) \delta 7.41$ (dd, $J=19.2$, $4.0 \mathrm{~Hz}, 10 \mathrm{H}), 4.19-3.98(\mathrm{~m}, 3 \mathrm{H}), 3.45-3.34(\mathrm{~m}, 2 \mathrm{H}), 2.95-2.80(\mathrm{~m}, 2 \mathrm{H}), 2.58-2.45(\mathrm{~m}$, $1 \mathrm{H}), 2.21(\mathrm{~d}, J=13.8 \mathrm{~Hz}, 1 \mathrm{H}), 2.00-1.84(\mathrm{~m}, 2 \mathrm{H}), 1.82-1.71(\mathrm{~m}, 1 \mathrm{H}), 1.69-1.52(\mathrm{~m}$, $3 \mathrm{H}), 1.46$ (s, 9H), $1.42-1.15(\mathrm{~m}, 4 \mathrm{H})$. ESI-MS $[\mathrm{M}+\mathrm{H}]^{+}=474.50$.

\section{rac-N-((1S,2R)-2-((S)-(1-Benzylpiperidin-4-yl)(cyano)(phenyl)methyl)}

cyclopentyl)- acetamide (97a): Compound 96a (20 mg, $0.042 \mathrm{mmol})$ was dissolved and stirred in TFA. After 15 min the TFA was removed in vacuo and the crude compound was redissolved in DCM $(3 \mathrm{~mL})$, and cooled to $0{ }^{\circ} \mathrm{C}$, then $\mathrm{Et}_{3} \mathrm{~N}$ and acetic anhydride were added and the mixture was stirred. After $30 \mathrm{~min}$ at $\mathrm{rt}$, the solvent was removed and the crude was purified by preparative HPLC to produce 97a as the TFA salt (8 mg, 47\%). ${ }^{1} \mathrm{H}$ NMR (400 $\left.\mathrm{MHz}, \mathrm{MeOH}-\mathrm{d}_{4}\right) \delta 7.56-7.31(\mathrm{~m}, 10 \mathrm{H}), 4.24(\mathrm{~s}, 2 \mathrm{H}), 4.17(\mathrm{q}, J=6.7 \mathrm{~Hz}, 1 \mathrm{H}), 3.51(\mathrm{~d}, J=$ $13.7 \mathrm{~Hz}, 1 \mathrm{H}), 3.44(\mathrm{~d}, J=12.7 \mathrm{~Hz}, 1 \mathrm{H}), 3.03(\mathrm{td}, J=12.9,3.0 \mathrm{~Hz}, 2 \mathrm{H}),(\mathrm{q}, J=7.9 \mathrm{~Hz}, 1 \mathrm{H})$, $2.51(\mathrm{tt}, J=12.2,9.0,3.4 \mathrm{~Hz}, 1 \mathrm{H}), 2.27-2.18(\mathrm{~m}, 1 \mathrm{H}), 2.18-2.08(\mathrm{~m}, 1 \mathrm{H}), 1.96-1.86(\mathrm{~m}$, $1 \mathrm{H}), 1.81-1.65(\mathrm{~m}, 3 \mathrm{H}), 1.64(\mathrm{~s}, 3 \mathrm{H}), 1.61-1.36(\mathrm{~m}, 4 \mathrm{H})$. 
rac-Methyl ((1S,2R)-2-((S)-(1-benzylpiperidin-4-yl)(cyano)(phenyl)methyl)cyclopentyl)-carbamate (98a): Starting with diastereomer 96a, the title compound was obtained as previously reported. ${ }^{25}{ }^{1} \mathrm{H}$ NMR $\left(400 \mathrm{MHz}, \mathrm{MeOH}-\mathrm{d}_{4}\right) \delta 7.51-7.34(\mathrm{~m}, 10 \mathrm{H})$, $4.24(\mathrm{~s}, 2 \mathrm{H}), 3.91-3.86(\mathrm{~m}, 1 \mathrm{H}), 3.53-3.46(\mathrm{~m}, 2 \mathrm{H}),(\mathrm{s}, 3 \mathrm{H}), 3.06-2.96(\mathrm{~m}, 2 \mathrm{H}), 2.86-2.80$ (m, 1H), $2.47(\mathrm{t}, J=12.1 \mathrm{~Hz}, 1 \mathrm{H}), 2.26(\mathrm{~d}, J=14.4 \mathrm{~Hz}, 1 \mathrm{H}), 2.13-2.07(\mathrm{~m}, 1 \mathrm{H}), 1.90$ (d, $J=$ $14.4 \mathrm{~Hz}, 1 \mathrm{H}), 1.79-1.72(\mathrm{~m}, 1 \mathrm{H}), 1.70-1.60(\mathrm{~m}, 2 \mathrm{H}), 1.58-1.40(\mathrm{~m}, 4 \mathrm{H}) ;$ ESI-MS m/z [M + $\mathrm{H}]^{+}=432.53$

rac-(S)-2-((1R,2S)-2-Hydroxycyclopentyl)-2-phenyl-2-(piperidin-4-yl)acetonitrile (99a)-Compound 99a was obtained according to the same procedure used for intermediate 48. ${ }^{1} \mathrm{H}$ NMR (400 MHz, MeOH-d $\left.{ }_{4}\right)$ 8 7.51-7.48 (m, 2H), 7.43-7.39 (m, 2H), 7.36-7.32 (m, $1 \mathrm{H}), 3.86-3.82(\mathrm{~m}, 1 \mathrm{H}), 3.06-2.98(\mathrm{~m}, 2 \mathrm{H}), 2.85-2.80(\mathrm{~m}, 1 \mathrm{H}), 2.65-2.58(\mathrm{~m}, 1 \mathrm{H}), 2.57-2.50$ $(\mathrm{m}, 1 \mathrm{H}), 2.28-2.20(\mathrm{~m}, 1 \mathrm{H}), 2.13-2.03(\mathrm{~m}, 2 \mathrm{H}), 1.80-1.71(\mathrm{~m}, 1 \mathrm{H}), 1.69-1.56(\mathrm{~m}, 4 \mathrm{H})$, $1.54-1.47(\mathrm{~m}, 1 \mathrm{H}), 1.20-1.08(\mathrm{~m}, 2 \mathrm{H})$. ESI-MS m/z [M + H $]^{+}=285.23$.

rac-4-(3-((4-((S)-Cyano((1R,2S)-2-hydroxycyclopentyl) (phenyl)methyl)piperidin-1-yl)methyl)azetidin-1-yl)benzonitrile (102a): 102a was obtained using 99a and 79 according to the procedure used to obtain compound $\mathbf{5}$. ${ }^{1} \mathrm{H}$ NMR $\left(400 \mathrm{MHz}, \mathrm{MeOH}-\mathrm{d}_{4}\right) \delta 7.51(\mathrm{~d}, J=7.2 \mathrm{~Hz}, 2 \mathrm{H}), 7.45-7.40(\mathrm{~m}, 4 \mathrm{H}), 7.38-7.33(\mathrm{~m}, 1 \mathrm{H}),(\mathrm{d}$, $J=8.9 \mathrm{~Hz}, 2 \mathrm{H}), 4.07-4.03(\mathrm{~m}, 2 \mathrm{H}), 3.85-3.82(\mathrm{~m}, 1 \mathrm{H}), 3.60-3.56(\mathrm{~m}, 2 \mathrm{H}), 3.00-2.93(\mathrm{~m}$, $3 \mathrm{H}), 2.85-2.79(\mathrm{~m}, 1 \mathrm{H}), 2.65(\mathrm{~d}, J=7.2 \mathrm{~Hz}, 2 \mathrm{H}), 2.18-2.01(\mathrm{~m}, 5 \mathrm{H}), 1.81-1.58(\mathrm{~m}, 5 \mathrm{H})$, $1.56-1.46(\mathrm{~m}, 1 \mathrm{H}), 1.33-1.22(\mathrm{~m}, 2 \mathrm{H})$; ESI-MS $\mathrm{m} / \mathrm{z}[\mathrm{M}+\mathrm{H}]^{+}=455.39$.

rac-(S)-2-(1-(4-Bromobenzoyl)piperidin-4-yl)-2-((1R,2S)-2hydroxycyclopentyl)-2-phenylacetonitrile (103): $\mathrm{Et}_{3} \mathrm{~N}(0.25 \mathrm{~mL}, 1.41 \mathrm{mmol})$ and HATU (320 mg, $0.844 \mathrm{mmol}$ ) were added at $0{ }^{\circ} \mathrm{C}$ to a solution of intermediate 99a (200 mg, $0.703 \mathrm{mmol}$ ) and $p$-bromobenzoic acid $(169 \mathrm{mg}, 0.844 \mathrm{mmol})$ in DCM. The reaction mixture was stirred at $\mathrm{rt}$ for $3 \mathrm{~h}$. Then the mixture was extracted with DCM, washed with brine, dried over $\mathrm{Na}_{2} \mathrm{SO}_{4}$, and the solvent was evaporated under vacuum. The residue was purified by flash chromatography to obtain the title compound as a white solid (210 $\mathrm{mg}$, 64\%). ${ }^{1} \mathrm{H}$ NMR (400 MHz, MeOH-d 4 ) $\delta 7.59$ (d, $\left.J=8.3 \mathrm{~Hz}, 2 \mathrm{H}\right), 7.50(\mathrm{~d}, J=7.5 \mathrm{~Hz}, 2 \mathrm{H})$, $7.43(\mathrm{t}, J=7.1 \mathrm{~Hz}, 2 \mathrm{H}), 7.38-7.35(\mathrm{~m}, 1 \mathrm{H}), 7.22(\mathrm{~d}, J=8.5 \mathrm{~Hz}, 2 \mathrm{H}), 4.69-4.60(\mathrm{~m}, 1 \mathrm{H})$, 3.87-3.84 (m, 1H), 3.75-3.64 (m, 1H), 3.17-3.09 (m, 1H), 2.86-2.76 (m, 2H), 2.54-2.47 (m, $1 \mathrm{H}), 2.27-2.08(\mathrm{~m}, 2 \mathrm{H}), 1.80-1.43(\mathrm{~m}, 6 \mathrm{H}), 1.18-1.13(\mathrm{~m}, 2 \mathrm{H})$; ESI-MS m/z $[\mathrm{M}+\mathrm{H}]^{+}=$ 467.27, 469.28.

rac-(S)-2-((1R,2S)-2-(Benzyloxy)cyclopentyl)-2-(1-benzylpiperidin-4-yl)-2phenylacetonitrile (104): $\mathrm{NaH}(65 \% \mathrm{wt}$ in oil, $263 \mathrm{mg}, 6.59 \mathrm{mmol})$ was added to a solution of $95 \mathbf{a}(821 \mathrm{mg}, 2.20 \mathrm{mmol})$ and tetrabutylammonium iodide $(8 \mathrm{mg}, 0.220 \mathrm{mmol})$ dissolved in dry $\mathrm{THF} / \mathrm{PhCH}_{3}(1: 1,10 \mathrm{~mL})$ at $0{ }^{\circ} \mathrm{C}$ and stirred. After $30 \mathrm{~min}$ at $0{ }^{\circ} \mathrm{C}$, benzyl bromide $(0.286 \mathrm{~mL}, 2.63 \mathrm{mmol})$ was added dropwise and the reaction was allowed to warm to rt. After overnight at $\mathrm{rt}$, the reaction was quenched with saturated $\mathrm{NH}_{4} \mathrm{Cl}$, extracted with EtOAc, concentrated and purified by column chromatography to produce $104(643 \mathrm{mg}) .{ }^{1} \mathrm{H}$ NMR (400 MHz, $\left.\mathrm{CDCl}_{3}\right) \delta 7.44(\mathrm{~d}, J=7.8 \mathrm{~Hz}, 2 \mathrm{H}), 7.37-7.17$ (m, 11H), 7.08 (dd, $J=7.4$, $2.1 \mathrm{~Hz}, 2 \mathrm{H}), 4.20(\mathrm{~d}, J=11.0 \mathrm{~Hz}, 1 \mathrm{H}), 3.79(\mathrm{~d}, J=10.9 \mathrm{~Hz}, 1 \mathrm{H}), 3.58(\mathrm{ddd}, J=5.8,3.7,2.1$ 
$\mathrm{Hz}, 1 \mathrm{H}), 3.48-3.35(\mathrm{~m}, 2 \mathrm{H}), 2.97-2.81(\mathrm{~m}, 3 \mathrm{H}), 2.09-2.00(\mathrm{~m}, 1 \mathrm{H}), 2.00-1.91(\mathrm{~m}, 2 \mathrm{H})$, $1.89-1.80(\mathrm{~m}, 3 \mathrm{H}), 1.79-1.57$ (m, 5H), $1.31-1.07$ (m, 2H).

rac-(S)-2-((1R,2S)-2-(Benzyloxy)cyclopentyl)-2-(1-benzylpiperidin-4-yl)-2phenylethan-1-amine (105): DIBALH $(3.92 \mathrm{~mL}, 6.89 \mathrm{mmol})$ was added dropwise to a solution of $104(640 \mathrm{mg}, 1.38 \mathrm{mmol})$ in toluene $(6 \mathrm{~mL})$ and stirred at RT. After $1 \mathrm{~h}$, the reaction was quenched by dropwise addition of $2 \mathrm{M} \mathrm{NaOH}$ and the aqueous was extracted with EtOAc, dried over $\mathrm{Na}_{2} \mathrm{SO}_{4}$, filtered through celite, and concentrated to produce crude compound $105(691 \mathrm{mg})$ that was used in the next step without further purification.

rac-(S)-4-((1R,2S)-2-(Benzyloxy)cyclopentyl)-4-(1-benzylpiperidin-4-yl)-2methyl-1,2,3,4-tetrahydroisoquinoline (108): Methyl chloroformate $(0.166 \mathrm{~mL}, 2.14$ $\mathrm{mmol})$ was added at $0{ }^{\circ} \mathrm{C}$ to a solution of crude $105(501 \mathrm{mg}, 1.07 \mathrm{mmol})$ and $\mathrm{Et}_{3} \mathrm{~N}(0.595$ $\mathrm{mL}, 4.28 \mathrm{mmol})$ in DCM $(10 \mathrm{~mL})$ and stirred. After $30 \mathrm{~min}$ at $0{ }^{\circ} \mathrm{C}$, the reaction was stirred at rt. After 30 min at $\mathrm{rt}$, the reaction was quenched with $\mathrm{H}_{2} \mathrm{O}$ and brine, extracted with EtOAc, dried over $\mathrm{Na}_{2} \mathrm{SO}_{4}$, filtered and concentrated to give crude $106(561 \mathrm{mg})$ that was used without further purification.

Crude $106(561 \mathrm{mg})$ was dissolved in $\mathrm{AcOH}(5 \mathrm{~mL})$, followed by addition of paraformaldehyde ( 3 eq.) and concentrated TFA $(2 \mathrm{~mL})$ at rt. After overnight at $\mathrm{rt}$, the reaction was slowly quenched with saturated $\mathrm{NaHCO}_{3}$, extracted with EtOAc, dried over $\mathrm{Na}_{2} \mathrm{SO}_{4}$, filtered and concentrated to give crude $107(572 \mathrm{mg})$ that was used without further purification.

Red-Al (3.2 $\mathrm{M}$ in toluene, 3 eq.) was added dropwise to a solution, at rt, of crude $\mathbf{1 0 7}$ in toluene $(15 \mathrm{~mL})$ and stirred. After $30 \mathrm{~min}$, the reaction was quenched by dropwise addition of $2 \mathrm{M} \mathrm{NaOH}$ and the aqueous was extracted with EtOAc and concentrated. The crude compound 108 was purified by reverse phase preparative HPLC and the pure compound was lyophilized to produce 108-TFA salt as a white powder. ${ }^{1} \mathrm{H}$ NMR $\left(400 \mathrm{MHz}, \mathrm{MeOH}-\mathrm{d}_{4}\right) \delta$ $7.64-7.10(\mathrm{~m}, 14 \mathrm{H}), 4.71-4.48(\mathrm{~m}, 1 \mathrm{H}), 4.48-4.26(\mathrm{~m}, 3 \mathrm{H}), 4.28-4.05(\mathrm{~m}, 3 \mathrm{H}), 3.90-$ $3.58(\mathrm{~m}, 1 \mathrm{H}), 3.40(\mathrm{~d}, J=12.3 \mathrm{~Hz}, 2 \mathrm{H}), 3.22-2.67(\mathrm{~m}, 5 \mathrm{H}), 2.66-2.49(\mathrm{~m}, 1 \mathrm{H}), 2.48-$ $2.38(\mathrm{~m}, 1 \mathrm{H}), 2.37-2.08(\mathrm{~m}, 1 \mathrm{H}), 2.05-1.06(\mathrm{~m}, 10 \mathrm{H})$.

rac-(1S,2R)-2-((S)-2-Methyl-4-(piperidin-4-yl)-1,2,3,4-tetrahydroisoquinolin-4yl)-cyclopentan-1-ol (109): Compound $108(110 \mathrm{mg}, 0.223 \mathrm{mmol})$ was dissolved in $\mathrm{MeOH}(10 \mathrm{~mL})$ and the solution was vacuumed briefly then put under $\mathrm{N}_{2}$ atmosphere - this was repeated 3 times. $\mathrm{Pd} / \mathrm{C}(10 \% \mathrm{wt} / \mathrm{wt}, 100 \mathrm{mg})$ was quickly added to the solution which was then vacuumed and put under an $\mathrm{N}_{2}$ atmosphere. The solution was briefly vacuumed to remove the $\mathrm{N}_{2}$ atmosphere then put under $\mathrm{H}_{2}$ atmosphere - this was repeated 3 times. After $4 \mathrm{~h}$, the reaction was filtered through celite and concentrated to give crude 109 (76 mg) that was used without further purification.

rac-(1S,2R)-2-((S)-2-Methyl-4-(1-((1-(4-(pyridin-4-ylsulfonyl)phenyl)azetidin-3yl)-methyl)piperidin-4-yl)-1,2,3,4-tetrahydroisoquinolin-4-yl)cyclopentan-1-ol (110): Compound 78 (44 mg, $0.115 \mathrm{mmol}), \mathrm{K}_{2} \mathrm{CO}_{3}(31 \mathrm{mg}, 0.228 \mathrm{mmol})$ and $\mathrm{KI}$ (cat.) were added to a solution of the intermediate $109(18 \mathrm{mg}, 0.057 \mathrm{mmol})$ in $\mathrm{MeCN}(3 \mathrm{~mL})$. The 
mixture was refluxed overnight. Then, the mixture was filtered through celite, concentrated and purified with preparative HPLC to give 110-TFA (29 mg) salt as white solid.

\section{Fluorescence Polarization (FP)-Based Binding Assay.}

Binding affinities of menin inhibitors to menin protein were determined using our established fluorescence-polarization (FP) binding assay described previously. ${ }^{25}, 28$ The FP competitive binding assay was developed and optimized using a novel FAM labeled fluorescent probe. Equilibrium dissociation constant $\left(\mathrm{K}_{d}\right)$ value of FAM-probe to menin protein was determined from protein saturation experiments by monitoring the total fluorescence polarization of mixtures composed with the fluorescent probe at a fixed concentration and the protein with increasing concentrations up to full saturation. FP values in millipolarization units $(\mathrm{mP})$ were measured using the Infinite M-1000 plate reader (Tecan U.S., Research Triangle Park, NC) in Microfluor 1 96-well, black, v-bottom plates (Thermo Scientific, Waltham, MA) at an excitation wavelength of $485 \mathrm{~nm}$ and an emission wavelength of $530 \mathrm{~nm} . \mathrm{K}_{d}$ value of FAM-probe, which was calculated by fitting the sigmoidal dose-dependent FP increases as a function of protein concentrations using Graphpad Prism 6.0 software (Graphpad Software, San Diego, CA), is determined as 1.4 $\mathrm{nM}$.

The $\mathrm{IC}_{50}$ and $\mathrm{K}_{i}$ values of compounds were determined in a competitive binding experiment, with a final concentration of the Menin protein at $4 \mathrm{nM}$, and final probe concentration at 2 $\mathrm{nM}$. Negative controls containing protein/probe complex only (equivalent to $0 \%$ inhibition), and positive controls containing only free probes (equivalent to $100 \%$ inhibition), were included in each assay plate. FP values were measured following the procedure described above. $\mathrm{IC}_{50}$ values were determined by nonlinear regression fitting of the competition curves. ${ }^{29}$

\section{Bio-Layer Interferometry (BLI) binding assay:}

Biotinylation of purified recombinant menin protein was accomplished by using the Thermo EZ-Link long-chain biotinylation reagent. Menin protein and biotinylation reagent were mixed with 1:1 molar ratio in PBS at $4^{\circ} \mathrm{C}$. This reaction was incubated at $4{ }^{\circ} \mathrm{C}$ for $2 \mathrm{~h}$. Reaction mixture was then dialyzed using Fishersci 10K MWCO dialysis cassettes to remove unreacted biotinylation reagent.

BLI binding assays were performed in 96-well microplates at room temperature with continuous $1000 \mathrm{rpm}$ shaking using the Octet Red 96 system (Fortebio, Menlo Park, CA, USA). PBS with $0.1 \%$ BSA, $0.01 \%$ Tween- 20 and $2 \%$ DMSO was used as the assay buffer. Biotinylated menin protein was tethered on Super Steptavidin (SSA) biosensors (ForteBio) by dipping sensors into $200 \mu \mathrm{L}$ per well $10 \mu \mathrm{g} / \mathrm{mL}$ protein solutions. Average saturation response level of 8-10 $\mathrm{nm}$ was achieved in 20 minutes. The measurement processes were all under computer control. Program procedures were established as follows: For the initial step, biosensors were washed in assay buffer for 60 seconds to form a baseline; the biosensors labeled with biotin-Menin were exposed to $100 \mathrm{nM}$ compounds for association, and were monitored for 1200 seconds; and then, the biosensors were moved back into assay 
buffer to disassociate for another 1800 seconds. Data were fit globally and generated automatically by Octet User software (version 9.0; Fortebio). ${ }^{25}$

\section{Cell Growth Inhibition Assay:}

The human acute leukemia MV4;11 cell line and HL-60 were purchased from the American Type Culture Collection, and the human acute leukemia MOLM-13 cell line was purchased from the DSMZ German cell bank. In all experiments, cultured human leukemia cells were used within two months of thawing fresh vials. Cells were cultured in RPMI 1640 media (MOLM13) or IMDM media (MV4;11 and HL60) supplemented with 10\% FBS and 1\% penicillin-streptomycin at $37{ }^{\circ} \mathrm{C}$ in a humidified atmosphere containing $5 \% \mathrm{CO}_{2}$ in air.

In the cell growth experiments, cells were seeded in 96-well cell culture plates at a density of 10000-20000 cells/well in $200 \mu \mathrm{L}$ of culture medium containing serial dilution of testing compounds. After 4 days of treatments, cell growth was measured by a lactate dehydrogenase-based WST-8 assay (Dojindo Molecular Technologies) using a Tecan Infinite M1000 multimode microplate reader (Tecan, Morrisville, NC). The WST-8 reagent was added to the each well and cells were incubated for an additional $1-2$ hours, and read at $450 \mathrm{~nm}$. The readings were normalized to the vehicle-treated cells, and the $\mathrm{IC}_{50}$ was calculated by nonlinear regression analysis using GraphPad Prism 6 software.

\section{Cellular Thermal Shift Assay:}

MV4;11 or MOLM-13 cells were treated with $\mathbf{M - 8 9}$ ranging from $\mathrm{nM}$ to $300 \mathrm{nM}$ for 1 hour in 6-well plates at a density of $5 \times 10^{6}$ cells per well. Centrifugation followed by washing with PBS produced cell pellets that were resuspended in $100 \mu \mathrm{L}$ of PBS containing Halt protease inhibitors, then transferred to PCR tubes, and heated to $45^{\circ} \mathrm{C}$ for 3 minutes. Two freeze-thaw cycles in liquid nitrogen achieved cell lysis and the lysates were clarified by centrifugation at 15,000 rpm. In clean tubes, the transferred supernatants were mixed with loading buffer, heated, and proteins were separated by SDS-PAGE. Membranes were blotted with an anti-menin antibody (CST, catalog \# 6891).

\section{Real-Time PCR:}

MV4;11 or MOLM-13 cells were treated for $48 \mathrm{~h}$ with vehicle or M-89 at $30 \mathrm{nM}, 100 \mathrm{nM}$, and $300 \mathrm{nM}$ concentrations for MV4;11 cells or $100 \mathrm{nM}, 300 \mathrm{nM}$, and $1 \mu \mathrm{M}$ for MOLM-13 cells. According to the manufacturer's protocol total RNA was isolated from cells using the RNEASY kit (QIAGEN). A High Capacity cDNA Reverse Transcription Kit (Applied Biosystems) was used to generate the cDNA. Using TacMan gene expression assays (Applied Biosystems) and primers specific for each gene Real-time PCR amplifications of Hoxa9 (Applied Biosystems, Hs00365956_m1), MEIS1 (Applied Biosystems, Hs00180020_m1), and GAPDH (Applied Biosystems, Hs02786624_g1) genes were carried out. Using comparative cycle threshold $(\mathrm{Ct})$ method the relative quantification of each gene transcript was calculated and the results were presented as relative expression to vehicle treatment after normalization to the internal control of GAPDH. 


\section{Cell apoptosis and Differentiation Analysis by Flow Cytometry:}

Flow cytometry was used to analyze effects of M-89 on apoptosis (annexin V and propidium iodide staining) or cell differentiation using $\mathrm{CD} 11 \mathrm{~b}$ expression as an indicator. Cells were treated with M-89 at the indicated concentrations for 24 or 48 hours, collected, stained with an apoptosis assay kit (Roche cat. No. 11988549 001) or a PE-anti-mouse/human CD11b antibody (BioLegend cat. No 101208), and analyzed by flow cytometry.

\section{In vivo Pharmacodynamic Assay:}

All animal experiments were performed under the guidelines of the University of Michigan Committee for Use and Care of Animals and using an approved animal protocol. Female immunodeficient (SCID) mice obtained from Charles River were injected subcutaneously in the right flank with 5 million MV4;11 cells in a $5 \mathrm{mg} / \mathrm{ml}$ solution of Matrigel. When tumors reached $100 \mathrm{~mm}^{3}$, mice were dosed by intraperitoneal injection with either vehicle or M-89 at $50 \mathrm{mg} / \mathrm{kg}$ daily for 3 days. Tumors were harvested at $6 \mathrm{~h}, 24 \mathrm{~h}$ or $48 \mathrm{~h}$ after the third dose of M-89 with three animals per time point. Tumors were immediately frozen in liquid nitrogen, ground into fine powder, placed on dry ice and stored at $-80^{\circ} \mathrm{C}$ for analysis. Expression levels of MEIS1 and Hoxa9 were analyzed by RT-PCR as described above.

Statistical analysis and graph creation were performed in GraphPad Prism version 7 for Windows (GraphPad Software, La Jolla California), using t-test (nonparametric test) to calculate significant 1 evels between treated groups and control groups. $* *(\mathrm{p}<0.01)$.

\section{Determination of the co-crystal structure of M-89 with recombinant human menin protein.}

Menin (residues 2-610 containing a deletion from 460-519) was purified as previously described. ${ }^{25}$ For crystallization, menin $(25 \mathrm{mg} / \mathrm{mL}$ in $20 \mathrm{mM}$ Tris $8.0,150 \mathrm{mM} \mathrm{NaCl}$ and 5mM DTT) was incubated for $1 \mathrm{hr}$ at $4{ }^{\circ} \mathrm{C}$ in a 1:1 molar ratio with M-89. Crystals grew at 4 ${ }^{\circ} \mathrm{C}$ in sitting drop vapor diffusion experiments over wells containing $2.0 \mathrm{M} \mathrm{NaCl}, 90.9 \mathrm{M}$ Bis-Tris pH 6.5, $0.182 \mathrm{M} \mathrm{MgCl}_{2}$ and $9 \mathrm{mM}$ Pr acetate. Crystals were annealed and cryoprotected through serial soaking in solutions containing $1 \mathrm{M}, 2 \mathrm{M}, 3 \mathrm{M}, 4 \mathrm{M}$ and $5 \mathrm{M}$ sodium formate in $0.1 \mathrm{M}$ Bis-Tris pH 6.5, 2.2 M NaCl, 0.2 $\mathrm{M} \mathrm{MgCl}_{2}$ and12 $\mathrm{mM}$ Pr acetate. Diffraction data were collected on at the Advanced Photon Source LS-CAT 21-ID-G beamline at Argonne National Laboratory with a wavelength of $0.9786 \AA$ and processed with HKL $2000^{30}$. The structure of menin bound to M- 89 was solved by molecular replacement (Molrep) ${ }^{31}$ using the apo menin structure (PDB ID 3U84) as the search model. The menin/M-89 co-crystal structure was produced via iterative rounds of electron density fitting and structural refinement using $\operatorname{Coot}^{32}$ and Buster $^{33}$, respectively. The coordinates and restraint files for the ligand were created from SMILES in Grade ${ }^{33}$. The initial Fo-Fc electron density map showed the presence of M-89 bound in the active site (Figure S2). The following regions were disordered in the structure: 71-73, 386-401, 528-547 and 582-610. Data collection and structural refinement statistics are shown in Table S2.

\section{Supplementary Material}

Refer to Web version on PubMed Central for supplementary material. 


\section{Acknowledgments}

Funding Sources

We are grateful for the financial support from the Prostate Cancer Foundation (to S. Wang), the National Cancer Institute, NIH (R01CA208267 to S. Wang), and the University of Michigan Comprehensive Cancer Center support grant from the National Cancer Institute, NIH (P30 CA046592). Use of the Advanced Photon Source, an Office of Science User Facility operated for the U.S. Department of Energy (DOE) Office of Science by Argonne National Laboratory, was supported by the U.S. DOE under Contract No. DE-AC02-06CH11357. Use of the LS-CAT Sector 21 was supported by the Michigan Economic Development Corporation and the Michigan Technology Tri-Corridor (Grant 085P1000817).

\section{ABBREVIATIONS}
ALL
acute lymphoblastic leukemia
AML
acute myeloid leukemia
Bis-Tris
Bis(2-hydroxyethyl)amino-tris(hydroxymethyl)methane
BLI
biolayer interferometry
CETSA
Cellular thermal shift assay
ESI-MS
electrospray ionization mass spectrometry
FP
Fluorescence polarization
HATU
1-[Bis(dimethylamino) methylene]-1H-1,2,3-triazolo[4,5-
b]pyridinium 3-oxid hexafluorophosphate
HMT histone methyltransferase
KHMDS Potassium bis(trimethylsilyl)amide
LiHMDS lithium bis(trimethylsilyl)amide
MeOH methanol
MLL mixed lineage leukemia protein
Oxone $^{\circledR} \quad$ potassium peroxymonosulfate
PPA polyphosphoric acid
qRT-PCR quantitative real-time polymerase chain reaction
RT
room temperature
UPLC
Ultra performance liquid chromatography

\section{REFERENCES}

1. Ernst P; Wang J; Korsmeyer SJ The role of MLL in hematopoiesis and leukemia. Curr Opin Hematol 2002, 9, 282-287. [PubMed: 12042701]

2. Marschalek R Mechanisms of leukemogenesis by MLL fusion proteins. Br J Haematol 2011, 152, 141-154. [PubMed: 21118195] 
3. Popovic R; Zeleznik-Le NJ MLL: How complex does it get? Journal of Cellular Biochemistry 2005, 95, 234-242. [PubMed: 15779005]

4. Slany RK When epigenetics kills: MLL fusion proteins in leukemia. Hematological Oncology 2005, 23, 1-9. [PubMed: 16118769]

5. Tomizawa D; Koh K; Sato T; Kinukawa N; Morimoto A; Isoyama K; Kosaka Y; Oda T; Oda M; Hayashi Y; Eguchi M; Horibe K; Nakahata T; Mizutani S; Ishii E Outcome of risk-based therapy for infant acute lymphoblastic leukemia with or without an MLL gene rearrangement, with emphasis on late effects: a final report of two consecutive studies, MLL96 and MLL98, of the Japan infant leukemia study group. Leukemia 2007, 21, 2258-2263. [PubMed: 17690691]

6. Cox MC; Panetta P; Lo-Coco F; Del Poeta G; Venditti A; Maurillo L; Del Principe MI; Mauriello A; Anemona L; Bruno A; Mazzone C; Palombo P; Amadori S Chromosomal aberration of the 11q23 locus in acute leukemia and frequency of MLL gene translocation: results in 378 adult patients. Am J Clin Pathol 2004, 122, 298-306. [PubMed: 15323147]

7. Dimartino JF; Cleary ML Mll rearrangements in haematological malignancies: lessons from clinical and biological studies. Br J Haematol 1999, 106, 614-626. [PubMed: 10468849]

8. Slany RK The molecular biology of mixed lineage leukemia. Haematologica 2009, 94, 984-993. [PubMed: 19535349]

9. Zhang Y; Chen A; Yan XM; Huang G Disordered epigenetic regulation in MLL-related leukemia. Int J Hematol 2012, 96, 428-437. [PubMed: 23054645]

10. Hess JL MLL: a histone methyltransferase disrupted in leukemia. Trends Mol Med 2004, 500-507. [PubMed: 15464450]

11. Krivtsov AV; Armstrong SA MLL translocations, histone modifications and leukaemia stem-cell development. Nat Rev Cancer 2007, 7, 823-833. [PubMed: 17957188]

12. Caslini C; Yang Z; El-Osta M; Milne TA; Slany RK; Hess JL Interaction of MLL amino terminal sequences with menin is required for transformation. Cancer Res 2007, 67, 7275-7283. [PubMed: 17671196]

13. Yokoyama A; Cleary ML Menin critically links MLL proteins with LEDGF on cancer-associated target genes. Cancer Cell 2008, 14, 36-46. [PubMed: 18598942]

14. Yokoyama A; Somervaille TC; Smith KS; Rozenblatt-Rosen O; Meyerson M; Cleary ML The menin tumor suppressor protein is an essential oncogenic cofactor for MLL-associated leukemogenesis. Cell 2005, 123, 207-218. [PubMed: 16239140]

15. Chen YX; Yan J; Keeshan K; Tubbs AT; Wang H; Silva A; Brown EJ; Hess JL; Pear WS; Hua X The tumor suppressor menin regulates hematopoiesis and myeloid transformation by influencing Hox gene expression. Proc Natl Acad Sci U S A 2006, 103, 1018-1023. [PubMed: 16415155]

16. Cierpicki T; Grembecka J Challenges and opportunities in targeting the menin-MLL interaction. Future Med Chem 2014, 6, 447-462. [PubMed: 24635524]

17. Huang J; Gurung B; Wan B; Matkar S; Veniaminova NA; Wan K; Merchant JL; Hua X; Lei M The same pocket in menin binds both MLL and JUND but has opposite effects on transcription. Nature 2012, 482, 542-546. [PubMed: 22327296]

18. Shi AB; Murai MJ; He SH; Lund G; Hartley T; Purohit T; Reddy G; Chruszcz M; Grembecka J; Cierpicki T Structural insights into inhibition of the bivalent menin-MLL interaction by small molecules in leukemia. Blood 2012, 120, 4461-4469. [PubMed: 22936661]

19. Grembecka J; He S; Shi A; Purohit T; Muntean AG; Sorenson RJ; Showalter HD; Murai MJ; Belcher AM; Hartley T; Hess JL; Cierpicki T Menin-MLL inhibitors reverse oncogenic activity of MLL fusion proteins in leukemia. Nat Chem Biol 2012, 8, 277-284. [PubMed: 22286128]

20. He S; Senter TJ; Pollock J; Han C; Upadhyay SK; Purohit T; Gogliotti RD; Lindsley CW; Cierpicki T; Stauffer SR; Grembecka J High-affinity small-molecule inhibitors of the menin-mixed lineage leukemia (MLL) interaction closely mimic a natural protein-protein interaction. J Med Chem 2014, 57, 1543-1556. [PubMed: 24472025]

21. Borkin D; Pollock J; Kempinska K; Purohit T; Li X; Wen B; Zhao T; Miao H; Shukla S; He M; Sun D; Cierpicki T; Grembecka J Property focused structure-based optimization of small molecule inhibitors of the protein-protein interaction between menin and mixed lineage leukemia (MLL). J Med Chem 2016, 59, 892-913. [PubMed: 26744767] 
22. Borkin D; Klossowski S; Pollock J; Miao H; Linhares BM; Kempinska K; Jin Z; Purohit T; Wen B; He M; Sun D; Cierpicki T; Grembecka J Complexity of blocking bivalent protein-protein interactions: Development of a highly potent inhibitor of the menin-mixed-lineage leukemia interaction. J Med Chem 2018, 61, 4832-4850. [PubMed: 29738674]

23. Borkin D; He S; Miao H; Kempinska K; Pollock J; Chase J; Purohit T; Malik B; Zhao T; Wang J; Wen B; Zong H; Jones M; Danet-Desnoyers G; Guzman ML; Talpaz M; Bixby DL; Sun D; Hess JL; Muntean AG; Maillard I; Cierpicki T; Grembecka J Pharmacologic inhibition of the MeninMLL interaction blocks progression of MLL leukemia in vivo. Cancer Cell 2015, 27, 589-602. [PubMed: 25817203]

24. He S; Malik B; Borkin D; Miao H; Shukla S; Kempinska K; Purohit T; Wang J; Chen L; Parkin B; Malek SN; Danet-Desnoyers G; Muntean AG; Cierpicki T; Grembecka J Menin-MLL inhibitors block oncogenic transformation by MLL-fusion proteins in a fusion partner-independent manner. Leukemia 2016, 30, 508-513. [PubMed: 26084867]

25. Xu S; Aguilar A; Xu T; Zheng K; Huang L; Stuckey J; Chinnaswamy K; Bernard D; FernandezSal as E; Liu L; Wang M; McEachern D; Przybranowski S; Foster C; Wang S Design of the firstin-class, highly potent irreversible inhibitor targeting the Menin-MLL protein-protein interaction. Angew Chem Int Ed Engl 2018, 57, 1601-1605. [PubMed: 29284071]

26. Molina DM; Jafari R; Ignatushchenko M; Seki T; Larsson EA; Dan C; Sreekumar L; Cao YH; Nordlund P Monitoring drug target engagement in cells and tissues using the cellular thermal shift assay. Science 2013, 341, 84-87. [PubMed: 23828940]

27. Jafari R; Almqvist H; Axelsson H; Ignatushchenko M; Lundback T; Nordlund P; Martinez Molina D The cellular thermal shift assay for evaluating drug target interactions in cells. Nat Protoc 2014, 9, 2100-2122. [PubMed: 25101824]

28. Zhou H; Liu L; Huang J; Bernard D; Karatas H; Navarro A; Lei M; Wang S Structure-based design of high-affinity macrocyclic peptidomimetics to block the menin-mixed lineage leukemia 1 (MLL1) protein-protein interaction. J Med Chem 2013, 56, 1113-1123. [PubMed: 23244744]

29. Nikolovska-Coleska Z; Wang R; Fang X; Pan H; Tomita Y; Li P; Roller PP; Krajewski K; Saito NG; Stuckey JA; Wang S Development and optimization of a binding assay for the XIAP BIR3 domain using fluorescence polarization. Anal Biochem 2004, 332, 261-273. [PubMed: 15325294]

30. Otwinowski Z; Minor W Processing of X-ray diffraction data collected in oscillation mode. Methods Enzymol 1997, 276, 307-326.

31. Vagin A; Teplyakov A MOLREP: an automated program for molecular replacement. Journal of Applied Crystallography 1997, 30, 1022-1025.

32. Emsley P; Cowtan K Coot: model-building tools for molecular graphics. Acta Crystallogr D Biol Crystallogr 2004, 60, 2126-2132. [PubMed: 15572765]

33. Roversi P; Sharff A; Smart OS; Vonrhein C; Womack TO BUSTER version 2.11.2. Cambridge, United Kingdom: Global Phasing Ltd 2011. 
<smiles>Cc1c(CN2CCC(Nc3ncnc4sc(CC(F)(F)F)cc34)CC2)ccc2[nH]c(C#N)cc12</smiles>

1 (Ml-463)<smiles>N#Cc1cc2cc(CN3CCC(Nc4ncnc5sc(CC(F)(F)F)cc45)CC3)c(O)cc2n1Cc1cn[nH]c1</smiles>

3 (MI-538)<smiles>Cc1c(CN2CCC(Nc3ncnc4sc(CC(F)(F)F)cc34)CC2)ccc2c1cc(C#N)n2C[C@H]1CNC(=O)CO1</smiles>

5 (MI-1481)<smiles>Cc1ccc2c(cc(C#N)n2Cc2cn[nH]c2)c1CN1CCC(Nc2ncnc3sc(CC(F)(F)F)cc23)CC1</smiles>

2 (MI-503)<smiles>N#Cc1ccc(OCCCN2CCC(C(N)(c3ccccc3)C3CCCC3)CC2)cc1</smiles>

4 (MIV-6)<smiles>COC(=O)NC1CCC[C@H]1C(C)(C)C1CCN(CC2CN(c3ccc(S(=O)(=O)C4CCC4)cc3)C2)CC1</smiles>

M-470<smiles>COC(=O)N[C@H]1CCC[C@]1(C)[C@](C)(c1cccc(F)c1)C1CCN(CC2CN(c3ccc(S(=O)(=O)C4CN(C(=O)/C=C/CN(C)C)C4)cc3)C2)CC1</smiles>

Figure 1.

Previously reported reversible and irreversible small-molecule menin inhibitors 


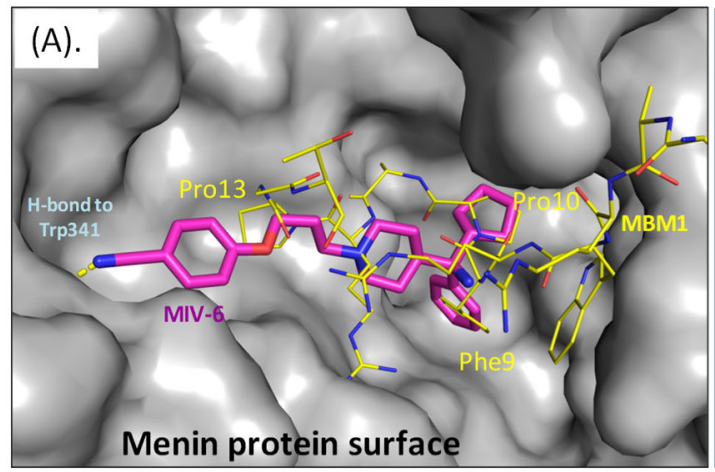

(B).

Site 3. To enhance

hydrophobic intere 2. To enhance the while maitaining the with an available

Site 2. To enhance the Site 4. To enhance the interactions hydrogen bonding with an available
hydrophobic pocket with an avaic

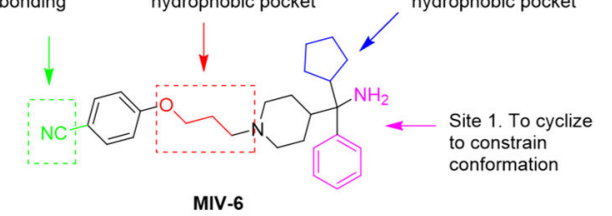

\section{Figure 2.}

(A). Superposition of co-crystal structure of menin in complex with menin binding motif 1 (MBM1 in yellow lines, PDB ID 4GQ6) from MLL onto the co-crystal structure of menin in complex with MIV-6 (magenta sticks) (PDB ID 4OG8). Menin protein is shown in grey surface. (B). Our proposed 4 modification sites in MIV-6. 

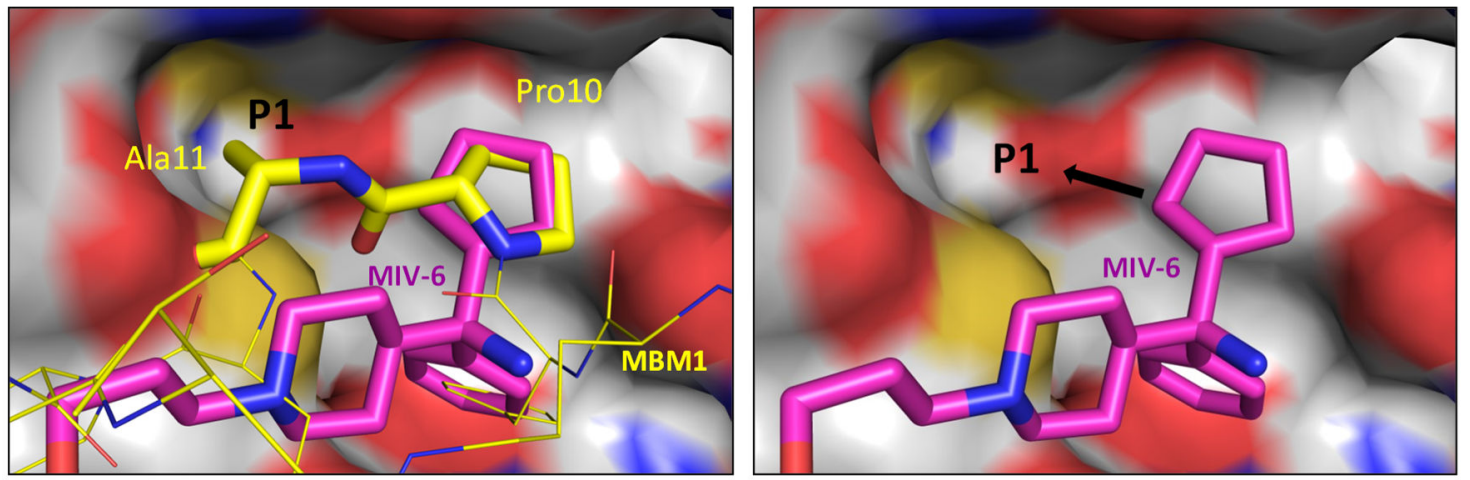

Figure 3.

Modifications of the cyclopentyl group of MIV-6 to access the P1 pocket, which was utilized by MBM1 (PDB ID 4GQ6) but not by MIV-6 (PDB ID 4OG8). 

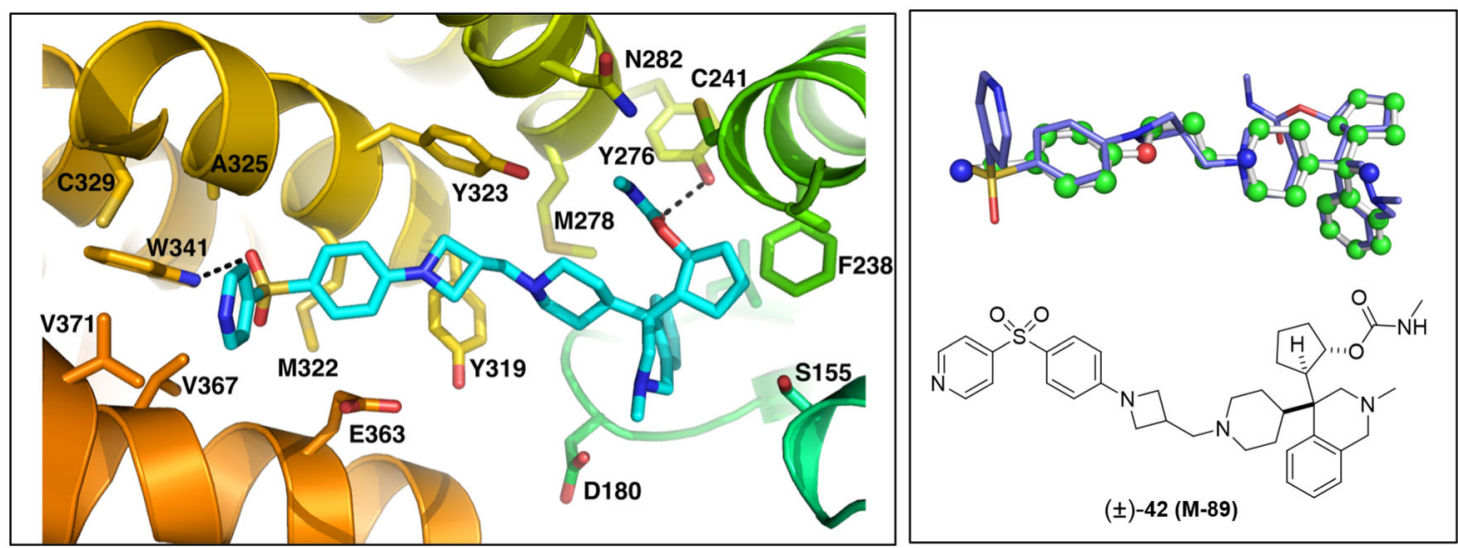

Figure 4.

Co-crystal structure of M-89 bound to menin (PDB ID 6E1A) (left panel) and superposition of MIV-6 and M-89 based upon their co-crystal structures (right panel). 

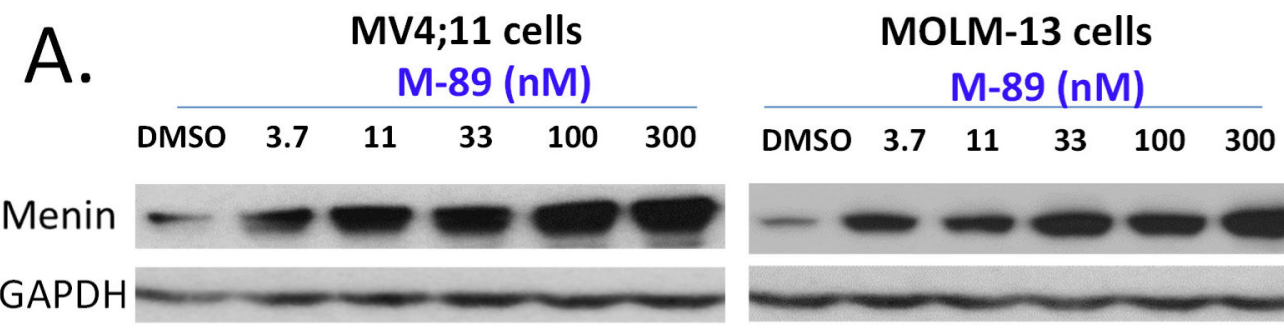

B.
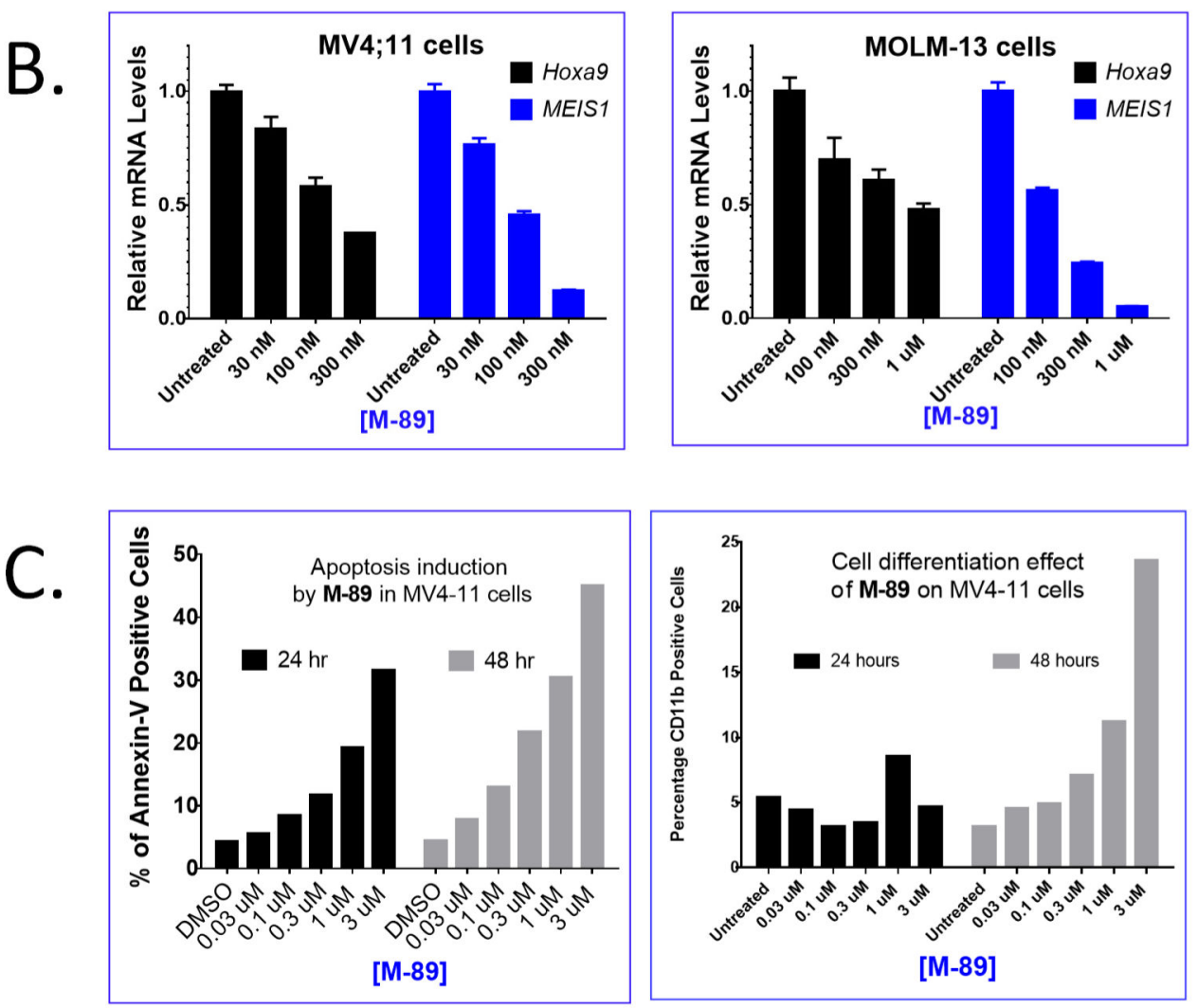

Figure 5.

(A). Stabilization of cellular menin protein by M-89 as assessed using the cellular thermal shift assay (CETSA) in MV4;11 cells. (B). qRT-PCR analysis of the effect of M-89 on the mRNA levels of Hoxa9 and MEIS1 genes in MV4;11 cells. (C). Flow cytometry analysis of the effect of M-89 on apoptosis and cell differentiation in MV4;11 cells. 
PD effect of M-89 on expression of genes in MV4;11 xenograft tissue after 3 days treatment $T=62448 \mathrm{~h}$
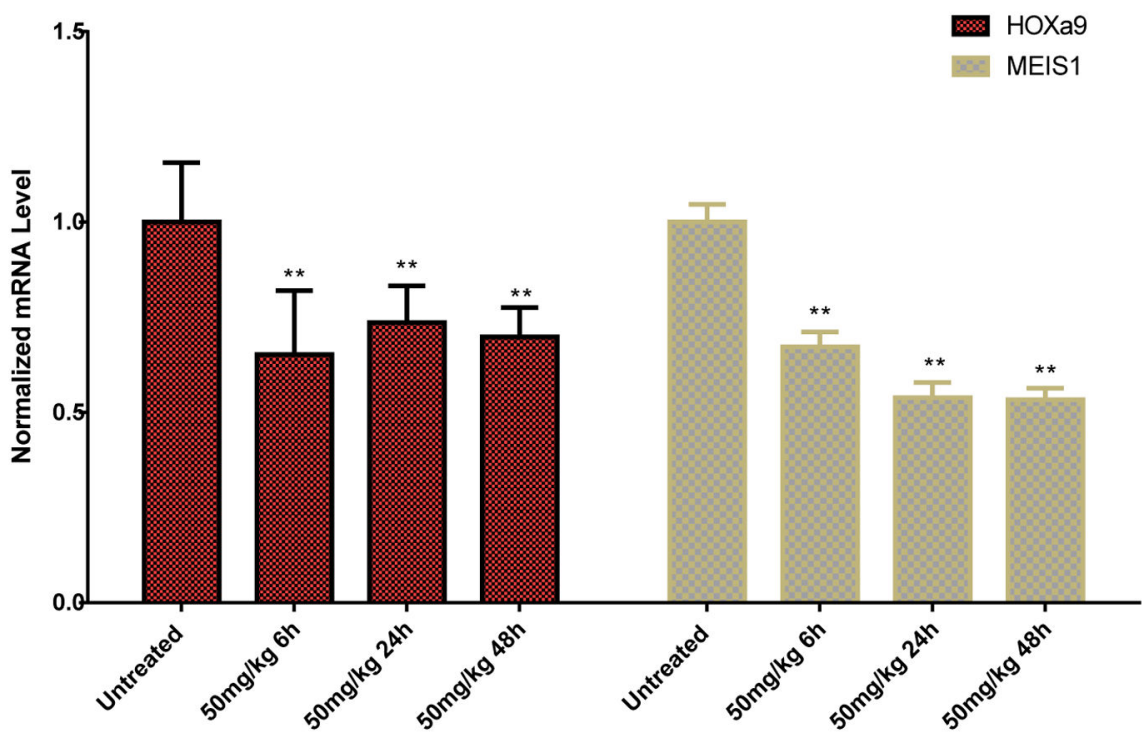

Figure 6.

Pharmacodynamic effect of M-89 on the expression of Hoxa9 and MEIS1 genes in the MV4;11 xenograft tissue in mice. Mice bearing MV4;11 xenograft tumors were dosed with M-89 for three days and tumors were harvested at 6, 24 and $48 \mathrm{~h}$ after the last administration for qRT-PCR analysis of Hoxa9 and MEIS1 gene expression. 
<smiles>CCN1CCC(C(=O)O)CC1</smiles><smiles>NCCc1ccccc1</smiles>

43<smiles>[131I-]</smiles>
$\stackrel{\mathrm{d}}{\longrightarrow}$<smiles>c1ccc2c(c1)CCNC2(C1CCCC1)C1CCNCC1</smiles>

48

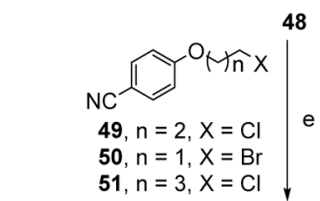

$51, \mathrm{n}=3, \mathrm{X}=\mathrm{Cl}$<smiles>N#Cc1ccc(OCCN2CCC(C3(C4CCCC4)NCCc4ccccc43)CC2)cc1</smiles>

6, $\mathrm{n}=2$

7, $n=1$

$8, n=3$<smiles>O=C(NCCc1ccccc1)C1CCN(Br)CC1</smiles>

45<smiles>CCCN1CCC(C2(C3CCCC3)NCCc3ccccc32)CC1</smiles>

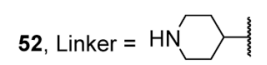

53, Linker $=\mathrm{HN} \longrightarrow \mathrm{CH}_{2}$

54, Linker $=\mathrm{HN}_{\mathrm{CH}_{2}}$,

55, Linker $=\mathrm{HN} \curlyvee-\mathrm{CH}_{2}-$

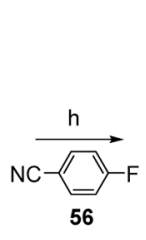

56

46<smiles>N#Cc1ccc(C(Cl)N2CCC(C3(C4CCCC4)NCCc4ccccc43)CC2)cc1</smiles>

9, Linker $=$

10, Linker $=\stackrel{\mathrm{N}}{\mathrm{CH}_{2}}$

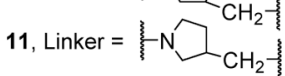

12, Linker $=\hat{\mathrm{H}} \widehat{\mathrm{N}}-\mathrm{CH}_{2}-\underline{\xi}$

Scheme 1.

Synthesis of compounds 6-12

Reagents and conditions: (a) i. 43, DCM, DMF (cat.), oxalyl chloride; ii. DCM, Et 3 N, 44, 0

${ }^{\circ} \mathrm{C}$ to rt overnight. (b) toluene, $\mathrm{POCl}_{3}, \mathrm{P}_{2} \mathrm{O}_{5}$, reflux; (c) THF, $\mathrm{BF}_{3}$. $\mathrm{Et}_{2} \mathrm{O}$, cyclopentyl magnesium bromide; (d) $\mathrm{MeOH}$, Pd-C (cat.), $\mathrm{H}_{2}$ (1 atm); (e) $\mathrm{CH}_{3} \mathrm{CN}, \mathrm{K}_{2} \mathrm{CO}_{3}, \mathrm{KI} . \mathrm{H}_{2} \mathrm{O}$ (cat.), 49 or 50 or 51, reflux; (f) DCM/AcOH (1:1), N-Boc-cyclic-amine-ketone or aldehyde, $\mathrm{NaBH}(\mathrm{OAc})_{3}$; (g) DCM/TFA (1:1) $15 \mathrm{~min}$; (h) DMSO, $\mathrm{K}_{2} \mathrm{CO}_{3}, \mathbf{5 6}, 90{ }^{\circ} \mathrm{C}$ overnight. 


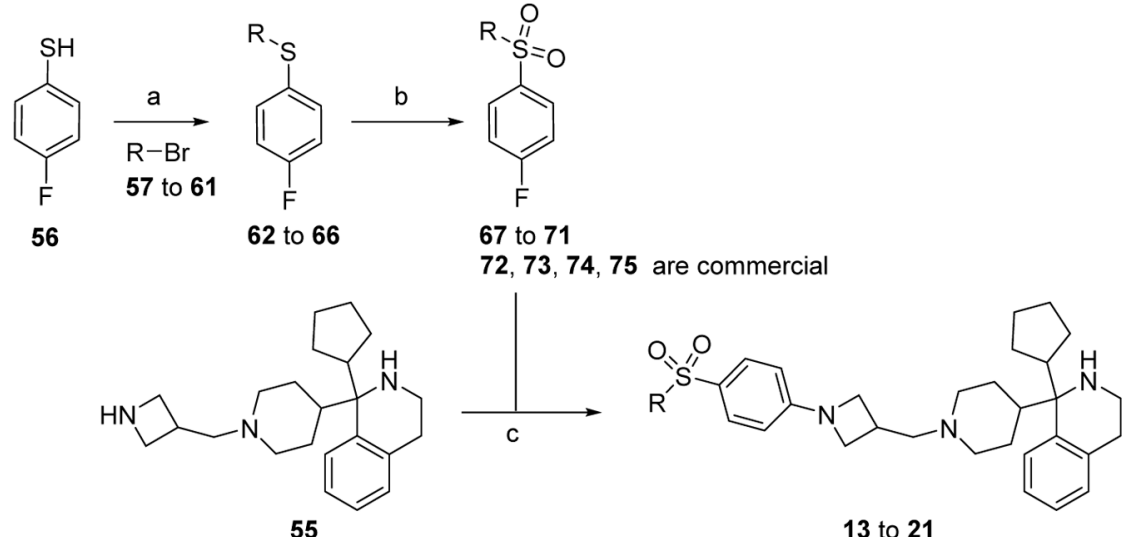

13 to 21

$$
\begin{aligned}
& 72,13, \mathrm{R}=\mathrm{Me} \\
& 73,14, \mathrm{R}=\mathrm{Et} \\
& 74,15, \mathrm{R}=>
\end{aligned}
$$$$
57,62,67,16, R=\square
$$

$58,63,68,17, \mathrm{R}=\diamond$ $59,64,69,18, R=\square$ $60,65,70,19, R=$

$75,20, R=$ $61,66,71,21, R=N$

Scheme 2.

Synthesis of compounds 13-21

Reagents and conditions: (a) For $\mathrm{R}=$ alkyl, $t$-BuONa, DMSO, R-Br, $90{ }^{\circ} \mathrm{C}$ overnight; for $\mathrm{R}$ = 4-bromopyridine, $\mathrm{K}_{2} \mathrm{CO}_{3}$, DMSO, $90{ }^{\circ} \mathrm{C}$ overnight; (b) for 62 - 65, DCM, mCPBA, overnight; for $66 \mathrm{Me}_{2} \mathrm{CO} / \mathrm{H}_{2} \mathrm{O}$ (5:1), oxone, overnight; (c) DMSO, $\mathrm{K}_{2} \mathrm{CO}_{3}$, 4-F-Ph- $\mathrm{SO}_{2}-\mathrm{R}$, $90{ }^{\circ} \mathrm{C}$ overnight. 

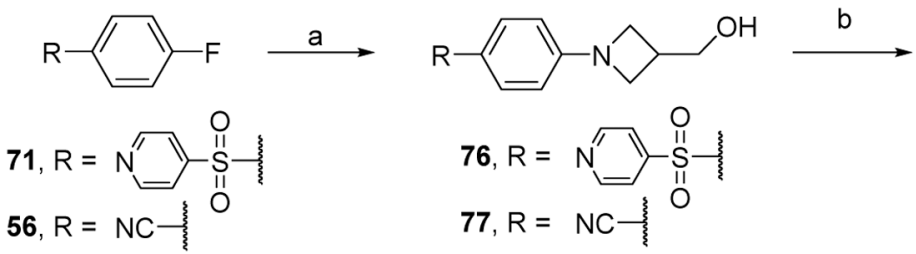

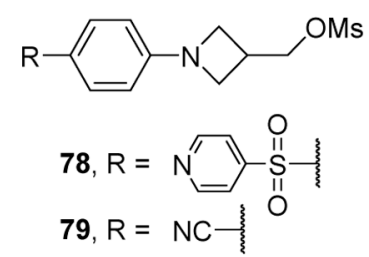

Scheme 3.

Synthesis of intermediates $\mathbf{7 8}$ and $\mathbf{7 9}$

Reagents and conditions: (a) DMSO, $\mathrm{K}_{2} \mathrm{CO}_{3}$, azetidin-3-ylmethanol. $\mathrm{HCl}, 80^{\circ} \mathrm{C}$, overnight; (b) $\mathrm{DCM}, \mathrm{Et}_{3} \mathrm{~N}, \mathrm{MsCl}, 0^{\circ} \mathrm{C}$ to $\mathrm{RT}, 30 \mathrm{~min}$. 


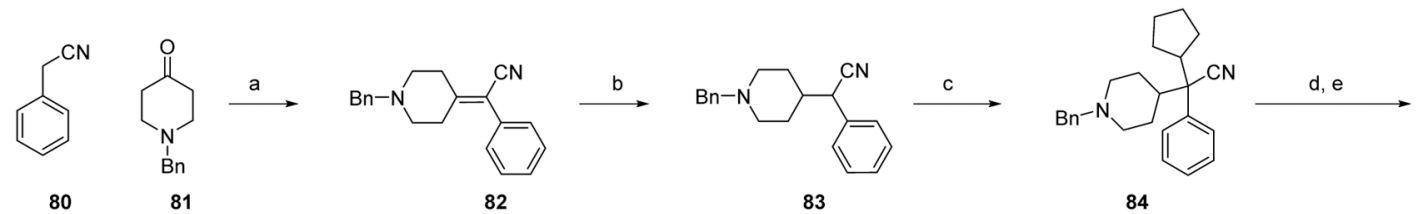

80

82

83

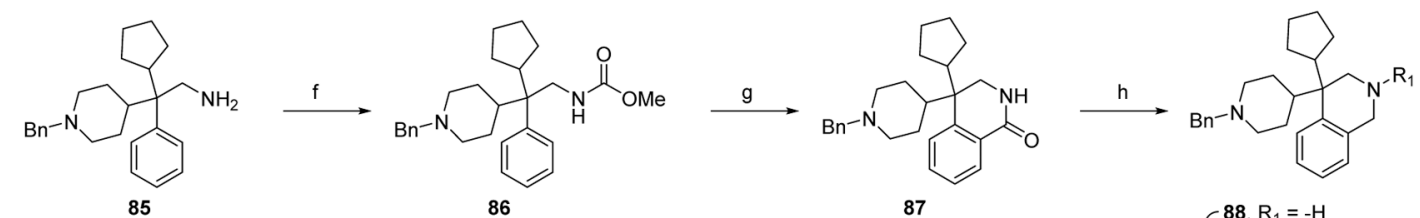

85

86
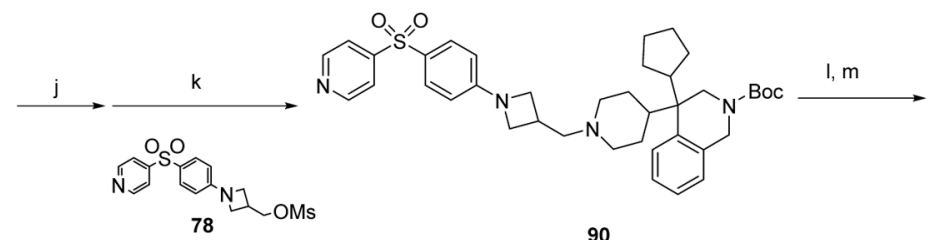

i $\left(\begin{array}{l}88, R_{1}=-H \\ 89, R_{1}=-B o c\end{array}\right.$

90

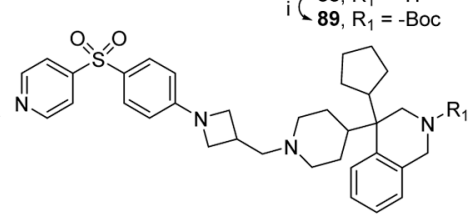

22, $\mathrm{R}_{1}=-\mathrm{H}_{\mathrm{H}} \quad 27, \mathrm{R}_{1}=\stackrel{-}{-\mathrm{CH}_{2} \triangleleft}$

$23, R_{1}=-\mathrm{CH}_{3} \quad 28, \mathrm{R}_{1}=-\mathrm{CH}_{2} \hat{\mathrm{CO}}$

$24, R_{1}=+$ Et 29, $R_{1}=-C_{2} \sim N$

$25, R_{1}=\vdash \quad 30, R_{1}=-\left(\mathrm{CH}_{2}\right)_{2}-\mathrm{N}$

$26, R_{1}=\longmapsto$

Scheme 4.

Synthesis of compounds $\mathbf{2 2}-\mathbf{3 0}$

Reagents and conditions: (a) $\mathrm{MeOH}, \mathrm{NaOMe}$, reflux; (b) $\mathrm{MeOH}^{\mathrm{NaBH}_{4}}$; (c) i. THF, LHMDS, $-78{ }^{\circ} \mathrm{C} 30 \mathrm{~min}$., ii. Cyclopentyl bromide, $-78{ }^{\circ} \mathrm{C}$ to rt; (d) toluene, DIBALH, 30 min. rt - work-up with aq. $\mathrm{NaOH}$; (e) $\mathrm{MeOH}, \mathrm{NaBH}_{4}$; (f) $\mathrm{DCM}^{\mathrm{E}} \mathrm{Et}_{3} \mathrm{~N}, \mathrm{ClCO}_{2} \mathrm{Me}, 0{ }^{\circ} \mathrm{C} 1 \mathrm{~h}$ (g) PPA, $150{ }^{\circ} \mathrm{C}, 1 \mathrm{~h}$; (h) toluene, Red-Al ${ }^{\circledR}, 30$ min. rt; (i) DCM, Et $3 \mathrm{~N}, \mathrm{Boc}_{2} \mathrm{O}, 0{ }^{\circ} \mathrm{C}$ to rt; (j) $\mathrm{MeOH}, \mathrm{Pd}-\mathrm{C}$ (cat.), $\mathrm{H}_{2}$ (1 atm); (k) $\mathrm{CH}_{3} \mathrm{CN}, 78, \mathrm{~K}_{2} \mathrm{CO}_{3}, \mathrm{KI}_{2} \mathrm{H}_{2} \mathrm{O}$, reflux; (l) DCM/ $\mathrm{CF}_{3} \mathrm{CO}_{2} \mathrm{H}, 15$ min.; (m) $\mathrm{CH}_{3} \mathrm{CN}$, AlkylBr, $\mathrm{KI}_{2} \mathrm{H}_{2} \mathrm{O}$, reflux or DCM/AcOH (1:1), alkyl aldehyde or ketone, $\mathrm{NaBH}(\mathrm{OAc})_{3}$. 

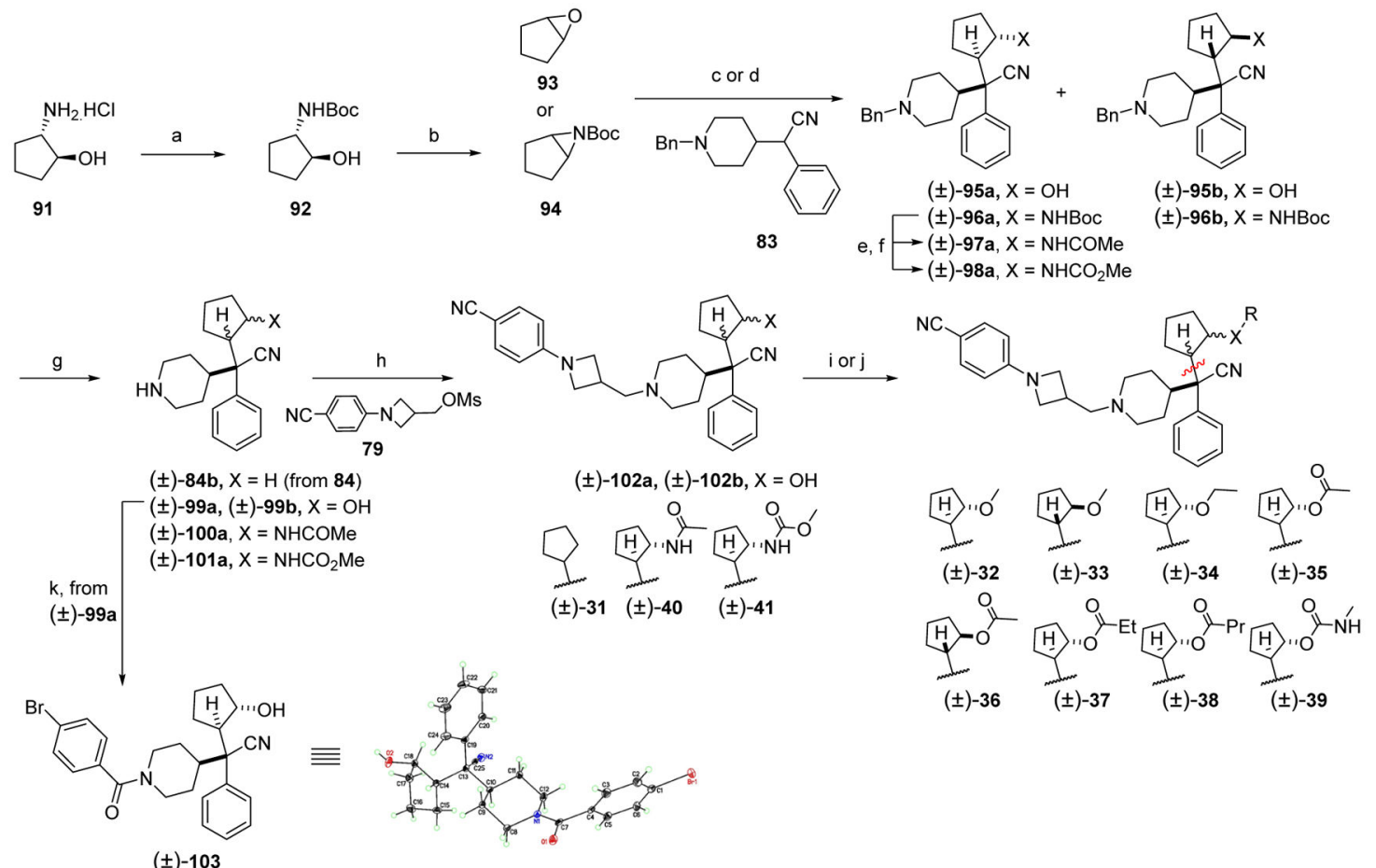

Scheme 5.

Synthesis of compounds $\mathbf{3 1} \mathbf{- 4 1}$

Reagents and conditions: (a) $\mathrm{MeOH}, \mathrm{Et}_{3} \mathrm{~N}, \mathrm{Boc}_{2} \mathrm{O}$; (b) THF, $\mathrm{PPh}_{3}$, diisopropylazodicarboxylate, $-78^{\circ} \mathrm{C}$ to rt overnight; (c) 83, THF, LHMDS, $-78{ }^{\circ} \mathrm{C}$ for 30 min then $93,-78{ }^{\circ} \mathrm{C}$ to rt overnight; (d) 83,18 -crown-6, toluene, KHMDS, $-78{ }^{\circ} \mathrm{C}$ for 30 min. then 94, $-78{ }^{\circ} \mathrm{C}$ to rt overnight; (e) DCM/TFA, $30 \mathrm{~min}$; (f) DCM, $\mathrm{Et}_{3} \mathrm{~N}, \mathrm{Ac}_{2} \mathrm{O}$ or $\mathrm{ClCO}_{2} \mathrm{Me}$; (g) $\mathrm{MeOH}$, Pd-C (cat.), $\mathrm{H}_{2}$ (1 atm); (h) $\mathrm{CH}_{3} \mathrm{CN}, \mathrm{K}_{2} \mathrm{CO}_{3}$, $\mathrm{KI}_{2} \mathrm{H}_{2} \mathrm{O}$, 79, reflux; (i) $\mathrm{NaH}, \mathrm{DMF}$, alkyl iodide; (j) DCM, $\mathrm{Et}_{3} \mathrm{~N}$, Alkyl anhydride or $\mathrm{MeN}=\mathrm{C}=\mathrm{O}$; (k) DCM, HATU, $\mathrm{Et}_{3} \mathrm{~N}, 4-\mathrm{Br}-\mathrm{PhCO}_{2} \mathrm{H}, 0{ }^{\circ} \mathrm{C}$ to rt. 

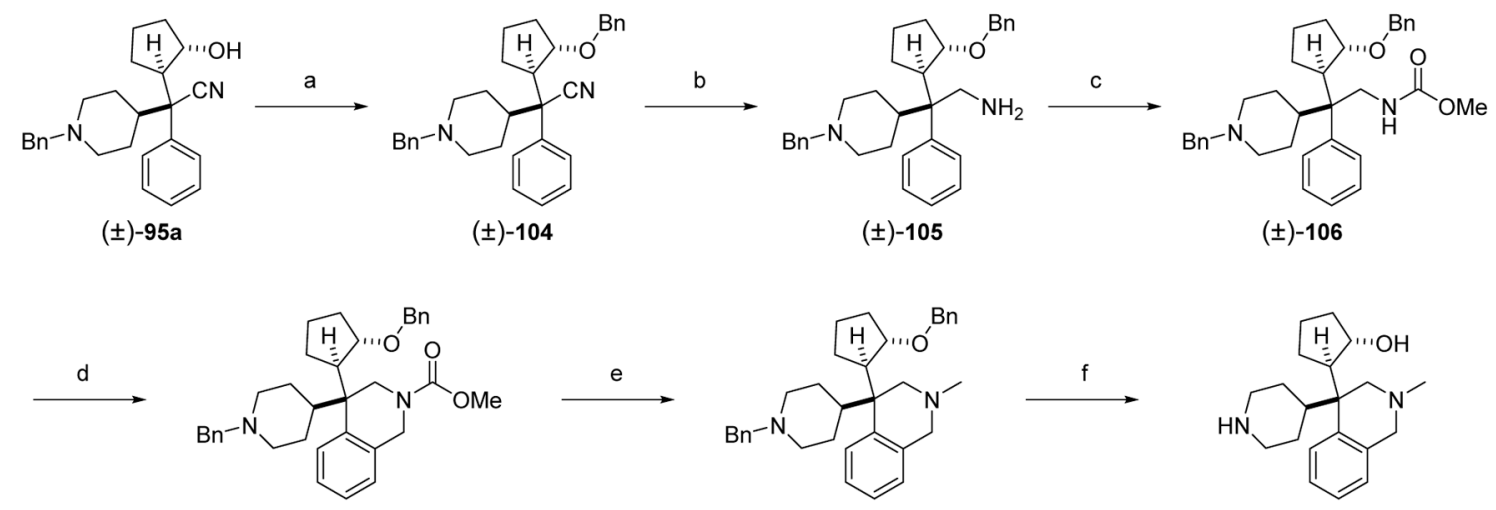

(士)-107

$( \pm)-108$

(士)-109

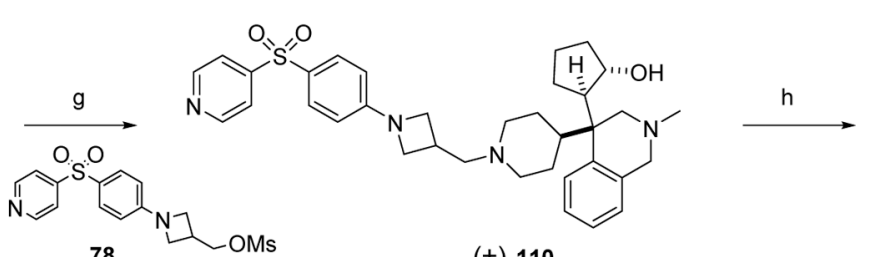

$( \pm)-110$

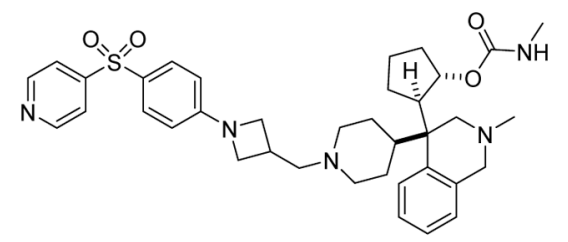

( \pm )-42 (M-89)

Scheme 6.

Synthesis of M-89

Reagents and conditions: (a) THF/toluene (1:1), $\mathrm{NaH}, \mathrm{BnBr}, \mathrm{Bu}_{4} \mathrm{NI}$; (b) toluene, DIBALH; (c) $\mathrm{DCM}, \mathrm{Et}_{3} \mathrm{~N}, \mathrm{ClCO}_{2} \mathrm{Me},{ }^{\circ} \mathrm{C}$ to $\mathrm{rt}$; (d) $\mathrm{AcOH}, \mathrm{CF}_{3} \mathrm{CO}_{2} \mathrm{H}$, paraformaldehyde; (e) toluene, Red-Al ${ }^{\circledR}$; (f) $\mathrm{MeOH}, \mathrm{Pd}-\mathrm{C}$ (cat.), $\mathrm{H}_{2}$ (1 atm); (g) $\mathrm{CH}_{3} \mathrm{CN}, \mathrm{K}_{2} \mathrm{CO}_{3}, \mathrm{KI} \cdot \mathrm{H}_{2} \mathrm{O}$, 78, reflux; (h) $\mathrm{DCM}, \mathrm{NaHCO}_{3}, \mathrm{Et}_{3} \mathrm{~N}, \mathrm{MeN}=\mathrm{C}=\mathrm{O}$, rt. 


\section{Table 1.}

Optimization of MIV-6 through cyclization of the core, rigidification of the linker and replacement of the nitrile tail group with a substituted sulfonyl group.

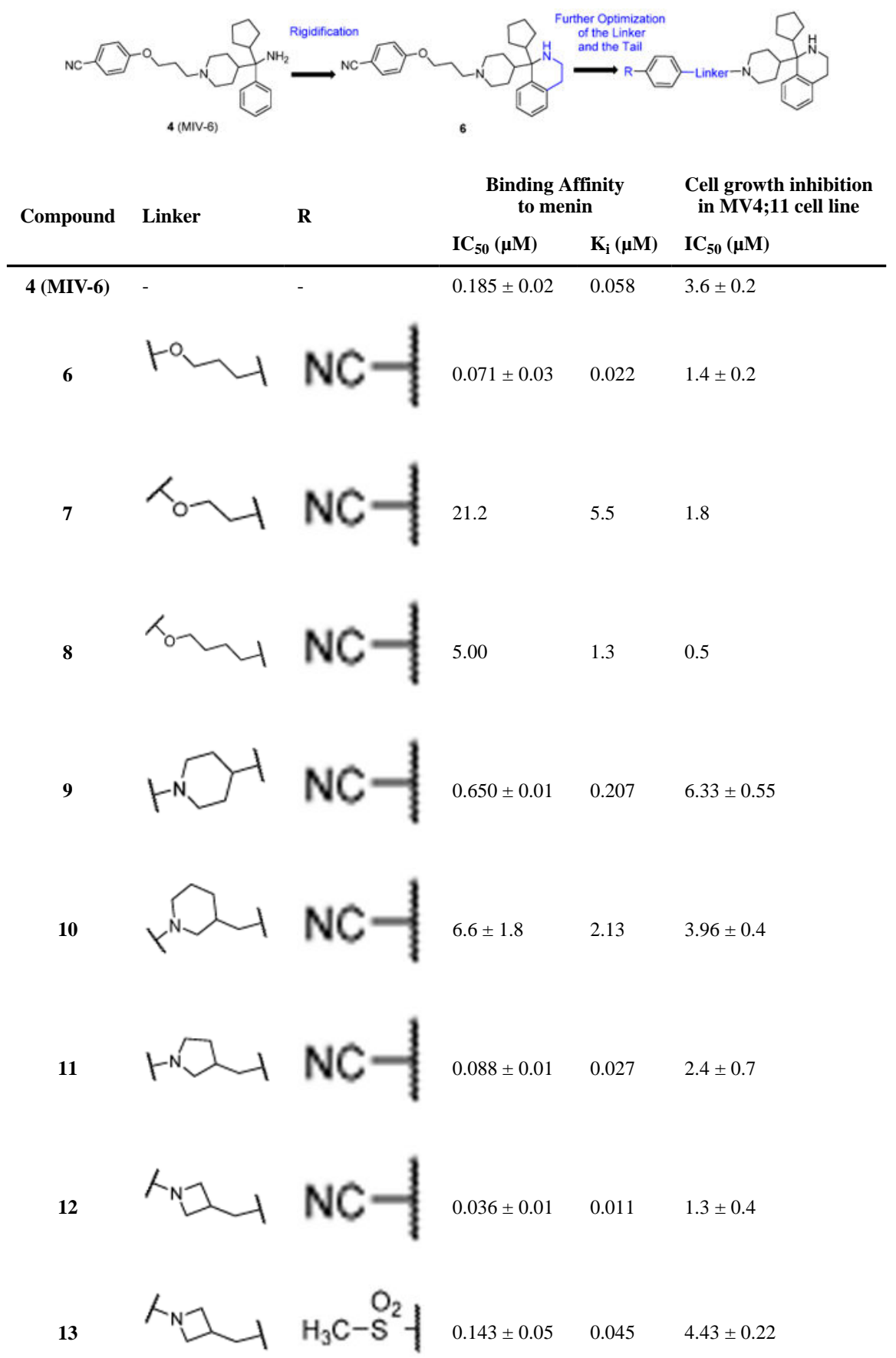

JMed Chem. Author manuscript; available in PMC 2020 July 11. 

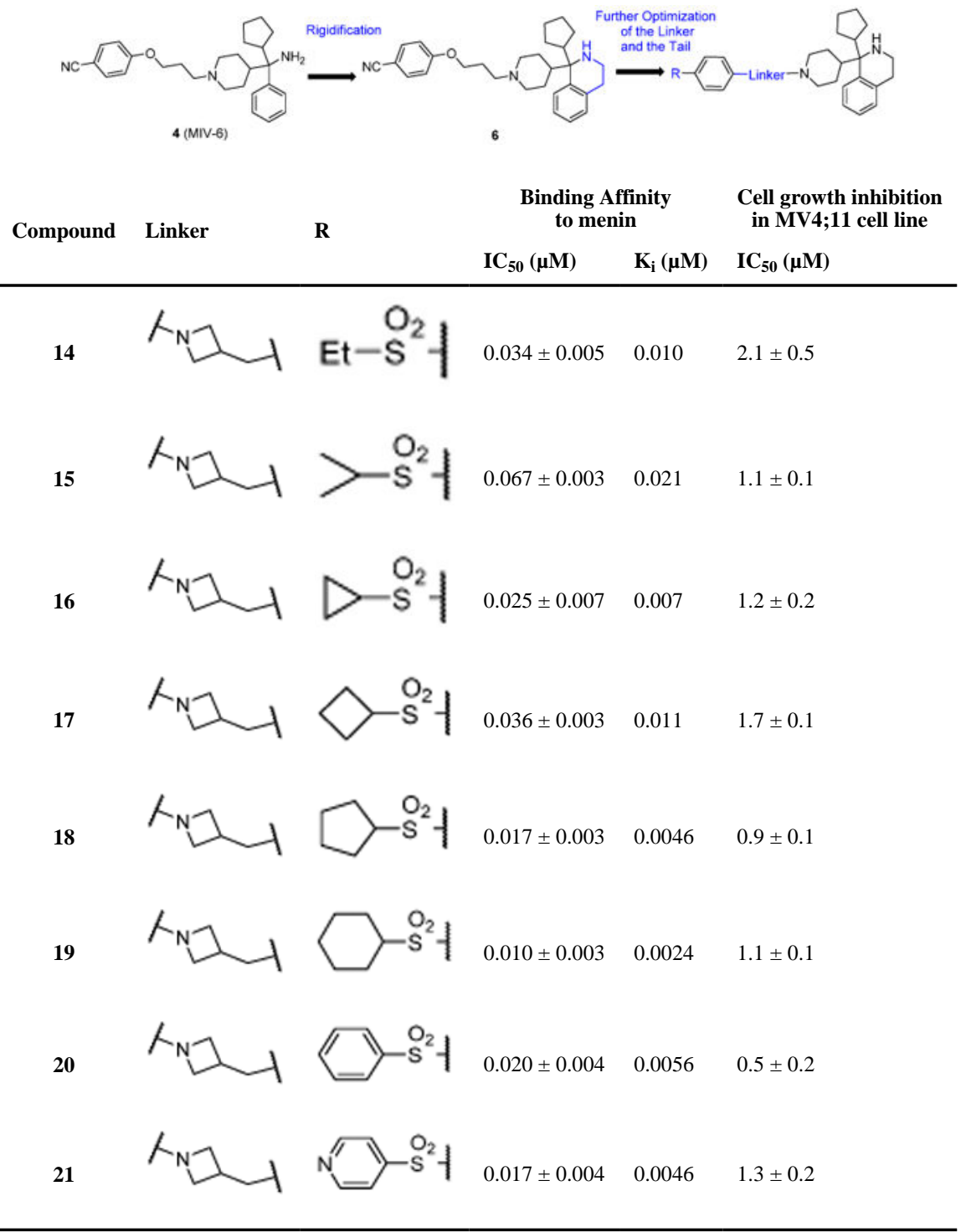

Values are average of at least two tests. $\mathrm{K}_{\mathrm{i}}$ 's were determined from averaged IC 50 values. 
Table 2.

Structure-activity relationship of the N-substituents

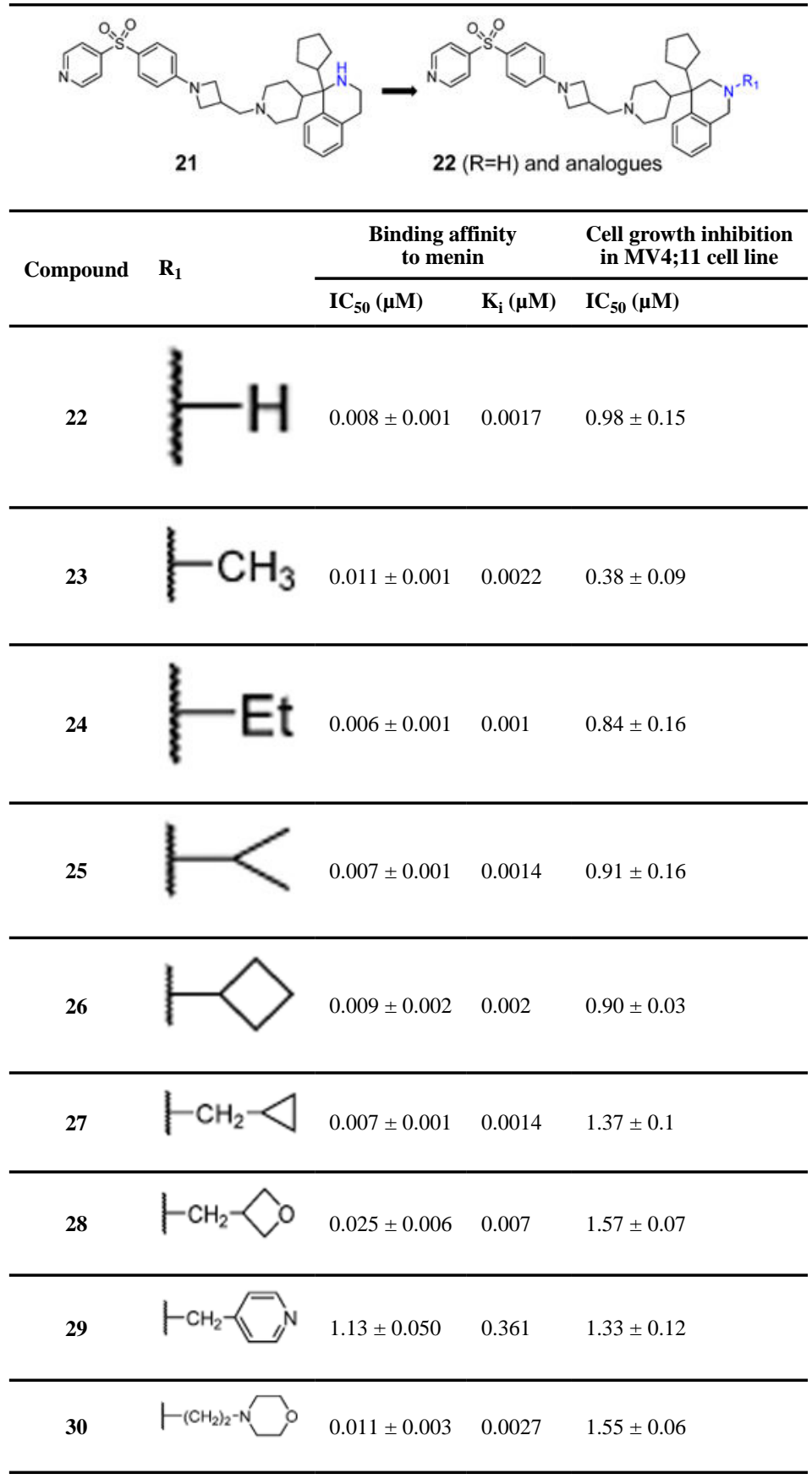

Values are average of at least two tests. $\mathrm{K}_{\mathrm{i}}$ was calculated from an averaged $\mathrm{IC} 50$ value in the binding experiments for each compound. 
Table 3.

Structure-activity relationship of cyclopentyl substituted compounds
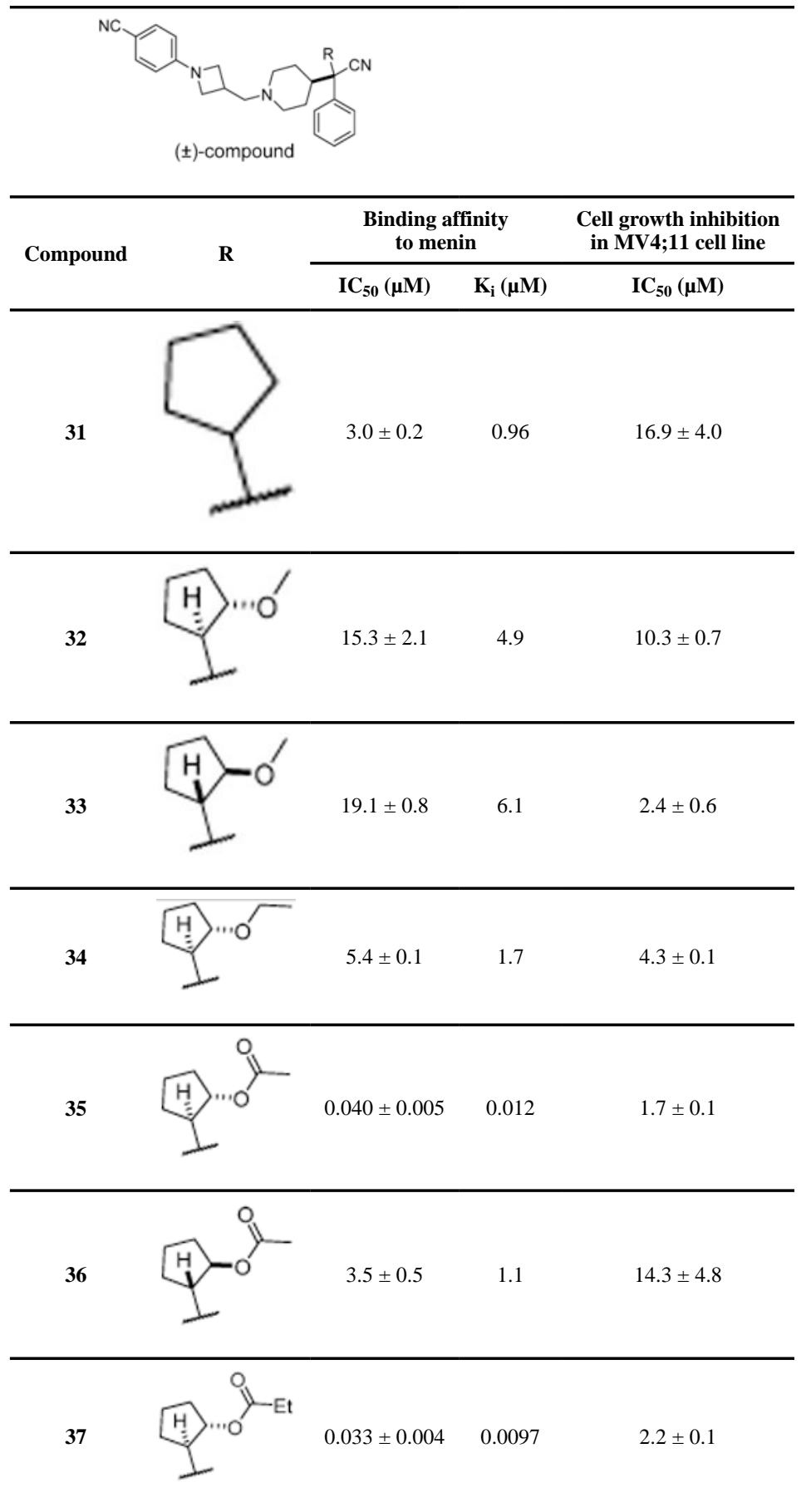

J Med Chem. Author manuscript; available in PMC 2020 July 11. 


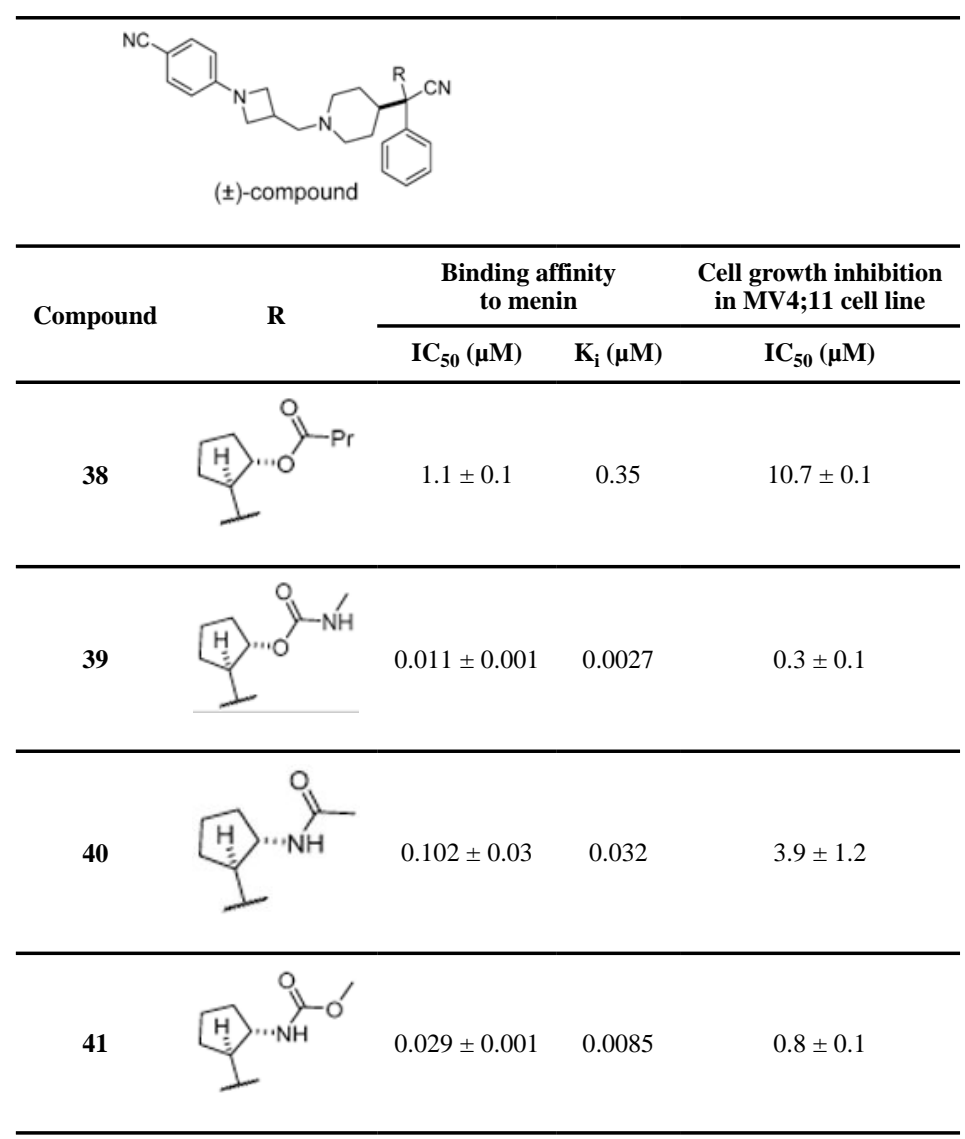

IC50 values are average of at least three independent experiments. $\mathrm{K}_{\mathrm{i}}$ values were calculated from averaged $\mathrm{IC}_{50}$ values. 
Table 4.

Design of compound 42 (M-89) by combination of the best structural features in compounds 23 and 39

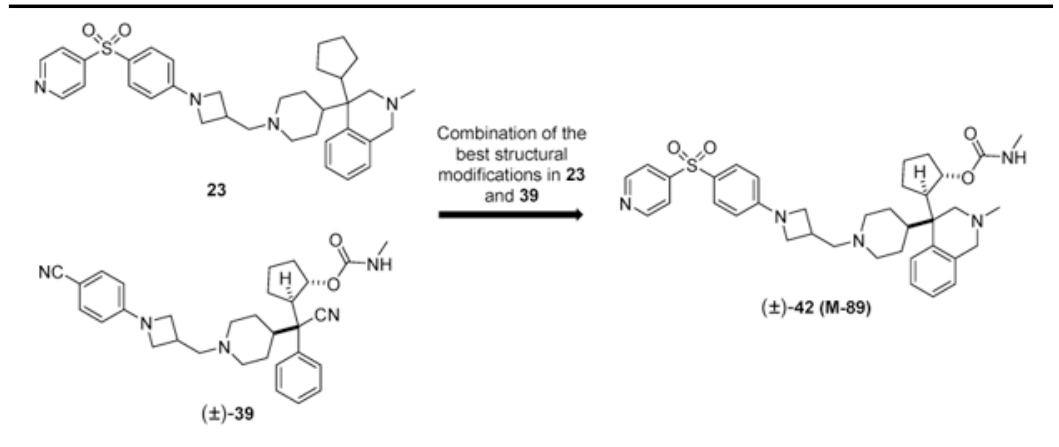

\begin{tabular}{clllll}
\hline \multirow{2}{*}{ Compound } & \multicolumn{2}{l}{ Binding affinity to menin } & \multicolumn{3}{c}{ Cell growth inhibition $\left(\mathrm{IC}_{\mathbf{5 0}}(\boldsymbol{\mu M})\right)$} \\
\cline { 2 - 6 } & $\mathbf{I C}_{\mathbf{5 0}}(\boldsymbol{\mu M})$ & $\mathbf{K}_{\mathbf{i}}(\boldsymbol{\mu M})$ & $\mathbf{M V 4 - 1 1}(\boldsymbol{\mu M})$ & $\operatorname{MOLM-13}(\boldsymbol{\mu M})$ & $\mathbf{H L 6 0}(\boldsymbol{\mu M})$ \\
\hline $\mathbf{2 3}$ & $0.011 \pm 0.0002$ & 0.002 & $0.384 \pm 0.09$ & $4.3 \pm 0.11$ & $2.5 \pm 0.71$ \\
\hline $\mathbf{4 2}(\mathrm{M}-89)$ & $0.005 \pm 0.001$ & $<0.001$ & $0.025 \pm 0.004$ & $0.054 \pm 0.015$ & $10.2 \pm 1.5$ \\
\hline
\end{tabular}

IC50 values are the average of at least three independent experiments. $\mathrm{K}_{\mathrm{i}}$ values for binding affinities were calculated from average IC 50 values. 
Table 5.

Determination of $\mathrm{K}_{\mathrm{d}}, k_{\text {on }}$ and $k_{\text {off }}$ values for two menin inhibitors with a label free, biolayer interferometry assay using an Octet RED system

\begin{tabular}{|c|c|c|c|c|}
\hline Compound & $\begin{array}{c}\mathbf{I C}_{\mathbf{5 0}}(\mathbf{n M}) \\
\text { to Menin by FP }\end{array}$ & $\begin{array}{c}\mathbf{K}_{\mathbf{d}} \\
(\mathbf{n M})\end{array}$ & $\begin{array}{c}\boldsymbol{k}_{\text {on }} \\
\left(\mathbf{1 0}^{\mathbf{5}} \mathbf{M}^{\mathbf{- 1}} \mathbf{s}^{\mathbf{- 1}}\right)\end{array}$ & $\begin{array}{c}\boldsymbol{k}_{\text {off }} \\
\left(\mathbf{1 0}^{-\mathbf{4}} \mathbf{s}^{\mathbf{- 1}}\right)\end{array}$ \\
\hline MIV-6 & $229 \pm 29$ & $110 \pm 29$ & $4.1 \pm 1.1$ & $460 \pm 102$ \\
\hline M-89 & $5.0 \pm 1.0$ & $1.4 \pm 0.6$ & $2.3 \pm 1.1$ & $2.9 \pm 0.2$ \\
\hline
\end{tabular}

